RENATA VIVIANE BASTOS

ESTUDO DA DEGRADAÇÃO DO ANTIBIÓTICO SULFAMETOXAZOL EM SOLUÇÃO AQUOSA POR FOTÓLISE 
RENATA VIVIANE BASTOS

\section{ESTUDO DA DEGRADAÇÃO DO ANTIBIÓTICO SULFAMETOXAZOL EM SOLUÇÃO AQUOSA POR FOTÓLISE}

Dissertação apresentada à Escola Politécnica da Universidade de São Paulo para obtenção do título de Mestre em Engenharia

Área de concentração:

Engenharia Química

Orientador: Prof. Dr. Antonio Carlos Silva Costa Teixeira 
Este exemplar foi revisado e alterado em relação à versão original, sob responsabilidade única do autor e com a anuência de seu orientador.

São Paulo, de junho de 2012.

Assinatura do autor

Assinatura do orientador

FICHA CATALOGRÁFICA

Bastos, Renata Viviane

Estudo da degradação do antibiótico sulfametoxazol em

Solução aquosa por fotólise / R.V. Bastos. -- ed.rev. -- São Paulo, 2012.

$98 \mathrm{p}$.

Dissertação (Mestrado) - Escola Politécnica da Universidade de São Paulo. Departamento de Engenharia Química.

1.Fármacos 2.Antibióticos 3.0xidação (Processos) 4.Poluentes emergentes I.Universidade de São Paulo. Escola Politécnica. Departamento de Engenharia Química II.t. 
DEDICATÓRIA

A minha família. 


\section{AGRADECIMENTOS}

À minha família por tudo

Ao meu orientador Prof. Dr. Antonio Carlos S. C. Teixeira, pelas discussões e contribuições e amizade.

À Profa. Dra. Carolina V. T. Giongo pelas contribuições ao trabalho.

À Profa. Dra.Suely Borrely pelas contribuições ao trabalho

Aos meus amigos do laboratório pelas conversas, o grande apoio e as risadas.

À Capes e ao CNPq pelo suporte financeiro. 


\section{RESUMO}

A presença de produtos farmacêuticos no meio ambiente é uma questão emergente, devido à crescente resistência bacteriana. As tecnologias utilizadas em instalações de tratamento de água não são eficientes para remover todos os resíduos farmacêuticos e os efeitos dessas substâncias não são bem conhecidos. No presente trabalho, estudou-se a degradação do antibiótico sulfametoxazol (SMX) por fotólise. $O$ SMX é uma sulfonamida, um dos grupos de antibióticos mais utilizados. A fotodegradação de SMX em solução aquosa foi realizada por radiação UVC, sendo o composto transformado por meio de absorção de fótons de comprimento de onda igual a $254 \mathrm{~nm}$. Os experimentos foram conduzidos em um reator fotoquímico anular tubular feito de vidro Pirex (volume irradiado de 3,9 L). A irradiação foi feita por uma lâmpada de mercúrio de baixa pressão de $36 \mathrm{~W}$ posicionada ao longo do eixo do reator. Utilizaram-se 5,5 L de solução aquosa do antibiótico (10-50 mg/L). Os efeitos das concentrações iniciais de SMX e do $\mathrm{pH}$ (5, 7 ou 9) foram estudados a partir de um projeto experimental Doehlert. Os resultados indicaram remoções de SMX superiores a 99\% em até 30 minutos de exposição à radiação UVC. A análise estatística dos resultados em termos do tempo necessário para redução de $50 \%$ da concentração inicial de SMX e da taxa inicial de degradação confirmou que para maior quantidade inicial do antibiótico é possível observar que o pH interfere na resposta, indicando que a fotólise do SMX é mais lenta em meio básico. Por outro lado, para concentrações iniciais mais baixas, não é possível afirmar se o pH interfere ou não na velocidade de degradação de SMX, já que esta ocorre muito rapidamente.

Os compostos resultantes da degradação do SMX mostraram-se recalcitrantes, obtendo-se remoções de COT menores que 7\%. Medidas de toxicidade baseadas na inibição da luminescência da bactéria Vibrio fischeri, segundo o método Microtox $500^{\circledR}$, indicaram aumento de toxicidade das soluções aquosas após irradiação. Além disso, bioensaios respirométricos sugeriram que os produtos gerados na degradação são mais favoráveis à oxidação em sistemas biológicos de tratamento. 
The presence of pharmaceuticals in the environment is an emerging issue due to the increasing bacterial resistance. The technologies used in sewage and wastewater treatment plants are not efficient to remove all pharmaceutical residues and the effect of these substances is not well known. In this work, the degradation of the antibiotic sulfamethoxazole (SMX) by photolysis has been studied. SMX belongs to the sulfonamides group, one of the first groups of antibiotics used. The photodegradation of SMX in aqueous solution was carried out by UV radiation, in which the target compound is transformed by absorbing photons with wavelength 254 $\mathrm{nm}$. The experiments were carried out in an annular photochemical reactor made of Pyrex glass (irradiated volume of $3.9 \mathrm{~L}$ ). The irradiation was provided by a $36 \mathrm{~W}$ lowpressure mercury vapor lamp set along the reactor axis. A total volume of $5.5 \mathrm{~L}$ of aqueous solution (10-50 mg/L) was used. The effects of SMX initial concentration and $\mathrm{pH}(5,7$ or 9$)$ were studied according to a Doehlert experimental design.

The results showed SMX removals greater than $99 \%$ after 30 minutes of UVC irradiation. Statistical analysis of the results in terms of the time needed to remove $50 \%$ of SMX initial concentration and the initial degradation rate showed that $\mathrm{pH}$ affects the response for higher initial amounts of antibiotic, showing that SMX photolysis is slower in basic medium. On the other hand, for lower initial concentrations, it is not possible to confirm wether $\mathrm{pH}$ affects the removal rate or not, because the decrease of SMX concentration is very fast.

The compounds resulting from SMX degradation were shown to be recalcitrant, with TOC removals not greater than $7 \%$. Bioassays based on the inhibition of Vibrio fischeri luminescence showed an increase of the toxicity of irradiated aqueous solutions. Moreover, respirometric bioassays suggested that the degradation products produced by SMX degradation are more favorable to oxidation in biological treatment systems. 


\section{LISTA DE FIGURAS}

Figura 1 - Caminho dos fármacos no meio ambiente

Figura 2 - a) Estrutura química do SMX. b) Estrutura química geral das sulfonamidas.

Figura 3 - Caminho de degradação por fotólise direta em água destilada proposto por Trovóet al., 2009.

Figura 4 - Reator fotoquímico tubular e equipamento associado.

Figura 5 - Esquema do equipamento experimental.

Figura 6 - Esquema do procedimento geral do teste de toxicidade aguda com a bactéria luminescente $V$. fischeri.

Figura 7 - Respirômetros manométricos fechados.

Figura 8 - Representação esquemática da distribuição dos experimentos segundo o planejamento experimental Doehlert. $X_{1}$ : valor codificado correspondente à concentração de sulfametoxazol. $X_{2}: \mathrm{pH}_{0}$. Os números dos experimentos são indicados nos vértices e no centro do hexágono.

Figura 9 - Resultado dos ensaios de hidrólise com valores médios da duplicata para $[S M X]_{0}=18,9$ mg/L. $(\diamond)$ controle; $(\square) \mathrm{pH} 3 ;(\Delta) \mathrm{pH} 5 ;(X) \mathrm{pH} 7$; e (॰) pH 9.

Figura 10 - Resultado dos ensaios de hidrólise com valores médios da duplicata

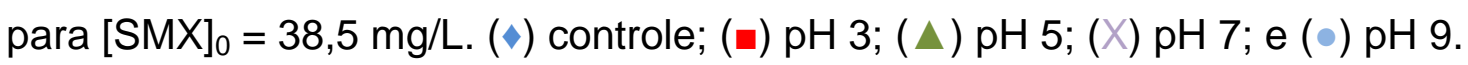

Figura 11 - Análise de espectrofotometria UV-visível do sulfametoxazol em solução aquosa na concentração 10 mg/L e (-)pH 5, (-)pH 7 e (-)pH 9. Varredura de 190 a 450 nm, com resolução de 5nm e caminho ótico de $1 \mathrm{~cm}$.

Figura 12 - Análise de espectrofotometria UV do sulfametoxazol em diferentes

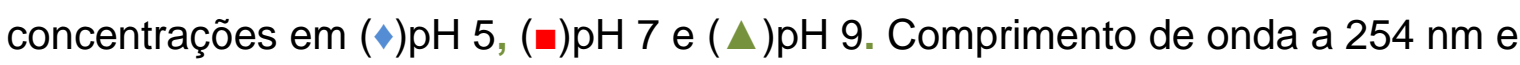
caminho ótico de $1 \mathrm{~cm}$

Figura 13 - Estado protonado da Sulfas. $\mathrm{SH}_{2}{ }^{+}=$forma catiônica, $\mathrm{SH}=$ forma neutra e $\mathrm{S}^{--}=$forma aniônica. Valores de $\mathrm{K}_{\mathrm{a}, 1}=1,6$ e $\mathrm{K}_{\mathrm{a}, 2}=5,7$ (BOREEN; ARNOLD; MC NEILL, 2004).

Figura 14 - Obtenção experimental do pKa do sulfmatoxazol em solução aquosa. 
Figura 15 - Estimativa no pKa.

Figura 16 - Resultados do experimento 1 realizado em triplicata.(^) $1 \mathrm{~A} ;(\bullet) 1 \mathrm{~B}$; e ( $\Delta$ ) $1 \mathrm{C}$. $[S M X]_{0}=22,6 \mathrm{mg} / \mathrm{L} ; \mathrm{pH}_{0}=7$.

Figura 17 - Resultados do experimento 1 , em termos de valores médios e barrasde desvio-padrão. [SMX $]_{0}=22,6 \mathrm{mg} / \mathrm{L} ; \mathrm{pH}_{0}=7$.

Figura 18 - Resultados dos experimentos de fotólise direta em $254 \mathrm{~nm}$ de

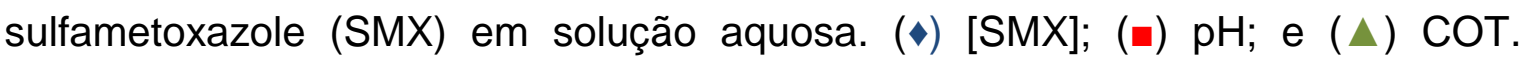
Condições: $1 \mathrm{~A}\left([S M X]_{0}=21,3 \quad \mathrm{mg} / \mathrm{L} ; \mathrm{pH}_{0}=7\right) ; 1 \mathrm{~B}\left([\mathrm{SMX}]_{0}=22,8 \mathrm{mg} / \mathrm{L} ; \mathrm{pH}_{0}=7\right)$;

Figura 19 - Resultados dos experimentos de fotólise direta em $254 \mathrm{~nm}$ de

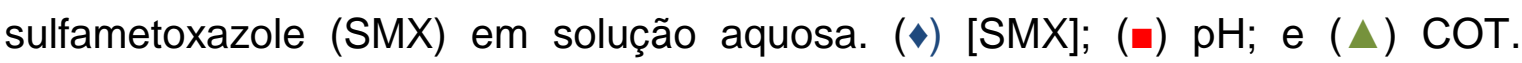
Condições: $1 \mathrm{C}\left([\mathrm{SMX}]_{0}=22,6 \mathrm{mg} / \mathrm{L} ; \mathrm{pH} \mathrm{H}_{0}=7\right) ; 2\left([\mathrm{SMX}]_{0}=35,6 \mathrm{mg} / \mathrm{L} ; \mathrm{pH} \mathrm{H}_{0}=7,1\right) .3$ $\left([\mathrm{SMX}]_{0}=29,8 \mathrm{mg} / \mathrm{L} ; \mathrm{pH}_{0}=8,9\right) ; 4 \quad\left([\mathrm{SMX}]_{0}=15,7 \mathrm{mg} / \mathrm{L} ; \mathrm{pH}_{0}=9,1\right) ; 5\left([\mathrm{SMX}]_{0}=7,2\right.$ $\left.\mathrm{mg} / \mathrm{L} ; \mathrm{pH}_{0}=6,8\right) ; 6\left([\mathrm{SMX}]_{0}=14,1 \mathrm{mg} / \mathrm{L} ; \mathrm{pH}_{0} 4,9\right) ; 7\left([\mathrm{SMX}]_{0}=29,9 \mathrm{mg} / \mathrm{L} ; \mathrm{pH}_{0}=4,9\right)$.

Figura 20 - Evolução de [SMX] em função do tempo para os experimentos 4 (•) $\left([\mathrm{SMX}]_{0}=15,7 \mathrm{mg} / \mathrm{L}\right.$ e pH 9,1) e $6(\backsim)\left([\mathrm{SMX}]_{0}=14,1 \mathrm{mg} / \mathrm{L}\right.$ e $\left.\mathrm{pH}_{0}=4,9\right)$

Figura 21 - Evolução de [SMX] em função do tempo para os experimentos3 ( $\left([S M X]_{0}=29,8 \mathrm{mg} / \mathrm{L}\right.$ e pH 8,9) e 7 ( $\left(\right.$ ) $\left([S M X]_{0}=29,9 \mathrm{mg} / \mathrm{L}\right.$ e p $\left.\mathrm{H}_{0}=4,9\right)$

Figura 22 - Comparação entre valores experimentais e calculados da resposta $Y_{1}$ (tempo necessário para remoção de $50 \%$ da quantidade inicial de SMX).

Figura 23 - Distribuição dos resíduos em função dos valores experimentais da resposta $Y_{1}$ (tempo necessário para remoção de $50 \%$ da quantidade inicial de SMX).

Figura 24 - Diagrama de Pareto para a resposta $Y_{1}$ (tempo necessário para remoção de $50 \%$ da quantidade inicial de SMX). $X_{1}$ : variável codificada correspondente a $[\mathrm{SMX}]_{0}(\mathrm{mg} / \mathrm{L}) ; X_{2}$ : variável codificada correspondente ao $\mathrm{pH}_{0}$.

Figura 25 - Superfície de resposta descrita pela eq. (12) para a variável dependente $Y_{1}$ (tempo necessário para remoção de $50 \%$ da quantidade inicial de $\mathrm{SMX}) . X_{1}$ : variável codificada correspondente a $[\mathrm{SMX}]_{0}(\mathrm{mg} / \mathrm{L}) ; X_{2}$ : variável codificada correspondente ao $\mathrm{pH}_{0}$. 
Figura 26 - Curvas de contorno para a superfície de resposta descrita pela eq. (12) para a variável dependente $Y_{1}$ (tempo necessário para remoção de $50 \%$ da quantidade inicial de SMX). $X_{1}$ : variável codificada correspondente a $[S M X]_{0}$ (mg/L); $X_{2}$ : variável codificada correspondente ao $\mathrm{pH}_{0}$.

Figura 27 - Comportamento da resposta $Y_{1}$ (tempo necessário para remoção de $50 \%$ da quantidade inicial de SMX). $X_{1}$ : variável codificada correspondente a $[S M X]_{0}(\mathrm{mg} / \mathrm{L}) ; X_{2}$ : variável codificada correspondente ao $\mathrm{pH}_{0}$.

Figura 28- Comparação entre valores experimentais e calculados da resposta $Y_{2}$ (taxa inicial da degradação do SMX).

Figura 29: Distribuição dos resíduos em função dos valores experimentais da resposta $Y_{2}$ (taxa inicial da degradação do SMX)

Figura 30- Diagrama de Pareto para a resposta $Y_{2}$ (taxa inicial da degradação do SMX). $X_{1}$ : variável codificada correspondente a $[S M X]_{0}(\mathrm{mg} / \mathrm{L}) ; X_{2}$ : variável codificada correspondente ao $\mathrm{pH}_{0}$.

Figura 31- Superfície de resposta descrita pela eq. (13) para a variável dependente $Y_{2}$ (taxa da degradação inicial do SMX). $X_{1}$ : variável codificada correspondente a $[\mathrm{SMX}]_{0}(\mathrm{mg} / \mathrm{L}) ; X_{2}$ : variável codificada correspondente ao $\mathrm{pH}$.

Figura 32- Curvas de contorno para a superfície de resposta descrita pela eq. (13) para a variável dependente $Y_{2}$ (taxa inicial da degradação do de SMX). $X_{1}$ : variável codificada correspondente a $[\mathrm{SMX}]_{0}(\mathrm{mg} / \mathrm{L}) ; X_{2}$ : variável codificada correspondente ao $\mathrm{pH}_{0}$.

Figura 33 - Evolução da concentração de SMX e do COT durante o experimento

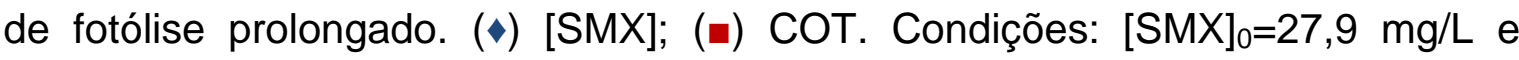
$\mathrm{pH}_{0}=7,2$

Figura 34 - Evolução da t, concentração de oxigênio dissolvido (OD) e pH ao longo do tempo durante o experimento de fotólise prolongado. (४) pH]; ( $)\left[\mathrm{O}_{2}\right]$. Condições: $[\mathrm{SMX}]_{0}=27,9 \mathrm{mg} / \mathrm{L}$ e $\mathrm{pH}_{0}=7,2$

Figura 35 - Evolução de $[S M X] /[S M X]_{0}$ em função do tempo para experimentos de fotólise realizados com ( $\bullet) \mathrm{pH}$ livre e $(\square) \mathrm{pH}$ controlado. Condições do experimento 1: $[\mathrm{SMX}]_{0}=28,6 \mathrm{mg} / \mathrm{L}$ e $\mathrm{pH}_{0}=7$.

Figura 36 - Evolução do $\mathrm{pH}$ em função do tempo para experimentos de fotólise realizados com $(\diamond) \mathrm{pH}$ livre e $(\varpi) \mathrm{pH}$ controlado. Condições do experimento 1: $[S M X]_{0}=28,6 \mathrm{mg} / \mathrm{L}$ e $\mathrm{pH}_{0}=7$. 
Figura 37 - Evolução de $[S M X] /[S M X]_{0}$ em função do tempo para experimentos de fotólise realizados com ( $\bullet) \mathrm{pH}$ livre e $(\square) \mathrm{pH}$ controlado. Condições do experimento 3: $[\mathrm{SMX}]_{0}=38,6 \mathrm{mg} / \mathrm{L}$ e $\mathrm{pH}_{0}=8,9$.

Figura 38 - Evolução do $\mathrm{pH}$ em função do tempo para experimentos de fotólise realizados com $(\star) \mathrm{pH}$ livre e $(\varpi) \mathrm{pH}$ controlado. Condições do experimento 3 : $[S M X]_{0}=38,6 \mathrm{mg} / \mathrm{L}$ e $\mathrm{pH}_{0}=8,9$.

Figura 39 - Evolução de [SMX]/[SMX $]_{0}$ em função do tempo para experimentos de fotólise realizados com $(\star) \mathrm{pH}$ livre e $(\square) \mathrm{pH}$ controlado. Condições do experimento 7: $[\mathrm{SMX}]_{0}=37,9 \mathrm{mg} / \mathrm{L}$ e $\mathrm{pH}_{0}=4,7$.

Figura 40 - Evolução do pH em função do tempo para experimentos de fotólise realizados com $(\star) \mathrm{pH}$ livre e $(\varpi) \mathrm{pH}$ controlado. Condições do experimento 7: $[S M X]_{0}=37,9 \mathrm{mg} / \mathrm{L}$ e $\mathrm{pH}_{0}=4,7$.

Figura 41 - Evolução de [SMX] em função do tempo para experimentos de fotólise realizados em ( $\downarrow)$ sistema aberto à atmosfera e ( $\bullet$ condições anóxicas. Condições do experimento 1: $[\mathrm{SMX}]_{0}=29,3 \mathrm{mg} / \mathrm{L}$ e $\mathrm{pH}_{0}=6,8$.

Figura 42 - Evolução de [SMX] em função do tempo para experimentos de fotólise realizados em $(\star)$ sistema aberto à atmosfera e $(\square)$ condições anóxicas. Condições do experimento 3: $[S M X]_{0}=37,9 \mathrm{mg} / \mathrm{L}$ e pH $\mathrm{H}_{0}=8,6$.

Figura 43 - Evolução de [SMX] em função do tempo para experimentos de fotólise realizados em ( $\downarrow$ ) sistema aberto à atmosfera; ( $\bullet$ condições anóxicas; e (А) meio saturado com $\mathrm{O}_{2}$. Condições do experimento 7: $[\mathrm{SMX}]_{0}=38,6 \mathrm{mg} / \mathrm{L}$ e $\mathrm{pH}_{0}=4,9$.

Figura 44 - Evolução de [SMX] em função do tempo para o experimento realizado com intervalos de irradiação/não-irradiação alternados ("liga-desliga"). Condições do experimento 7: $[S M X]_{0}=38,5 \mathrm{mg} / \mathrm{L}$ e $\mathrm{pH}_{0}=4,9$.

Figura 45 - Cromatogramas obtidos na fotólise do SMX. (-) 0 min; (-) $5 \mathrm{~min}$; (-) $10 \mathrm{~min}$; (-) $20 \mathrm{~min}$; (-) $30 \mathrm{~min}$; (-) $40 \mathrm{~min}$; (-) $50 \mathrm{~min}$; e (-) $60 \mathrm{~min}$. Condições: $[S M X]_{0}=14,1 \mathrm{mg} / \mathrm{L}$ e $\mathrm{pH}_{0}=4,9$.

Figura 46 - Cromatogramas obtidos na fotólise do SMX. (-) $10 \mathrm{~min} ;(-) 20 \mathrm{~min}$; (-) $30 \mathrm{~min} ;(-) 40 \mathrm{~min} ;(-) 50 \mathrm{~min}$; e (一) 60min. Condições: [SMX] $]_{0}=14,1 \mathrm{mg} / \mathrm{L}$ e $\mathrm{pH}_{0}=4,9$.

Figura 47 - Cromatogramas correspondentes ao $(-)$ produto de degradação do SMX e ao (-) padrão ácido sulfanílico. 
Figura 48 - Possíveis quebras de ligações devido à fotólise de sulfonamidas (BOREEN; ARNOLD; MCNEILL K., 2004).

Figura 49 - Resultados dos ensaios respirométricos (médias de resultados em triplicata). ( DBO$_{\mathrm{P}}$ : demanda bioquímica de oxigênio da solução padrão glicoseácido glutâmico; $(\triangle)$ DBO$_{\top}$ : demanda bioquímica de oxigênio do padrão glicoseácido glutâmico contendo solução de SMX após fotólise; (๓) DBO ${ }_{N}$ : demanda bioquímica de oxigênio do padrão glicose-ácido glutâmico contendo solução de SMX não irradiada. Condições do experimento 7: $[\mathrm{SMX}]_{0}=39,6 \mathrm{mg} / \mathrm{L} ; \mathrm{pH}_{0}=5$.

Figura 50 - Resultados dos ensaios respirométricos (médias de resultados em triplicata). ( DBO$_{\mathrm{P}}$ : demanda bioquímica de oxigênio da solução padrão glicoseácido glutâmico; ( $\triangle$ ) DBOT: demanda bioquímica de oxigênio do padrão glicoseácido glutâmico contendo solução de SMX após fotólise; (๓) $\mathrm{DBO}_{\mathrm{N}}$ : demanda bioquímica de oxigênio do padrão glicose-ácido glutâmico contendo solução de SMX não irradiada. Condições do experimento 5: [SMX $]_{0}=8,6 \mathrm{mg} / \mathrm{L} ; \mathrm{pH}_{0}=7$.

Figura 51 - Curvas de inibição da atividade microbiana frente ao padrão glicoseácido glutâmico para (๓) sistema contendo solução de SMX irradiada e (») sistema contendo solução de SMX não irradiada. Condições do experimento 7: $[\mathrm{SMX}]_{0}=38,7 \mathrm{mg} / \mathrm{L}$ e $\mathrm{pH}_{0}=7$.

Figura 52 - Curvas de inibição da atividade microbiana frente ao padrão glicoseácido glutâmico para ( $₫$ ) sistema contendo solução de SMX irradiada e (») sistema contendo solução de SMX não irradiada. Condições do experimento 5: $[S M X]_{0}=8,5 \mathrm{mg} / \mathrm{L}$ e $\mathrm{pH}_{0}=5$.

Figura 53 - Efeito gama $\left(I_{0} / I_{t}\right)$. (ロ) Solução de SMX irradiada; (•) Solução de SMX não irradiada. Condições do experimento 7: $[S M X]_{0}=38,6 \mathrm{mg} / \mathrm{L}$ e pH $\mathrm{pH}_{0}=7$. 


\section{LISTA DE TABELAS}

Tabela 1 - Fármacos encontrados no meio ambiente (MELO et al., 2009)

Tabela 2 - Domínio experimental dos valores nominais das variáveis estudadas.

Tabela 3 - Resultados do ensaio de hidrólise.

Tabela 4 - Equações dos ajustes lineares de absorbância (abs) em função da concentração de SMX ([SMX]) a diferentes $\mathrm{pH}$ e valores de $R^{2}$ correspondentes.

Tabela 5 - Resultados dos experimentos de fotólise de SMX em solução aquosa.

Tabela 6 - Análise de variância (ANOVA) para a resposta $Y_{1}$. Consideramse $95 \%$ de confiança e 6 graus de liberdade $(t=12,7062)$. $X_{1}$ :variável codificada correspondente à concentração de sulfametoxazol; $X_{2}$ :variável codificada correspondente ao $\mathrm{pH}$

Tabela 7 - Domínio experimental dos novos valores das variáveis estudadas.

Tabela 8 - Análise de variância (ANOVA) para a resposta $Y_{1}$ (tempo necessário para remoção de $50 \%$ da quantidade inicial de SMX). Consideram-se $95 \%$ De confiança e 3 graus de liberdade $(t=3,1825) . X_{1}$ : variável codificada correspondente a $[\mathrm{SMX}]_{0} ; X_{2}$ : variável codificada correspondente ao $\mathrm{pH}_{0}$.

Tabela 9 - Experimento com intervalos de irradiação/não-irradiação alternados ("liga-desliga"). 


\section{LISTA DE SIGLAS}

CE50

COT

DW

ETA

ETE

HPLC

LC-TOF-MS

LC-ESI-Q-TOF-MS

OD

POA

SMX

SW
Concentrações efetivas do agente tóxico que causam $50 \%$ da morte dos micro-organismos

Carbono Orgânico Total

Água destilada (distilled water)

Estação de Tratamento de Água

Estação de Tratamento de Efluentes

Cromatografia Líquida de Alta Eficiência

Cromatografia Líquida e Analisador por Tempo de

VooAcoplado a Espectrometria de Massa

Cromatografia Líquida de Ionização por Electrospray e Analisador Quadrupolo por Tempo de Voo

Oxigênio Dissolvido

Processos Oxidativos Avançados

Sulfametoxazol

Água do mar (sea water) 


\section{LISTA DE SÍMBOLOS}

$\mathrm{K}_{\mathrm{a}} \quad$ Constante de equilíbrio ácido-base 


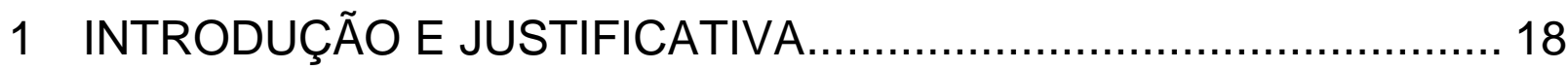

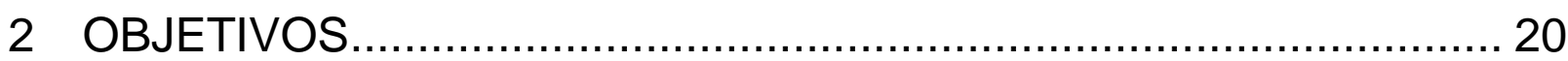

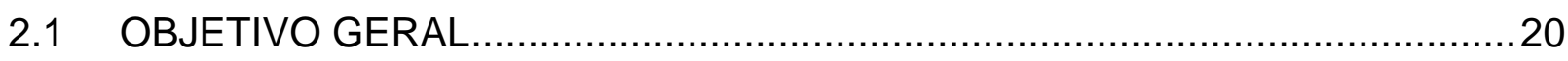

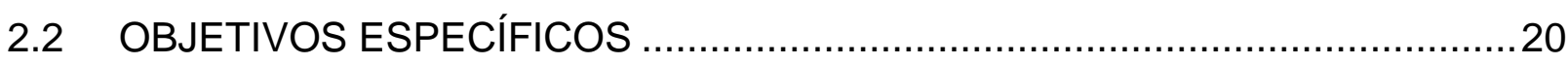

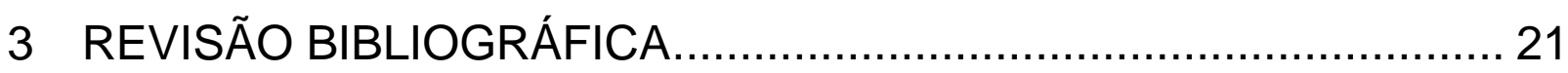

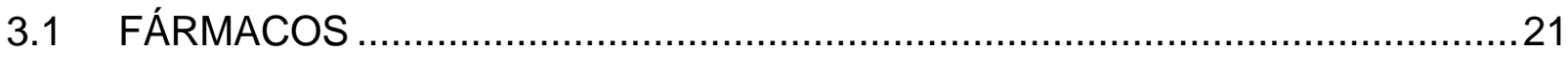

3.2 FÁRMACOS NO MEIO AMBIENTE ...........................................................22

3.3 TRATAMENTO DE EFLUENTES CONTENDO PRODUTOS FARMACÊUTICOS 24

3.4 EFEITOS ECOTOXICOLÓGICOS E IMPLICAÇÕES PARA A SAÚDE HUMANA 27

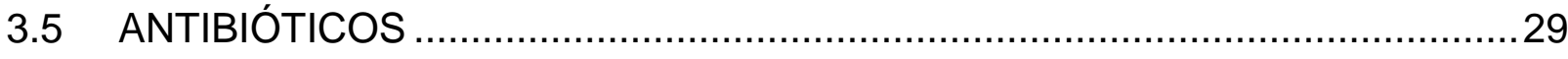

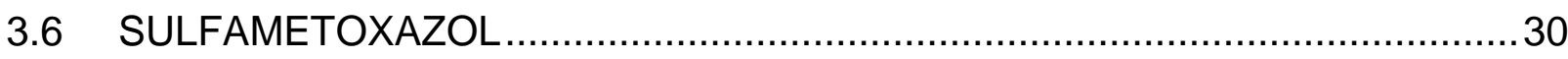

3.7 TOXICIDADE DO SULFAMETOXAZOL EM SOLUÇÃO AQUOSA...................33

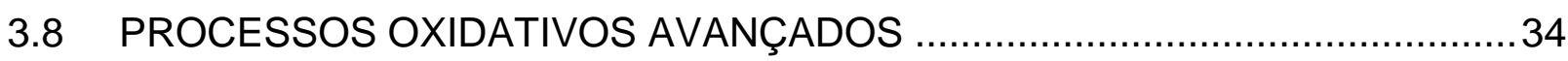

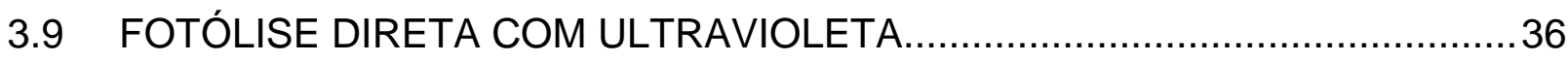

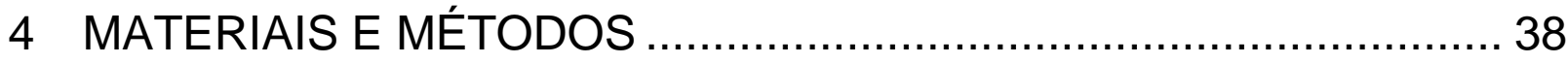

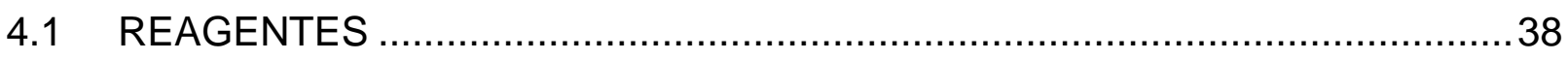

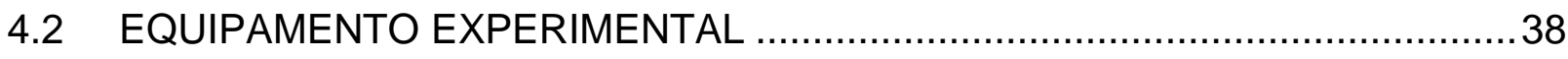

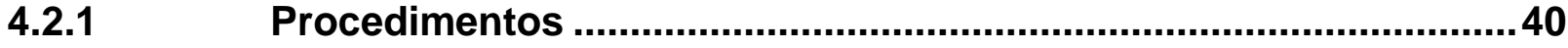

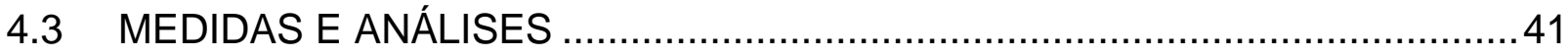

4.3.1 $\mathrm{pH}$, temperatura e concentração de oxigênio dissolvido (OD) ......41

4.3.2 Carbono orgânico total (COT) .....................................................41

Espectrofotometria UV-visível ..................................................41

4.3.4 Cromatografia Líquida de Alta Eficiência - detector de fluorescência42

Análise de toxicidade. 42

4.3.6 Bioensaios de respirometria ......................................................44

4.3.7 Ensaio de hidrólise de sulfametoxazol em solução aquosa ..........47

4.3.8 Actinometria .............................................................................47 


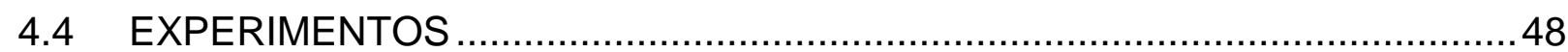

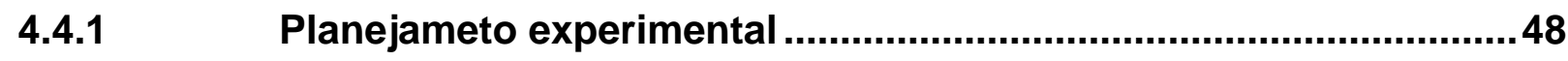

5 RESULTADOS E DISCUSSÃO ............................................. 51

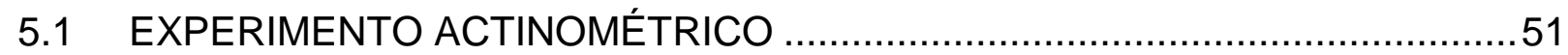

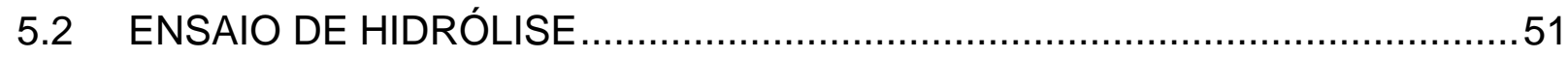

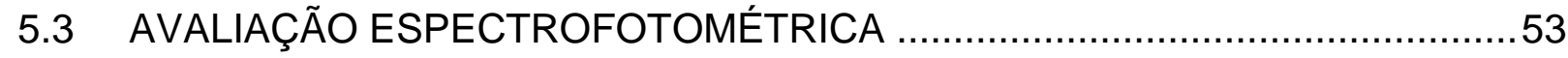

5.4 OBTENÇÃO DO pKA DE SOLUÇÕES AQUOSAS DE SMX …......................55

5.5 ESTUDO DA DEGRADAÇÃO DO SULFAMETOXAZOL POR FOTÓLISE

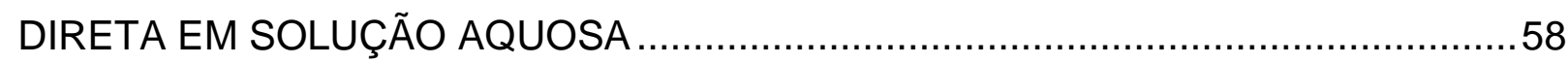

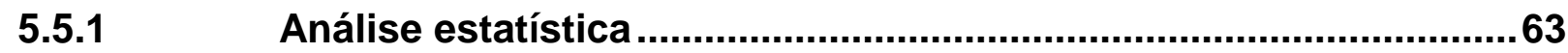

5.5.2 Análise da degradação do sulfametoxazol em 180 minutos ..........72

5.5.3 Análise da influência do pH na degradação de sulfametoxazol ....73

5.5.4 Experimentos em meio anóxico .......................................................77

5.5.5 Experimento com intervalos de irradiação/não-irradiação alternados 79

5.6 PRODUTOS FORMADOS NA FOTÓLISE DO SULFAMETOXAZOL ................81

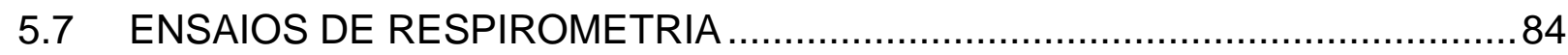

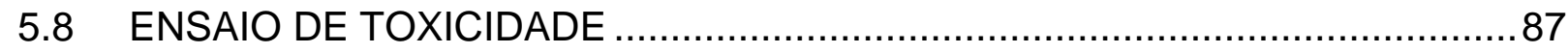

6 CONCLUSÕES E SUGESTÕES ............................................ 89

7 REFERÊNCIAS BIBLIOGRÁFICAS ....................................... 91 


\section{INTRODUÇÃO E JUSTIFICATIVA}

O Brasil é um dos maiores consumidores de medicamentos, assim como EUA, França e Alemanha. Em algumas investigações realizadas na Áustria, Brasil, Canadá, Croácia, Inglaterra, Alemanha, Grécia, Itália, Espanha, Suíça, nos Países Baixos e EUA, mais de 80 compostos farmacêuticos foram encontrados em concentrações acima de $\mu \mathrm{g} / \mathrm{L}$ em esgoto, águas subterrâneas e superficiais (BILA; DEZOTTI, 2003). Em 2011, o consumo anual de antibióticos no Brasil foi de 94,7 milhões de unidades (ANVISA, 2011). Estes são os compostos farmacêuticos mais encontrados em ambientes aquáticos, pois são apenas parcialmente degradados em estações de tratamento biológico devido a sua natureza e também o seu uso em aquicultura e na criação de animais. Os principais caminhos de contaminação são os efluentes das Estações de Tratamento de Esgoto (ETE) e o lançamento de esgoto não tratado. Na última década, o aumento da resistência das bactérias foi acelerado devido à presença desses compostos de ação específica e potente. Há indícios de que o desenvolvimento dessa resistência é favorecido por baixas concentrações de antibiótico no meio ambiente. O risco da exposição crônica, como ingerir água contaminada com fármacos ainda está em debate, mas estudos mostram que o crescimento de células embrionárias é inibido quando tais células são expostas a treze diferentes tipos de medicamentos em concentração de ng/L (HENSCHEL et al. 1997; HEBERER, 2002; STUMPF et al., 1999; TROVÓ et al., 2009; LOCATELLI; SODRÉ; JARDIM, 2010; HU et al., 2007).

Uma avaliação criteriosa dos efeitos desses fármacos no meio aquático é necessária e, uma vez conhecidos, devem-se estabelecer limites de concentrações para o descarte seguro de efluentes domésticos tratados em corpos receptores. $O$ monitoramento da eficiência de remoção desses fármacos pelos processos convencionais de tratamento de efluentes domésticos das ETE é de grande importância e no futuro devem ser feitas adaptações, ou mesmo a implantação de outros processos de tratamento, que levem a remoção adequada desses fármacos (BILA; DEZOTTI, 2003). Entre os novos processos de descontaminação, os chamados "Processos Oxidativos Avançados" (POA) vêm atraindo grande interesse devido a seu potencial como alternativa ou complementos aos processos 
convencionais de tratamento de efluentes. São baseados na formação de radicais hidroxila $\left({ }^{\circ} \mathrm{OH}\right)$, agente altamente oxidante que pode reagir com uma grande variedade de classes de compostos (NOGUEIRA, 1998).

Os POA podem ser aplicados à degradação de resíduos de fármacos, tanto na saída das ETEs quanto em etapas finais do processo de tratamento das Estações de Tratamento de água (ETA). A remoção desses resíduos de efluentes de ETEs (municipais e de indústrias farmacêuticas) evitaria a contaminação de águas superficiais por essa fonte e, consequentemente, os efeitos em organismos aquáticos poderiam ser minimizados. Por outro lado, a água captada para tratamento em ETA, que pode estar contaminada por resíduos de fármacos provenientes de outras fontes, como esgoto doméstico in natura e de origem rural, após passar pelos processos convencionais de tratamento poderia ser submetida a um POA para a remoção de compostos orgânicos, inclusive os resíduos de fármacos. Dessa forma, esses resíduos não estariam presentes na água potável evitando, assim, possíveis efeitos prejudiciais à saúde humana (MELO et al., 2009).

Neste trabalho foi estudada a degradação do antibiótico sulfametoxazol (SMX), intensamente utilizado desde os anos 1940; vários estudos têm apontado sua presença em ambientes aquáticos. O processo estudado para sua degradação é a fotólise direta, no qual se utiliza apenas irradiação UV para quebra do composto. Desenvolveu-se a metodologia analítica para acompanhamento da degradação do SMX utilizando-se como ferramenta a cromatografia líquida de alta eficiência (HPLC). O planejamento experimental baseado na matriz Doehlert foi empregado no estudo da degradação do antibiótico. 


\section{OBJETIVOS}

\subsection{OBJETIVO GERAL}

O objetivo deste trabalho é estudar a degradação do composto sulfametoxazol em solução aquosa por meio de fotólise direta.

\subsection{OBJETIVOS ESPECÍFICOS}

- Avaliar a degradação do fármaco em termos das variáveis: concentração inicial do sulfametaxazol e pH;

- Caracterizar soluções aquosas antes e após o tratamento quanto à degradação do fármaco, à remoção de carbono orgânico total, à biodegradabilidade e à toxicidade, a fim de avaliar a eficiência dos processos estudados;

- Interpretar o possível mecanismo de degradação do antibiótico a partir dos resultados obtidos. 


\section{REVISÃO BIBLIOGRÁFICA}

\subsection{FÁRMACOS}

Fármaco é uma denominação genérica para compostos utilizados tanto na medicina humana como veterinária. Os esgotos municipais contêm uma gama de compostos orgânicos persistentes derivados das diversas atividades humanas, entre os quais são encontrados os produtos farmacêuticos, usados em grandes quantidades em todo o mundo (ALMEIDA; WEBER, 2005).

$\mathrm{Na}$ década de 1970, a presença de fármacos em ambientes aquáticos começou a ser observada. Desde então, diversos estudos têm sido realizados e revelam a presença de resíduos de fármacos em várias partes do mundo (MELO et al., 2009). Tais compostos não têm limites ambientais estabelecidos e pouco se conhece sobre sua transformação em ambientes aquáticos naturais e os possíveis efeitos sinérgicos que podem ocorrer no ambiente. No entanto a ocorrência desses compostos pode apresentar efeitos adversos em organismos aquáticos e terrestres, os quais provavelmente devem ser dependentes do comportamento farmacocinético de cada fármaco, como meia-vida, metabolismo, excreção etc. Alguns desses efeitos podem ser observados em concentrações da ordem de ng/L. Uma das razões da falta de dados é que a regulamentação de drogas é feita por agências de saúde, as quais não consideram as questões ambientais, pois até recentemente, os fármacos não eram vistos como substâncias potencialmente tóxicas ao meio ambiente (ALMEIDA; WEBER, 2005).

No mundo inteiro, tem-se constatado o aumento da resistência bacteriana a diversas drogas de uso comum. Entretanto, nas últimas três décadas, foram desenvolvidos poucos antibióticos novos, sendo, pois necessário conservar os antibióticos já existentes. As bactérias, quando expostas a baixas doses de antibióticos, vão gradualmente se tornando tolerantes a estes antibióticos e desenvolvendo resistência (SAHOO et al., 2010). Este quadro é agravado, uma vez que os fármacos não são completamente eliminados durante os processos convencionais de tratamento de esgotos (BILA; DEZOTTI, 2003; ALMEIDA; WEBER, 2005). 


\subsection{FÁRMACOS NO MEIO AMBIENTE}

Pouco se conhece sobre o destino dos fármacos no meio ambiente. A Figura 1 mostra esquematicamente a introdução de produtos farmacêuticos no ambiente aquático. Os problemas ocasionados por fármacos no meio ambiente não são diferentes de outros resíduos descartados. Grandes quantidades de fármacos são lançadas nas redes de tratamento de esgoto e os de uso veterinário são descartados diretamente no solo (ISIDORI et al., 2005).

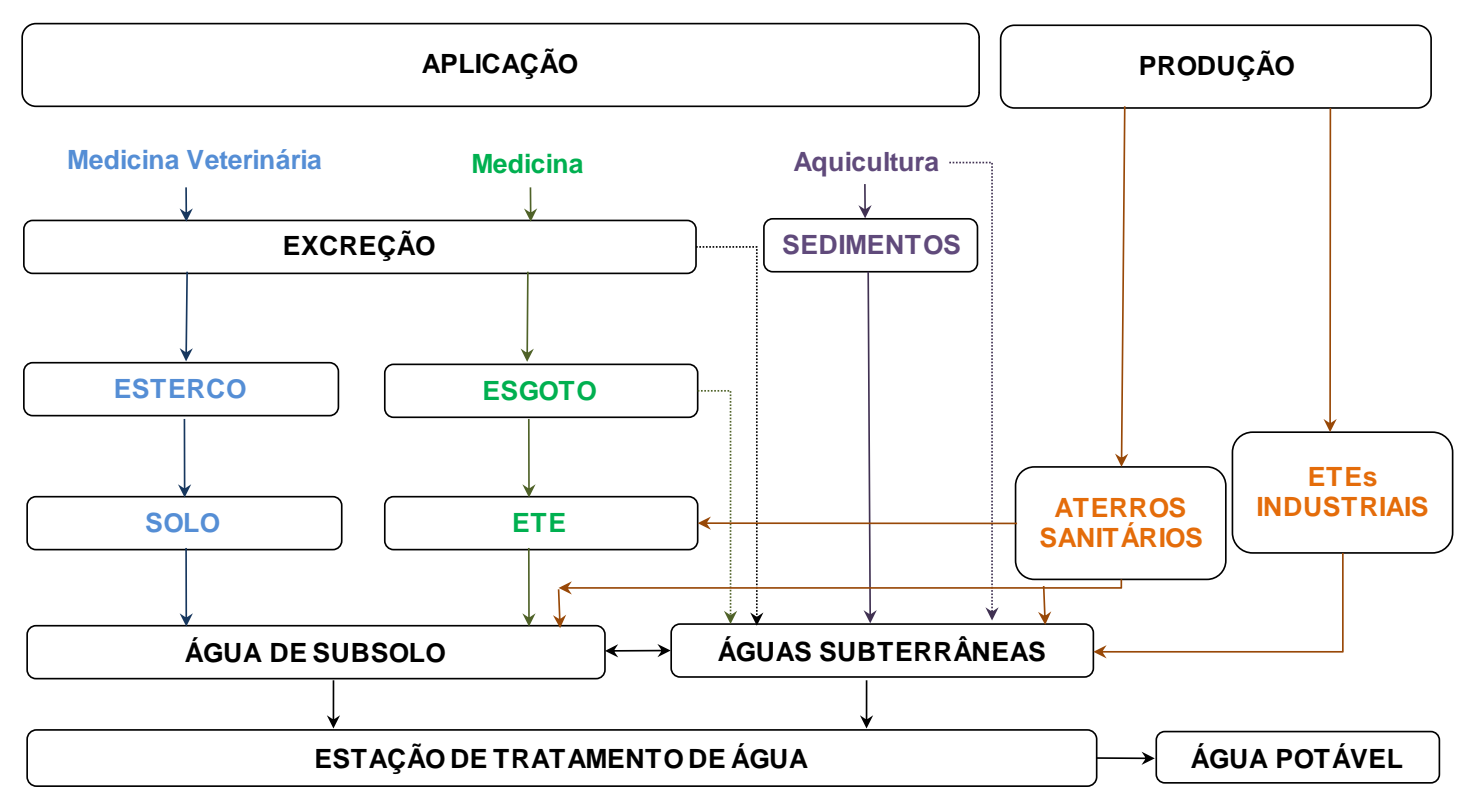

Figura 1 - Caminho dos fármacos no meio ambiente (adaptado de BILA e DEZOTTI, 2003).

Estudos mostram que os valores típicos de concentração dos fármacos encontrados em ambientes aquáticos está relacionado com o padrão de consumo dos mesmos pela população, taxa de remoção nas ETEs, tipo de efluente que aporta nas ETEs e sazonalidade (MELO et al., 2009).

As estações de tratamento de esgotos (ETEs) têm papel fundamental na remoção desses compostos para o ambiente aquático, pois os fármacos podem ser degradados, adsorvidos ou ainda reativados, como resultado da atividade microbiana. Estudos de degradação em ETEs mostram que a adsorção em sedimentos e lodos, bem como a biodegração dos compostos como analgésicos, 
antibióticos, oncolíticos, hormônios, entre outros, é bastante variável (LI, 2010). Os efluentes hospitalares, nos quais as concentrações de drogas individuais ocorrem a cima de $100 \mu \mathrm{g} / \mathrm{L}$, também contribuem enormemente para o lançamento de fármacos no ambiente (ALMEIDA; WEBER, 2005).

Investigações sobre a contaminação de diferentes ambientes aquáticos por fármacos residuais revelam que esses contaminantes estão presentes em todo o mundo. A Tabela 1 apresenta um resumo das concentrações médias de fármacos detectados no meio ambiente.

Tabela 1 -Fármacos encontrados no meio ambiente (MELO et al., 2009).

\begin{tabular}{|c|c|c|}
\hline $\begin{array}{c}\text { Fármaco } \\
\text { (classe terapêutica) }\end{array}$ & $\begin{array}{c}\text { Concentração média } \\
\text { no meio ambiente } \\
(\mu \mathrm{g} / \mathrm{L})\end{array}$ & Matriz \\
\hline $\begin{array}{l}\text { Amoxicilina } \\
\text { (antibiótico) }\end{array}$ & 0,013 & $\begin{array}{l}\text { Esgoto bruto } \\
\text { Itália }\end{array}$ \\
\hline $\begin{array}{c}\text { Ciprofloxacina } \\
\text { (antibiótico) }\end{array}$ & 0,060 & $\begin{array}{c}\text { Efluente de ETE } \\
\text { França }\end{array}$ \\
\hline $\begin{array}{c}\text { Diclofenaco } \\
\text { (anti-inflamatório) }\end{array}$ & 0,810 & $\begin{array}{c}\text { Efluente de ETE } \\
\text { Alemanha }\end{array}$ \\
\hline $\begin{array}{l}\text { 17a-etinilestradiol } \\
\text { (hormônio } \\
\text { contraceptivo) }\end{array}$ & 0,001 & $\begin{array}{c}\text { Efluente de ETE } \\
\text { Canadá }\end{array}$ \\
\hline $\begin{array}{c}\text { Ibuprofeno } \\
\text { (anti-inflamatório) }\end{array}$ & 0,190 & $\begin{array}{c}\text { Água superficial } \\
\text { Brasil }\end{array}$ \\
\hline $\begin{array}{c}\text { Sulfametoxazol } \\
\text { (antibiótico) }\end{array}$ & 0,410 & $\begin{array}{c}\text { Água subterrânea } \\
\text { Alemanha }\end{array}$ \\
\hline $\begin{array}{l}\text { Trimetropim } \\
\text { (antibiótico) }\end{array}$ & 0,080 & $\begin{array}{c}\text { Efluente de ETE } \\
\text { Grécia }\end{array}$ \\
\hline
\end{tabular}




\subsection{TRATAMENTO DE EFLUENTES CONTENDO PRODUTOS FARMACÊUTICOS}

A atividade farmacêutica pode ser classificada de acordo com o processo de fabricação utilizado, em fermentação, síntese química, extração e formulação. Os efluentes gerados em cada um dos processos apresentam características distintas e quantidade variada. São caracterizados por uma fração orgânica rapidamente biodegradável e compostos refratários, que não são removidos por tratamentos biológicos convencionais, como no caso da formulação de antibióticos, cujo efluente apresenta em geral baixa biodegradabilidade. Estudos recentes indicam que antibióticos, como os do grupo das penicilinas, podem exercer efeitos tóxicos a organismos aquáticos e até promover o desenvolvimento de cepas bacterianas multi-resistentes (ALMEIDA et al., 2004)

No Brasil, os estudos de remoção de fármacos em ETEs brasileiras são raros e esparsos. Ternes et al. (1999) e Stumpf et al. (1999) foram os primeiros a reportar a presença de hormônios e anti-inflamatórios em esgoto, efluentes e em águas de rios no Estado do Rio de Janeiro.

Os processos químicos convencionais baseiam-se na oxidação dos contaminantes pela reação com oxidantes fortes, como peróxido de hidrogênio $\left(\mathrm{H}_{2} \mathrm{O}_{2}\right)$, gás cloro $\left(\mathrm{Cl}_{2}\right)$, dióxido de cloro $\left(\mathrm{ClO}_{2}\right)$ e permanganato $\left(\mathrm{MnO}_{4}{ }^{-}\right)$. Na maioria dos casos, no entanto, a utilização deste tipo de tratamento não promove a mineralização completa dos contaminantes a $\mathrm{CO}_{2}$, havendo a formação de uma grande variedade de subprodutos de degradação, em geral, ácidos orgânicos. No caso da utilização do $\mathrm{Cl}_{2}$, há a formação de compostos organoclorados, que podem ser mais tóxicos que o contaminante inicial, sendo este o principal inconveniente quanto ao uso deste oxidante (MELO et al., 2009).Neste sentido, devido à preocupação quanto à preservação dos ecossistemas aquáticos e ao risco potencial de contaminação da água de abastecimento público, tem-se incentivado em todo o mundo estudos com o objetivo de identificar e quantificar esses resíduos para que se possa minimizar o descarte e desenvolver processos eficientes para removê-los, assim como estão sendo realizados estudos de biodegradação de fármacos (CRESTANA; SILVA, 2011)

A remoção de poluentes orgânicos persistentes, como os fármacos, na água e em efluentes, pode ser obtida utilizando-se biorreatores com membranas, 
Processos Oxidativos Avançados (POAs) e adsorção em carvão ativado (TAMBOSI, 2008). Dentre os citados métodos, um grande destaque tem sido dado ao uso de filtros de carvão ativado biologicamente. Este processo combina adsorção e biodegradação, minimizando a flutuação da qualidade da água tratada, pois uma grande concentração de poluentes na água causa um crescimento na taxa de adsorção, mas quando a concentração decai, a biodegradação toma lugar.

A remoção de fármacos e fragrâncias pelo tratamento primário em uma ETE foi investigada por Carballa et al. (2005). Avaliaram dois processos físico-químicos, coagulação/floculação e flotação. Selecionaram oito compostos, representando os três principais grupos de acordo com suas propriedades físico-químicas. Compostos lipofílicos (fragrâncias sintéticas galoxilina e tonalida), compostos neutros (o tranquilizante diazepan e o antiepilético carbamazepina) e compostos ácidos (os antiinflamatórios ibuprofeno, naproxeno e diclofenaco). Durante a coagulaçãofloculação, os parâmetros considerados foram a seleção dos aditivos, suas doses e a temperatura de operação $\left(12\right.$ ou $25^{\circ} \mathrm{C}$ ). As fragrâncias altamente lipofílicas e o diclofenaco foram removidos com eficiência entre 50 e $70 \%$ em ambas as temperaturas, independentemente das doses e do tipo de coagulantes utilizados. Entretanto, para os demais compostos, que possuem caráter hidrofílico, a redução foi baixa (redução máxima de 25\%). Como exceção a este comportamento a carbamazepina e o ibuprofeno não foram removidos em nenhuma condição testada. Durante a flotação, os parâmetros estudados foram o teor de gordura inicial do efluente e a temperatura. As fragrâncias foram removidas com maior eficiência (35 a $60 \%$ ), seguidas pelo diazepan (40 a 50\%) e pelo diclofenaco (20 a $45 \%$ ), carbamazepina (20-35\%), ibuprofeno (10-25\%) e naproxeno (10-30\%). Os melhores resultados foram obtidos a $25^{\circ} \mathrm{C}$. Os resultados obtidos indicaram que os compostos com maior propriedade de adsorção, como as fragrâncias (galaxolida e tonalida) e o diclofenaco, apresentaram significativa porcentagem de remoção, em torno de $70 \%$ a temperaturas de 12 e $25^{\circ} \mathrm{C}$.

Existem ainda poucos detalhes disponíveis sobre as cinéticas de degradação biológica dos fármacos e dos subprodutos formados (metabólitos). Devido à baixa concentração in-situ, supõe-se que a degradação dos fármacos não contribui significativamente ao crescimento microbiano, sendo necessárias outras fontes de carbono e outros nutrientes (TERNES, 2006). Dentre os fatores que provavelmente exercem influência na capacidade dos microrganismos presentes no lodo em 
remover os fármacos, os principais seriam a biodiversidade da biomassa, fração ativa da biomassa dentro da totalidade dos sólidos suspensos totais e o tamanho dos flocos bacterianos (TERNES, 2006). A idade do lodo mostrou ser um parâmetro crucial na remoção dos fármacos, confirmando que a versatilidade bioquímica do lodo aumenta com sua idade (CLARA et al., 2005).

Drillia et al. (2005) estudaram a biodegradação do antibiótico sulfametoxazol em condições aeróbias através da adaptação de uma cultura mista de microrganismos aeróbios. Os experimentos foram feitos com o objetivo de investigar o impacto de outras fontes de carbono e nitrogênio na degradação do antibiótico. Sulfametoxazol pode servir como fonte de carbono ou nitrogênio ao consórcio bacteriano enriquecido, porém o mesmo é pouco biodegradável. Em condições de ausência de carbono ou nitrogênio, o antibiótico sulfametoxazol foi degradado. Porém, na presença de acetato ou amônia (fontes alternativas de carbono e nitrogênio respectivamente), o sulfametoxazol permaneceu intacto devido a sua baixa biodegradabilidade.

O uso da ultrafiltração, combinado com a clarificação e desinfecção de águas, vem apresentando um aumento significativo desde a década de 1990 (TERNES, 2006). Para membranas com tamanho nominal de poro de $10 \mathrm{~nm}$, a turbidez causada pelos microrganismos (incluindo parasitas, bactérias e vírus) é removida. Entretanto, a maioria das moléculas orgânicas, incluindo os fármacos, permanece no permeado.

Estudos evidenciaram que os processos convencionais de tratamento de esgoto não são eficientes para a remoção de vários resíduos de fármacos. Ressaltase que, ainda são escassas as informações sobre a toxicidade das amostras após tratamento, informações estas fundamentais para garantir a efetividade e segurança da aplicação de tais processos no tratamento de efluentes contendo resíduos de fármaco (CRESTANA; SILVA, 2011). 


\subsection{EFEITOS ECOTOXICOLÓGICOS E IMPLICAÇÕES PARA A SAÚDE HUMANA}

Poucos compostos farmacêuticos foram submetidos à avaliação de riscos, utilizando testes ecotoxicológicos. Os fármacos são fabricados para atingir órgãos ou rotas metabólicas e moleculares específicas tanto em seres humanos quanto em animais, mas também possuem efeitos colaterais importantes. Alguns fármacos não possuem efeito específico ou modo de ação bem conhecidos e, muitas vezes, muitos modos diferentes de ações ocorrem, quando introduzidos no meio ambiente, e assim, podem afetar os animais pelas mesmas rotas e atingir órgãos, tecidos, células ou biomoléculas com funções semelhantes a dos humanos. Os ensaios ecotoxicológicos realizados hoje são desenvolvidos com testes estabelecidos com micro-organismos tradicionais, com o objetivo de determinar a concentração letal necessária para um dado organismo-teste. Esses testes, entretanto, deveriam ser realizados buscando efeito do fármaco em organismos vertebrados e invertebrados baseados na hipótese de semelhança no modo de ação. Assim, a ecotoxicologia testa geralmente o efeito agudo (exposição em curto prazo) desses compostos em organismos vivos de diferentes níveis tróficos e, só raramente os testes são conduzidos a exposições crônicas (longo prazo) (FENT et al., 2006).

O efeito de fármacos residuais na saúde humana deve ser examinado de maneira ordenada e qualitativa. Assim, pode-se destacar que o emprego indiscriminado de antibióticos pode ocasionar o desenvolvimento de resistência em populações bacterianas. $\mathrm{O}$ aumento do uso e tipos de antibióticos durante as últimas cinco décadas resultou em seleção genética de bactérias resistentes, com efeito em longo prazo e, provavelmente, irreversíveis (SANDERSON et al., 2004).

Jørgensen e Halling-Sørensen (2000) relatam em seus estudos que 0 desenvolvimento de resistência é favorecido pela exposição a baixas concentrações de compostos antibióticos. De acordo com Halling-Sørensen et al. (1998), 30 a 90\% da dose da maior parte dos antibióticos administrados aos seres humanos e animais, são excretados na urina como substância ativa. Na medicina veterinária, os antibióticos podem ser utilizados como promotores de crescimento para a produção de gado, como coccidiostáticos na produção avícola ou como aditivos alimentares na criação de peixes. Devido à utilização na criação de peixes, antibióticos como o cloranfenicol e a oxitetraciclina têm sido detectados em sedimentos de lagoas na 
aquicultura (CHIEN et al., 1999). Recentemente, alguns pesquisadores investigaram um grupo específico de compostos químicos, presentes no meio ambiente, que são responsáveis por causar perturbações no sistema endócrino (hormonal) de organismos humanos e animais: são os chamados perturbadores endócrinos (EDCs). Dentre esse grupo de substâncias estão os estrogênios naturais e contraceptivos (BILA et al., 2007). Alguns autores relatam que, dependendo da dose e do tempo de exposição, é possível que essas substâncias estejam relacionadas com doenças como câncer de mama, testicular e de próstata, ovários policísticos e redução da fertilidade masculina (MILLS; CHICHESTER, 2005).

Os peixes são um dos grupos de organismos mais completamente estudados em termos de efeito de substâncias com atividade estrogênica no desenvolvimento de anomalias no sistema reprodutivo. De acordo com Sumpter (1998), as pesquisas relacionadas ao efeito de substâncias estrogênicas sobreo sistema reprodutor de peixes começaram na década de 1980. Os impactos de substâncias químicas como os fármacos, podem incluir qualquer nível de hierarquia biológica: células, órgãos, organismos, populações e ecossistemas. Efeitos sutis podem incluir seleção genética, perturbação endócrina, genotoxicidade e subsequentemente alterar 0 comportamento metabólico e funções da espécie no ecossistema (JØRGENSEN; HALLING-SØRENSEN, 2000).

Atualmente, dois tópicos sobre o efeito desses fármacos no meio ambiente são os mais discutidos. O desenvolvimento de resistência bacteriana aos antibióticos e avaliações de perturbações no sistema endócrino por substâncias como estrogênios. Outros efeitos possíveis têm sido pouco discutidos (BILA; DEZOTTI, 2003) 


\subsection{ANTIBIÓTICOS}

Antibióticos correspondem à maior categoria de fármacos utilizados na medicina humana e veterinária. São utilizados como promotores de crescimento ou para propósitos terapêuticos e normalmente detectados em afluentes e efluentes de plantas de tratamento de esgotos municipais na ordem de $\mathrm{ng} / \mathrm{L}$ e $\mu \mathrm{g} / \mathrm{L}$. Estudos recentes mostraram que vários antibióticos de uso veterinário possuem persistência moderada em águas superficiais, tanto em condições aeróbias, como anaeróbias. Vários pesquisadores relatam que durante testes de biodegradação, certos antibióticos são ativos contra diferentes grupos de bactérias presentes (KÜMERER, et al., 2000). Porém, outros autores não observaram nenhuma inibição significativa da atividade biológica em condições anaeróbias.

A importância da remoção dos antibióticos em sistemas de tratamento de efluentes se deve ao fato deles promoverem a resistência bacteriana. Vários trabalhos vêm sendo realizados nos Estados Unidos e na Europa, para investigar a ocorrência e o destino de antibióticos em plantas de tratamento de esgotos e águas superficiais, incluindo antibióticos da classe das fluorquinolonas (ciprofloxacina, norfloxacina), sulfonamidas (sulfametoxazol), trimetropim, antibióticos macrolidas (claritromicina, dehidro-eritromicinam, que é um metabólito da eritromicina, e da classe das tetraciclinas (HARTING et al., 1999). Diversos antibióticos pertencentes à classe das macrolidas, sulfonamidas, penicilinas e tetraciclinas, foram estudadas por Hirschet al. (1999) em efluentes de ETE e em águas de rios verificou-se a ocorrência frequente de eritromicina, roxitromicina e sulfametoxazol em concentrações acima de $6 \mu \mathrm{g} / \mathrm{L}$. Goletet al. (2002) estudou a dispersão de fluoroquinolas em lagos do vale do Rio Glatt, na Suécia. Os compostos contendo fluoroquinolonas mais consumidos na Suécia, ciprofloxacina e norfloxacina, foram encontrados em efluentes municipais e águas superficiais daquele rio. Suas concentrações individuais no afluente e na saída de uma ETE variaram de 568 para 255 ng/L e de 106 para 36 ng/L, respectivamente. No Rio Glatt, fluoroquinolonas estavam presentes em concentrações abaixo de $19 \mathrm{ng} / \mathrm{L}$. A remoção de fluorquinolonas nas ETEs variou entre 79 e $87 \%$. A concentração encontrada dos antibióticos em águas superficiais e subterrâneas geralmente está na faixa de $\mu \mathrm{g} / \mathrm{L}$ e ng/L (KRAUSE, 2009). 


\subsection{SULFAMETOXAZOL}

O grupo bactericida sulfonamida é considerado um dos primeiros antibióticos utilizados no combate de infecções humanas e vem sendo produzido intensamente desde os anos 1940. As sulfonamidas são antibióticos sintéticos, de amplo espectro, que inibem a síntese do ácido fólico de bactérias, composto essencial para sua sobrevivência. Atualmente, apenas algumas sulfonamidas continuam sendo utilizadas, devido ao desenvolvimento da resistência bacteriana. O sulfametoxazol (SMX), pertencente ao grupo sulfonamida, é considerado um micro-contaminante emergente, devido ao seu potencial efeito adverso ao ecossistema e à saúde humana (SADAÑA et al., 2004; AVISAR; LESTER; RONEN, 2009; ISIDORI et al., 2005).

O SMX é denominado pela IUPAC como 4-amino-N-(5-metil-3-isoxazolil) benzenossulfonamida e tem fórmula molecular $\mathrm{C}_{10} \mathrm{H}_{11} \mathrm{~N}_{3} \mathrm{O}_{3} \mathrm{~S}$. Possui amplo espectro e picos de concentração plasmática de 1 a 4 horas e tempo de meia-vida de 11 horas; o SMX é encontrado na urina inalterado e em concentrações próximas de $10 \%$ a 30\% em relação à concentração inicial(IQUEGO, 2009).

Na Figura 2 estão representadas as estruturas químicas do SMX e a estrutura geral das sulfonamidas.

a)

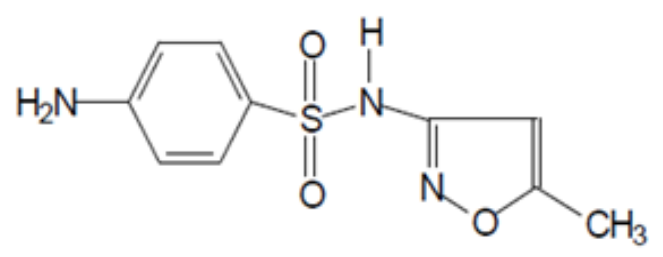

b)

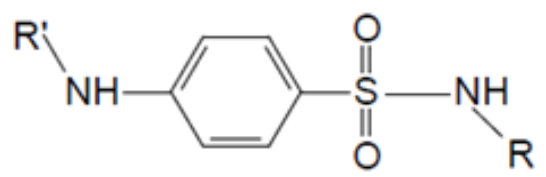

Figura 2 - a) Estrutura química do SMX. b) Estrutura química geral das sulfonamidas.

As sulfonamidas (sulfadimetoxina, sulfametazina, e sulfametoxazol) foram detectadas em amostras de águas superficiais e efluentes de ETE nos Estados Unidos e na Alemanha em concentrações na faixa de $\mu \mathrm{g} / \mathrm{L}$ (BILA; DEZOTTI, 2003). Locatelli, Sodré e Jardim (2010) avaliaram as concentrações de antibióticos no Rio 
Atibaia, região de Campinas - SP e encontraram concentração média de $0,1 \mu \mathrm{g} / \mathrm{L}$ de SMX. Na Espanha, França Grécia, Itália, Alemanha e Suécia as concentrações de SMX nos efluentes das plantas de ETE variaram entre 0,01 e $2 \mu \mathrm{g} / \mathrm{L}$ e nas águas superficiais,suas concentração variaram entre 0.03 e 0,48 $\mu \mathrm{g} / \mathrm{L}$ (TROVÓ et al., 2009). Avisar, Lester e Ronen (2009) quantificaram a concentração de SMX no lençol freático em Israel, encontrando concentração de $37 \mathrm{ng} / \mathrm{L}$; nas águas superficiais a concentração média foi de $20 \mathrm{ng} / \mathrm{L}$.

Cruz et al. (2010) avaliaram a degradação dos compostos sulfametoxazol, trimetropim e diclofenaco potássico por processos fotocatalíticos empregando $\mathrm{TiO}_{2} \mathrm{e}$ $\mathrm{ZnO}$. Os processos de fotocatálise heterogênea permitiram degradação eficiente dos fármacos em solução aquosa, reduzindo sua concentração até níveis não detectáveis pelo método cromatográfico utilizado $(0,5 \mathrm{mg} / \mathrm{L})$ em tempos de reação de 30 minutos para trimetoprima e 10 minutos para diclofenaco e sulfametoxazol. Em condições ótimas de tratamento $\left(\mathrm{pH}=4\right.$ e $50 \mathrm{mg} / \mathrm{L}$ de $\left.\mathrm{TiO}_{2}\right)$, alcançaram-se valores de aproximadamente $80 \%$ de mineralização para os fármacos estudados após 120 minutos de tratamento.

Goméz-Ramos et al. (2011) estudaram o mecanismo de degradação do antibiótico SMX por ozonização. Encontraram duas rotas principais de degradação, uma relacionada ao ataque molecular do ozônio e outra ao ataque do radical hidroxila, levando à formação de seis intermediários, que foram identificados por cromatografia líquida associada a espectrometria de massas(LC-ESI-Q-TOF-MS). Ambas as rotas ocorreram simultaneamente nas diferentes condições testadas, levando à reação de hidroxilação do anel bezênico, à oxidação do grupo amino do anel benzênico, à oxidação do grupo metila do anel isoxazol e à clivagem da ligação dupla do anel isoxazol, bem como da ligação S-N. A reação intermediária mais comum foi a resultante clivagem da ligação S-N. A toxicidade foi avaliada utilizando os organismos-teste Daphnia magna e Pseudokirchneriellae revelou a formação de subprodutos tóxicos a esses organismos durante os estágios iniciais da reação, que persistiram até o final da reação.

Trovóet al. (2009) investigaram a transformação fotoquímica do SMX em diferentes matrizes de água: água destilada (DW), água destilada + nitrato (10 e 20 $\mathrm{mg} / \mathrm{L}$ ) e água do mar (SW) para avaliar sua toxicidade, persistência e via de degradação. Um simulador solar foi utilizado para os experimentos sob irradiação. A identificação de subprodutos foi realizada por cromatografia líquida associada a 
espectrometria de massas (LC-TOF-MS). Observaram-se diferenças nas taxas de degradação em DW e SW, sendo as reações mais lentas na matriz SW. A presença de nitrato (fotólise indireta) em água destilada não afetou a taxa de degradação SMX. Não houve remoção de carbono orgânico dissolvido (COD) em nenhum caso, indicando a formação de produtos persistentes. A análise por LC-TOF-MS permitiu a identificação de até nove produtos de transformação durante a fotólise em DW e apenas três deles haviam sido relatados na literatura. A clivagem da ligação sulfonamida e a foto-isomerização por rearranjo do anel isoxazol representam os principais caminhos de degradação, que geram os intermediários mais abundantes e persistentes. A toxicidade aguda da solução de SMX variou de acordo com organismos de teste, tendo sido o organismo Daphnia magna o mais sensível, mostrando um aumento de $60 \%$ para $100 \%$ de imobilização após $30 \mathrm{~h}$ de irradiação, quando a destruição de SMX foi alcançada, indicando a maior toxicidade dos produtos gerados após irradiação do SMX.

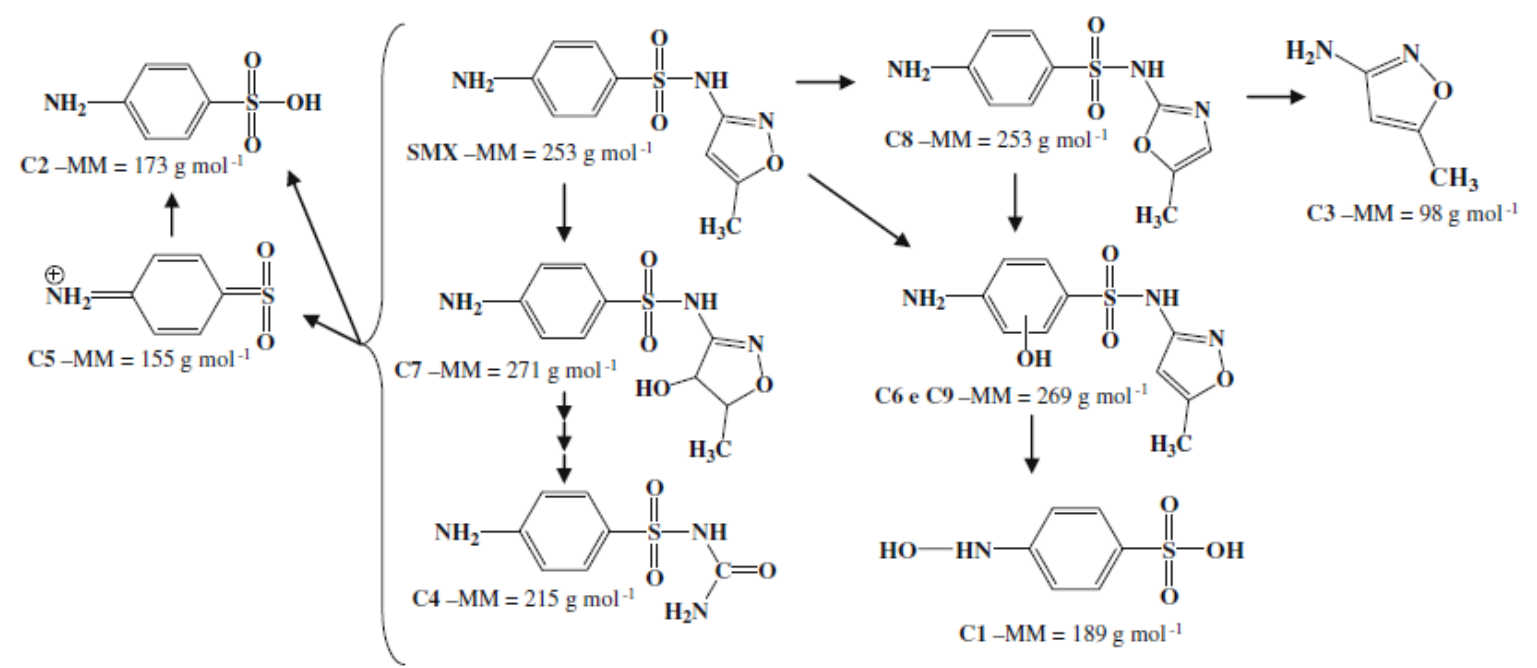

Figura 3 - Caminho de degradação por fotólise direta em água destilada proposto por Trovóet al., 2009.

O mecanismo proposto por Trovó et al. (2009) para as reações fotoquímicas, apresentado na Figura 3, mostra a clivagem da ligação sulfonamida e o rearranjo do anel isoxazol. Esses dois caminhos geram os intermediários mais abundantes e persistentes (C2, C3 e C8);reações de hidroxilação também ocorrem no anel aromático, como mostra a Figura 3. A adição do radical hidroxila ao anel isoxazol 
ocorre em toda a formação de $\mathrm{C} 7$, bem como ocorre com $\mathrm{C} 4$, que representa a única evidência da abertura do anel isoxazol.

\subsection{TOXICIDADE DO SULFAMETOXAZOL EM SOLUÇÃO AQUOSA}

Efeitos de toxicidade costumam ser observados somente em concentrações acima de $1 \mu \mathrm{g} / \mathrm{L}$. No entanto, é importante salientar que os bioensaios de toxicidade medem frequentemente efeitos agudos, quando na realidade os organismos aquáticos são expostos a baixas concentrações de forma contínua e, portanto, efeitos crônicos são mais prováveis. Estes últimos são mais escassamente avaliados, pois um longo prazo é requerido para constatação da toxicidade crônica (MELO et al., 2008). Agentes antibacterianos são conhecidos por causar efeitos irreversíveis aos genes dos micro-organismos, mas existem poucas informações sobre os efeitos causados aos processos de tratamento de efluentes e a vida dos micro-organismos nas águas de superfície(ISIDORI et al., 2005).

No momento, um ponto crítico neste tema é saber se existe um nível elevado dessas substâncias no meio ambiente, que sejam suficientes para exercer efeitos adversos em seres vivos. Esta questão estimula o desenvolvimento de estudos de impacto ambiental causado por diferentes fármacos presentes no meio ambiente. Dados ecotoxicológicos têm sido levantados por pesquisadores, para identificar fármacos que são potencialmente perigosos para o meio ambiente (BILA; DEZOTTI, 2003).

De acordo com a norma da CETESB L.5.227 (2001) o teste de toxicidade com a bactéria luminescente Vibrio fischeri é utilizado para determinar a toxicidade aguda de amostras líquidas. Nesse ensaio a emissão de luz é medida, em condições padronizadas, antes e após a exposição da bactéria Vibrio Fischeri a várias concentrações da amostra, por um período de 15 a 30 minutos, sendo a redução da emissão de luz entre a primeira e a segunda medição proporcional à toxicidade da amostra testada. Utilizam-se as concentrações efetivas do agente tóxico que causam $50 \%$ da redução na quantidade de luz (CE50) emitida pelo microorganismo-teste, após sua exposição a esse agente durante determinado tempo. 
A avalição de toxidade aguda com a Daphnia magna consiste em expor indivíduos jovens do microcrustáceo a várias diluições do agente teste por um período de 48 horas, onde o efeito tóxico agudo é determinado através da perda de movimento do organimos (RODRIGUES, 2005).

Trovó e colaboradores (2009) avaliaram a toxicidade do SMX utilizando bactérias luminescentes Vibrio fischeri e microcrustáceos Daphnia magna. Observou-se para concentração de $50 \mathrm{mg} / \mathrm{L}$ mortalidade menor que $50 \%$ para a bactéria Vibrio fischeri; para o teste de imobilização de Daphnia magna foram observados $85 \%$ de inibição da mobilidade após 48 horas de exposição.

Estudos baseados nos parâmetros estabelecidos no documento técnico EU Directive 93/67/EEC pela Comissão da Comunidade Europeia mostraram que o SMX é considerado tóxico para algas $\left(C_{50}=1,53 \mathrm{mg} / \mathrm{L}\right)$. O SMX mostrou-se prejudicial para a bactéria marinha Vibrio fischeri em 15 minutos de exposição $\left(\mathrm{CE}_{50}=78,1 \mathrm{mg} / \mathrm{L}\right)$.

Estudos avaliaram os efeitos causados pelo SMX à planta aquática Leiosyla gibba. Em um teste de sete dias de exposição ao SMX, observou-se $E_{50}=81 \mu \mathrm{g} / \mathrm{L}$ e para algas verdes $0 \mathrm{EC}_{50}$ encontrado foi $16 \mathrm{mg} / \mathrm{L}$, sendo assim, prejudicial a esses organismos (BRENNER, 2009).

\subsection{PROCESSOS OXIDATIVOS AVANÇADOS}

A oxidação química é um tratamento com grande potencial de destruição de compostos não biodegradáveis e contaminantes orgânicos presentes na água. Os POAs estão entre os mais efetivos processos de oxidação química e possuem um potencial importante na área de tratamento de água.

$\mathrm{Na}$ maioria dos POA a oxidação ocorre por meio de radicais hidroxila $\left({ }^{\circ} \mathrm{OH}\right)$, espécies extremamente reativas frente a moléculas orgânicas. Em condições ótimas ocorre a mineralização, ou seja, a completa oxidação do contaminante, os produtos finais formados são dióxido de carbono, água e, dependendo da composição química do contaminante, cloretos, nitratos, sulfatos e fostatos inorgânicos. (ANIPSTAKIS, 2005). 
Os POA podem ser divididos em processos fotolíticos que constituiem, por exemplo, na associação de radiação UV com $\mathrm{H}_{2} \mathrm{O}_{2}$ ou $\mathrm{O}_{3}$ ou fotólise direta de contaminantes, fotocatalíticos homogêneos $\left(\mathrm{H}_{2} \mathrm{O}_{2} / \mathrm{Fe}(\mathrm{II})-\mathrm{UV}\right.$ ou Fenton) e fotocatálise heterogênea (por exemplo, $\mathrm{TiO}_{2} / \mathrm{UV}$ ). Novos tipos de oxidante vêm sendo pesquisados, como o peroximonossulfato de potássio (CRISTINO, 2006).

A eficiência dos POA é fortemente influenciada pela qualidade do efluente a ser tratado. Por exemplo, concentrações altas de espécies sequestradoras de radicais hidroxilas, como o carbonato, bicarbonato e o íon cloreto também reduzem a eficiência do tratamento (CRISTINO, 2006).

$O$ aspecto econômico do POA pode ser uma desvantagem, devido ao consumo de energia elétrica pelas lâmpadas UV utilizadas. Contudo, a combinação de um POA como tratamento preliminar ou como tratamento de polimento pode constituir uma opção interessante. 


\subsection{FOTÓLISE DIRETA COM ULTRAVIOLETA}

A fotólise direta com ultravioleta utiliza a radiação UV como forma de induzira destruição de poluentes, em comparação com processos fotocatalíticos ou que empregam oxidantes auxiliares e que envolvem a geração de radicais hidroxila como principais agentes oxidantes; dessa forma, geralmente a fotólise direta apresenta eficiência mais baixa, o que depende também do papel do oxigênio dissolvido na solução. Na fotólise direta, o contaminante-alvo deve absorver a radiação incidente, o que pode resultar em reações que levam à sua degradação (ou não) a partir de seu estado eletrônico excitado, ou o contaminante pode retornar ao estado fundamental inicial (VASCONCELOS; GOMES, 2009).

A maioria dos estudos quantifica a contribuição da fotólise da matéria orgânica em processos de oxidação em que ela atua de forma conjunta, por exemplo, $\mathrm{H}_{2} \mathrm{O}_{2} / \mathrm{UV}, \mathrm{O}_{3} / \mathrm{UV}$ e $\mathrm{H}_{2} \mathrm{O}_{2} / \mathrm{O}_{3} / \mathrm{UV}$, os quais não exigem que o poluente-alvo absorva a radiação incidente, o que cabe ao(s) oxidante(s) auxiliar(es) empregado(s) ou ao(s) fotocatalisador(es). Contudo, há casos em que os poluentes absorvem significativamente a radiação UV, e, consequentemente, a fotólise UV destes compostos pode tornar-se eficiente e atrativa (PARSONS, 2005; VASCONCELOS; GOMES, 2009).

$O$ estado eletronicamente excitado $A B^{*}$, gerado a partir do processo de absorção da radiação UV (eq. (1)), é altamente energético e pode retornar ao estado fundamental ou por processos físicos (tais como fluorescência, fosforescência ou desativação não-radiativa) ou por reações químicas térmicas (PARSONS, 2005). As etapas mais comuns em reações químicas iniciadas por estados excitados são resumidas nas eq. (1) a (6).

$\mathrm{AB}+h v \rightarrow \mathrm{AB}^{*}$

$A B^{*} \rightarrow\left(A^{*} \ldots{ }^{*} B\right) \rightarrow A^{*}+{ }^{*} B$

$\left(A^{*} \ldots{ }^{*} B\right) \rightarrow A B$

$\mathrm{AB}^{*} \rightarrow\left(\mathrm{A}^{*} \ldots{ }^{*} \mathrm{~B}\right) \rightarrow \mathrm{A}^{+}+\mathrm{B}^{-}$ 


$$
\begin{aligned}
& A B^{*}+O_{2} \rightarrow A B^{+\bullet}+O_{2}^{-\bullet} \\
& A B^{*}+{ }^{3} O_{2} \rightarrow A B+{ }^{1} O_{2}
\end{aligned}
$$

A cisão homolítica de ligação química (eq.(2)) corresponde à etapa de reação predominante e ocorre com aprisionamento por solvente (solvente cage). Ao difundir na solução, os radicais seguem reações de oxidação/redução, de acordo com a estrutura da molécula em questão. Os poluentes orgânicos podem seguir diferentes mecanismos de reação na presença e na ausência de oxigênio dissolvido, resultando em diferentes produtos de degradação. A recombinação dos radicais primários, devido ao aprisionamento por solvente (eq.(3)), ocorre com alta probabilidade, o que explica o baixo rendimento quântico da fotólise direta observado com moléculas orgânicas em meio condensado, se comparado à o que se observa em fase gasosa. Processos de transferência de energia e elétron para o oxigênio (eq.(5) e eq.(6)) também podem ocorrer, mas requerem tempo de vida relativamente longo para o estado excitado, tal como o estado triplete. $O$ oxigênio dissolvido é o parceiro de reação mais comumente encontrado para o composto orgânico no estado excitado, principalmente se a concentração em fase aquosa dos demais constituintes é baixa. Espécies altamente reativas, como o radical superóxido (eq.(5)) e oxigênio singlete (eq.(6)), podem ser geradas em conjunto com o cátion-radical do poluente orgânico (eq. (5)) e com a recombinação molecular no estado fundamental (eq.(3)) (PARSONS, 2005).

A degradação de compostos farmacêuticos por radiação UV tem sido reportada na literatura. De acordo com Isidori et al. (2005), a foto-transformação parece ser o seu principal processo de eliminação no meio ambiente, na qual os compostos presente na água pode ser parcialmente transformado por irradiação em diferentes fotoprodutos. 


\section{MATERIAIS E MÉTODOS}

\subsection{REAGENTES}

Utilizou-se água milli-Q (Millipore) no preparo de soluções para obtenção das curvas de calibração cromatográficas. Para a fase móvel foram utilizados: ácido acético $100 \%$, adquirido da Merck; trietilamina grau HPLC e acetonitrila grau HPLC (J.T. BAKER). Para os experimentos de degradação, utilizou-se água purificada por osmose inversa produzida no equipamento PURELAB Prima (ELGA). Para o controle do $\mathrm{pH}$ foram utilizados ácido sulfúrico $98 \%$ P.A. e hidróxido de sódio P.A. (Vetec). O antibiótico sulfametoxazol (CAS 723-46-6, com pureza 99,7\%) foi adquirido da Sigma-Aldrich.

\subsection{EQUIPAMENTO EXPERIMENTAL}

Os experimentos foram realizados em um reator fotoquímico tubularcom escoamento anular, que consiste em um tubo externo em vidro borossilicato com duas peças rosqueáveis em teflon dispostas nas extremidades que permitem a inserção de uma lâmpada de vapor de mercúrio de baixa pressão tubular (Philips, modelo TUV). Um módulo eletrônico é utilizado para acionamento da lâmpada. Durante a operação, o reator é envolvido com papel alumínio. O reator fotoquímico possui as seguintes dimensões: comprimento do tubo, $1120 \mathrm{~mm}$; diâmetro externo, $80 \mathrm{~mm}$; diâmetro interno, $73 \mathrm{~mm}$. A lâmpada UV de $36 \mathrm{~W}$ tem diâmetro de $26 \mathrm{~mm}$, de modo que o volume irradiado é igual a 3,93 L. A entrada e saída de líquido no reator são feitas por tubos posicionados tangencialmente à circunferência do reator. O reator foi operado em batelada com recirculação de líquido, conectado a um tanque de recirculação em vidro com volume de $1 \mathrm{~L}$, termostatizado por meio de um banho (Julabo, modelo EC). O conteúdo do tanque é agitado por meio de um agitador (Tecnal, TE139). A circulação de líquido é feita por meio de uma bomba 
centrífuga, sendo a vazão ajustada por meio de uma válvula agulha e lida em um rotâmetro. Amostras são retiradas diretamente do tanque usando uma pipeta automática.

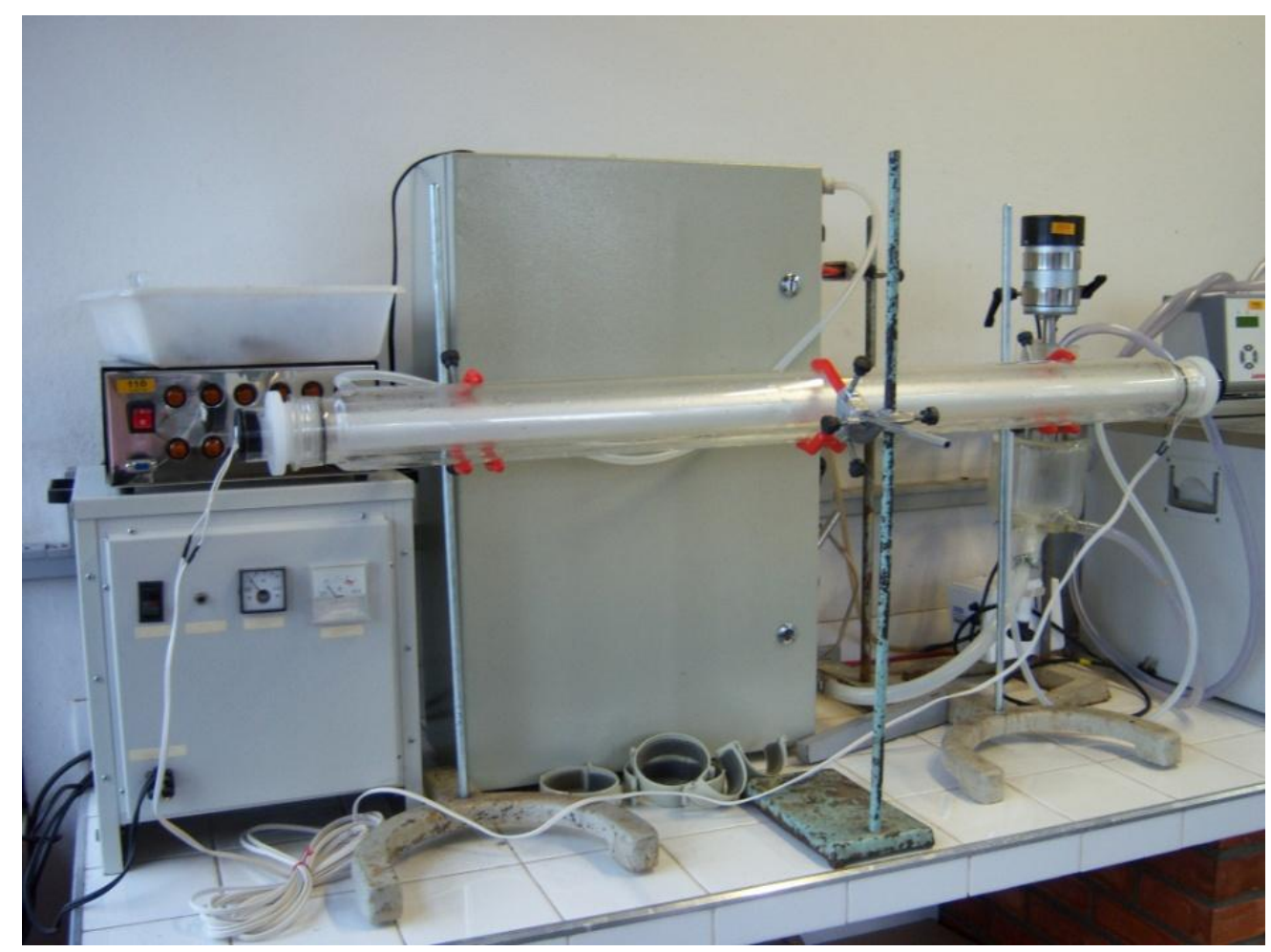

Figura 4 - Reator fotoquímico tubular e equipamento associado.

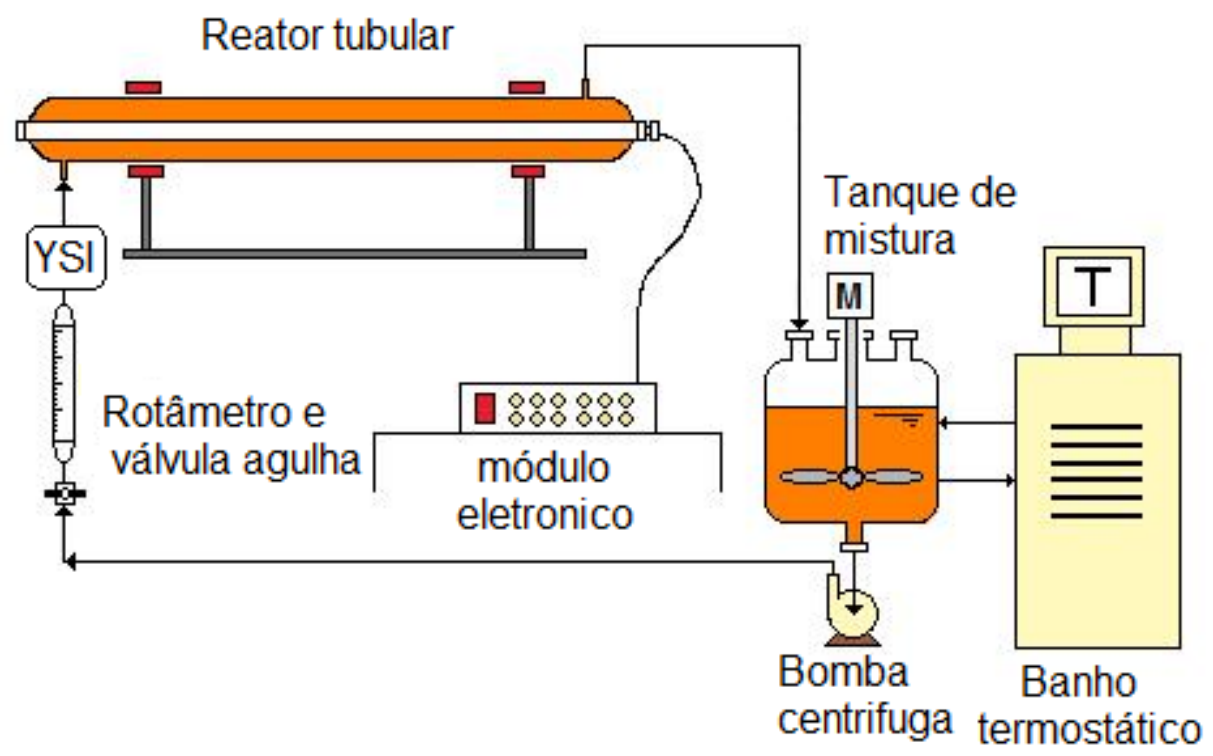

Figura 5 - Esquema do equipamento experimental. 


\subsubsection{Procedimentos}

Os experimentos foram realizados de acordo com as seguintes etapas:

- Limpeza do reator com água destilada;

- Utilizou-se uma balança analítica (Mettler Toledo, modelo XS205 Dual Range) para pesar a massa do antibiótico;

- A massa pesada foi dissolvida com água purificada por osmose inversa produzida no equipamento PURELAB Prima ELGA em um balão volumétrico de 2L, utilizando-se um banho ultrassônico (Fisher Scientific, modelo FS110);

- A solução do balão foi transferida para o reator e mais $3,5 \mathrm{~L}$ de água foram adicionados para completar o volume necessário para os experimentos;

- Após preencher o sistema, a bomba foi ligada e a vazão, ajustada em 40L/h;

- $\quad \mathrm{O} \mathrm{pH}$ foi ajustado ao valor inicial desejado com solução aquosa de $\mathrm{H}_{2} \mathrm{SO}_{4} 10 \%$ ou solução aquosa de $\mathrm{NaOH} 2 \mathrm{~mol} \mathrm{~L}^{-1}$;

- O banho termostático foi ligado com objetivo de manter o líquido a $25^{\circ} \mathrm{C}$;

- $\quad$ Com o pH, temperatura e vazão de recirculação constantes, coletou-se a amostra inicial;

- $\quad$ Acionou-se a lâmpada e deu-se início à coleta de amostras a cada 5 minutos. A temperatura e o pH foram medidos ao longo do tempo; em alguns casos, mediu-se também a concentração de oxigênio dissolvido (OD);

- As amostras foram caracterizadas segundo as técnicas analíticas descritas posteriormente;

- Ao final do experimento, o conteúdo do reator foi descarregado e foi feita a limpeza do equipamento. 


\subsection{MEDIDAS E ANÁLISES}

\subsection{1 pH, temperatura e concentração de oxigênio dissolvido (OD)}

$\mathrm{O} \mathrm{pH}$ foi medido pelo método potenciométrico utilizando um medidor de $\mathrm{pH}$ (Hanna Instruments), previamente calibrado com soluções tampão de pH 4,0 e 7,0. Em alguns experimentos, utilizou-se uma sonda multiparamétrica (YSI, 556 MPS), localizada na entrada do reator, para realizar leituras de $\mathrm{pH}$, de concentração de oxigênios dissolvido (OD) e de temperatura.

\subsubsection{Carbono orgânico total (COT)}

A análise de Carbono Orgânico Total (COT) foi realizada em um equipamento Shimadzu (modelo 5000A), que quantifica as frações de Carbono Total (TC) e Carbono Inorgânico (IC), contidas nas amostras. A diferença entre essas medidas fornece como resultado a concentração de carbono presente na solução aquosa na forma de compostos orgânicos solúveis.

\subsubsection{Espectrofotometria UV-visível}

Os espectros de absorção UV-vísivel foram medidos em um espectrofotômetro Varian (modelo Cary 50), entre 190 a 820 nm e resolução de $5 \mathrm{~nm}$. Foram utilizadas cubetas de quartzo com caminho óptico de $1 \mathrm{~cm}$. 


\subsubsection{Cromatografia Líquida de Alta Eficiência - detector de fluorescência}

Utilizou-se um sistema de cromatografia líquida de alta eficiência HPLC (Shimadzu, modelo 10-AD), com detector de fluorescência (Shimadzu, modelo RF10AXL), para a quantificação do sulfametoxazol. O comprimento de onda utilizado para excitação foi de $268 \mathrm{~nm}$ e para emissão, de $333 \mathrm{~nm}$. As separações em HPLC foram realizadas pela coluna de fase reversa C18 modelo SGE WAKOSILL II (dimensão $250,0 \mathrm{~mm} \times 4,6 \mathrm{~mm}$ ), equipada com pré-coluna apropriada (Phenomenex).

O método cromatográfico usado por Cruz et al. (2010) foi utilizado como referência e adaptado para este trabalho. As leituras foram realizadas utilizando análise isocrática, à temperatura de $40^{\circ} \mathrm{C}$ e vazão de fase móvel de $1 \mathrm{~mL} / \mathrm{min}$, composta por:

- $22 \%$ de acetronitrila;

- $1 \%$ de trietilamina;

- $\quad 77 \%$ de agua milli-Q com pH 5 ajustado com ácido acético.

$\mathrm{O}$ volume injetado de amostra foi igual a $30 \mu \mathrm{L}$. No presente trabalho, o limite de quantificação para o sulfametoxazol foi de $5 \mu \mathrm{g} / \mathrm{L}$.

\subsubsection{Análise de toxicidade}

O equipamento Microtox ${ }^{\circledR}$ M 500 é um fotômetro e controlador de temperatura (entre 15 e $27^{\circ} \mathrm{C}$ ). O sistema é autocalibrado para registrar a luminescência proveniente da bactéria Vibrio fischeri. O teste tem duração de 15 minutos. Os dados de cada ensaio podem ser analisados pelo software Microtox Omni. Os ensaios consistem na análise da luminescência produzida pelas bactérias Vibrio fischeri em amostras com diferentes diluições. A partir da diferença entre as intensidades de luminescência de cada amostra é atribuída a toxicidade da amostra, conforme a 
norma da CETESB/L.5227/dez/2001 (MICROTOX $^{\circledR}$ TEST SYSTEMS FOR TOXICITY TESTING, 2011).

Os testes foram realizados de forma a se obter uma curva dose-resposta estatisticamente aceitável, que permita a interpolação do valor CE50. A diluição da amostra é feita com diluente (solução de $\mathrm{NaCl} 2 \%$ ) em uma série de cubetas aqui denominadas série $A$. Para um segunda série de cubetas $B$ são transferidos volumes adequados de diluente e "reagente" (bactéria Vibrio fischeri). Realiza-se uma primeira medida de luminescência das cubetas da série $B$. Em seguida completa-se o volume dessas cubetas com o conteúdo das cubetas da série A. Após 15 minutos são realizadas novas medidas de luminescência.
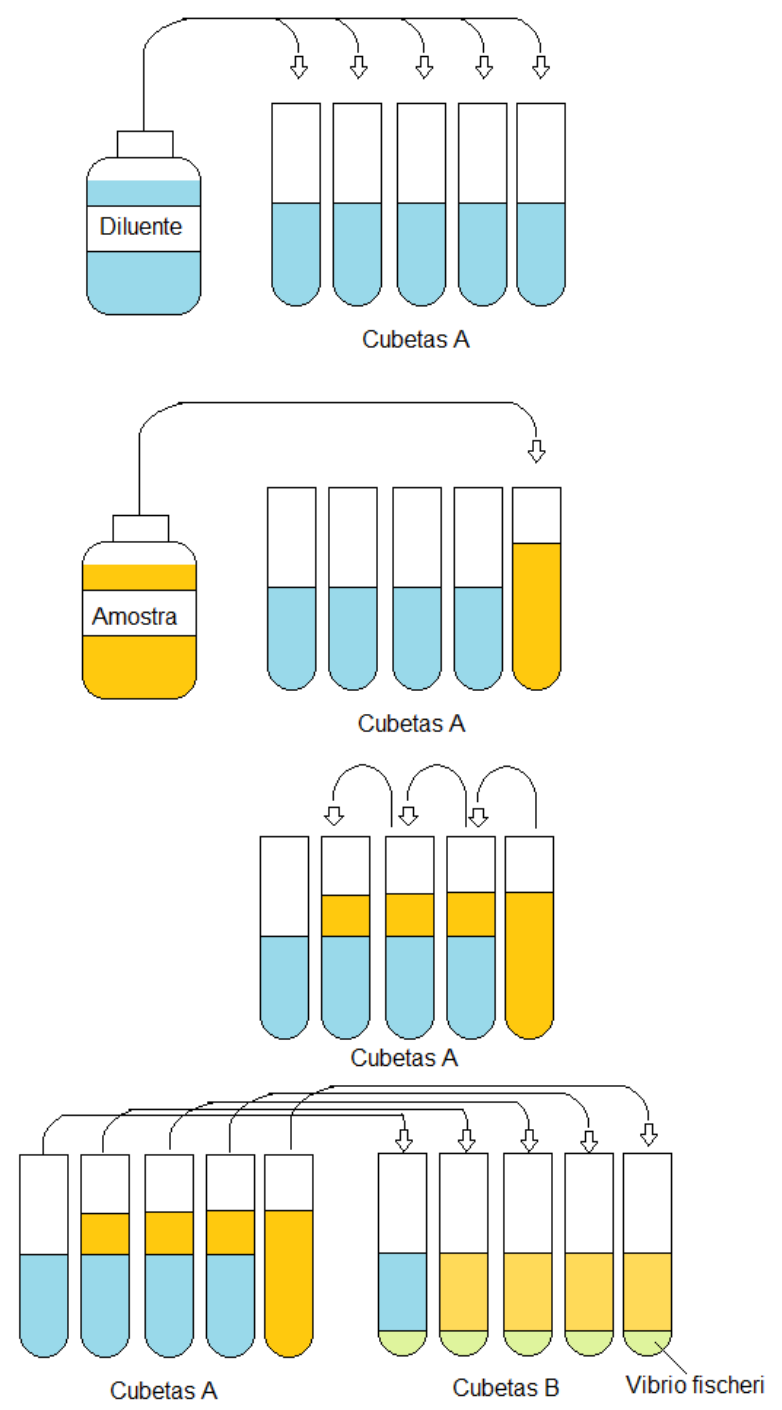

Figura 6 - Esquema do procedimento geral do teste de toxicidade aguda com a bactéria luminescente Vibrio fischeri conforme o equipamento Microtox ${ }^{\circledR} 500$. 


\subsubsection{Bioensaios de respirometria}

Nos bioensaios de respirometria utilizou-se o sistema Oxitop ${ }^{\circledR}$ (WTW).Os ensaios de respirometria foram realizadas utilizando frascos de vidro âmbar fechados, contendo inóculo(consórcio de micro-organismos), nutrientes e soluçõesteste, à temperatura controlada de $20^{\circ} \mathrm{C}$, com volume constante e sob agitação. Este método baseia-se no fato de que durante a respiração aeróbia de micro-organismos há consumo de oxigênio dissolvido na fase líquida, com consequente reposição pelo oxigênio presente na fase gasosa no volume acima do líquido. Desta forma a pressão parcial do oxigênio nesse volume tende a diminuir devido ao consumo de oxigênio pela atividade microbiana. Durante a degradação aeróbia ocorre a produção de gás carbônico, removido por reação com pastilhas de $\mathrm{NaOH}$ colocadas em um suporte em contato com a fase gasosa, através do qual os gases são obrigados a passar antes de atingirem o transdutor de pressão, responsável pela medida da variação de pressão devido ao consumo de oxigênio.

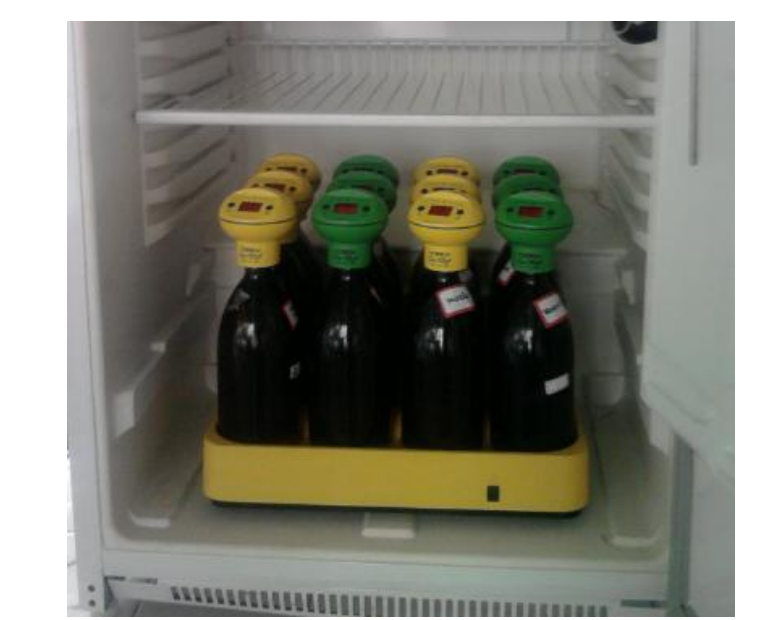

Figura 7 - Respirômetros manométricos fechados.

Para realização do teste, inicialmente prepararam-se as seguintes soluções aquosas em balões volumétricos de $100 \mathrm{~mL}$ :

- Solução tampão de $\mathrm{NaH}_{2} \mathrm{PO}_{4} \cdot \mathrm{H}_{2} \mathrm{O} 1,5 \mathrm{~mol} / \mathrm{L}$; 
- Solução de $\mathrm{NH}_{4} \mathrm{Cl} 0,71 \mathrm{~mol} / \mathrm{L}$;

- Solução de $\mathrm{CaCl}_{2} \cdot 2 \mathrm{H}_{2} \mathrm{O} 0,25 \mathrm{~mol} / \mathrm{L}$;

- Solução de $\mathrm{MgSO}_{4} \cdot 7 \mathrm{H}_{2} \mathrm{O} 0,41 \mathrm{~mol} / \mathrm{L}$;

- Solução de $\mathrm{FeCl}_{3} \cdot 6 \mathrm{H}_{2} \mathrm{O} 0,018 \mathrm{~mol} / \mathrm{L}$.

Para o controle do $\mathrm{pH}$, prepararam-se as solução de ácido sulfúrico $1 \mathrm{~mol} / \mathrm{L}$ e hidróxido de potássio $6 \mathrm{~mol} / \mathrm{L}$, também em balão de $100 \mathrm{~mL}$. Já o preparo das soluções de glicose e de ácido glutâmico foi realizado conforme as seguintes etapas:

- Em um vidro de relógio pesou-se a massa de 1,5 g de ácido glutâmico;

- Pesaram-se, da mesma forma, 1,5 g de glicose;

- A massa de cada composto foi transferida para cadinhos de porcelana;

- Os cadinhos foram mantidos em mufla a $200^{\circ} \mathrm{C}$ por 1 hora para secagem dos compostos;

- Em seguida, pesaram-se 0,75 g de ácido glutâmico e 0,75 g de glicose secos;

- As massas foram transferidas para um béquer de $250 \mathrm{~mL}$, ao qual se adicionaram $120 \mathrm{~mL}$ de água purificada;

- A mistura foi levada ao agitador magnético e foi aquecida até a dissolução dos compostos;

- A solução diluída foi em seguida transferida para um balão volumétrico, avolumado para $500 \mathrm{~mL}$.

Com todas as soluções prontas, iniciou-se a hidratação do inóculo, utilizando um agitador magnético e um béquer com $500 \mathrm{~mL}$ de água purificada. $O$ inóculo foi hidratado pelo período de 6 horas antes de ser transferido para o frasco âmbar. Obtém-se assim uma suspensão aquosa para os experimentos de respirometria.

Prepararam-se os frascos âmbar, com as quantidades de nutrientes e inóculo conforme a seguir:

\section{PADRÃO INÓCULO:}

Adicionaram-se a três frascos de vidro âmbar: 
- $1 \mathrm{~mL}$ de solução tampão de $\mathrm{NaH}_{2} \mathrm{PO}_{4} \cdot \mathrm{H}_{2} \mathrm{O} 1,5 \mathrm{~mol} / \mathrm{L}$;

- $1 \mathrm{~mL}$ de solução de $\mathrm{NH}_{4} \mathrm{Cl}$ 0,71 mol/L;

- $1 \mathrm{~mL}$ de solução de $\mathrm{CaCl}_{2} \cdot 2 \mathrm{H}_{2} \mathrm{O} 0,25 \mathrm{~mol} / \mathrm{L}$;

- $1 \mathrm{~mL}$ de solução de $\mathrm{MgSO}_{4} \cdot 7 \mathrm{H}_{2} \mathrm{O}$ 0,41 mol/L;

- $1 \mathrm{~mL}$ de solução de $\mathrm{FeCl}_{3} \cdot 6 \mathrm{H}_{2} \mathrm{O} 0,018 \mathrm{~mol} / \mathrm{L}$.

- $425 \mathrm{~mL}$ de água purificada.

$\mathrm{O} \mathrm{pH}$ foi em seguida ajustado entre 6,8 e 7,2 e adicionaram-se $2 \mathrm{~mL}$ da suspensão aquosa de inóculo.

\section{PADRÃO GLICOSE-ÁCIDO GLUTÂMICO:}

Adicionaram-se a três frascos de vidro âmbar:

- $1 \mathrm{~mL}$ de solução tampão de $\mathrm{NaH}_{2} \mathrm{PO}_{4} \cdot \mathrm{H}_{2} \mathrm{O} 1,5 \mathrm{~mol} / \mathrm{L}$;

- $1 \mathrm{~mL}$ de solução de $\mathrm{NH}_{4} \mathrm{Cl}$ 0,71 mol/L;

- $1 \mathrm{~mL}$ de solução de $\mathrm{CaCl}_{2} \cdot 2 \mathrm{H}_{2} \mathrm{O}$ 0,25 mol/L;

- $1 \mathrm{~mL}$ de solução de $\mathrm{MgSO}_{4} \cdot 7 \mathrm{H}_{2} \mathrm{O}$ 0,41 mol/L;

- $1 \mathrm{~mL}$ de solução de $\mathrm{FeCl}_{3} \cdot 6 \mathrm{H}_{2} \mathrm{O} 0,018 \mathrm{~mol} / \mathrm{L}$.

- $20 \mathrm{~mL}$ de solução de glicose-ácido glutâmico;

- $137 \mathrm{~mL}$ de água purificada.

$\mathrm{O} \mathrm{pH}$ foi em seguida ajustado entre 6,8 e 7,2 e adicionaram-se $2 \mathrm{~mL}$ da suspensão aquosa de inóculo.

\section{SOLUÇÃO-TESTE(TRATADA OU NÃO TRATADA):}

Adicionaram-se a três frascos de vidro âmbar:

- $1 \mathrm{~mL}$ de solução tampão de $\mathrm{NaH}_{2} \mathrm{PO}_{4} \cdot \mathrm{H}_{2} \mathrm{O} 1,5 \mathrm{~mol} / \mathrm{L}$;

- $1 \mathrm{~mL}$ de solução de $\mathrm{NH}_{4} \mathrm{Cl}$ 0,71 mol/L; 
- $1 \mathrm{~mL}$ de solução de $\mathrm{CaCl}_{2} \cdot 2 \mathrm{H}_{2} \mathrm{O} 0,25 \mathrm{~mol} / \mathrm{L}$;

- $1 \mathrm{~mL}$ de solução de $\mathrm{MgSO}_{4} \cdot 7 \mathrm{H}_{2} \mathrm{O} 0,41 \mathrm{~mol} / \mathrm{L}$;

- $1 \mathrm{~mL}$ de solução de $\mathrm{FeCl}_{3} \cdot 6 \mathrm{H}_{2} \mathrm{O}$ 0,018 mol/L.

- $20 \mathrm{~mL}$ da solução de glicose-ácido glutâmico;

- $137 \mathrm{~mL}$ de solução-teste(tratada ou não tratada).

$\mathrm{O} \mathrm{pH}$ foi em seguida ajustado entre 6,8 e 7,2 e adicionaram-se $2 \mathrm{~mL}$ da suspensão aquosa de inóculo.

Os frascos, contendo em seu interior as soluções preparadas e uma barra magnética, foram levados à estufa e mantidos em agitação, à temperatura de $20^{\circ} \mathrm{C}$ por 5 dias.

\subsubsection{Ensaio de hidrólise de sulfametoxazol em solução aquosa}

Os ensaios de hidrólise em meio aquoso foram realizados para duas concentrações de sulfametoxazol (SMX) (20 mg/L e $40 \mathrm{mg} / \mathrm{L})$ e 5 diferentes valores de $\mathrm{pH}$. O ensaio foi realizado a $25^{\circ} \mathrm{C}$, em frascos mantidos sob agitação orbital constante de $100 \mathrm{rpm}$ em uma incubadora termostatizada da TECNAL (modelo TE 421) e ajustou-se o $\mathrm{pH}_{\text {inicial, }}$, com soluções de $\mathrm{H}_{2} \mathrm{SO}_{4}$ e $\mathrm{NaOH}$, para os valores de 3 , 5,7 e 9 . Os experimentos foram realizados em duplicata e as amostras foram retiradas nos tempos $0 \mathrm{~h}, 12 \mathrm{~h}$ e $24 \mathrm{~h}$ e analisadas em HPLC.

\subsubsection{Actinometria}

A actinometria é realizada para avaliar a taxa de incidência de fótons no reator fotoquímico. Utilizou-se o método da actinometria de ferrioxalato (BRAUN; MAURETTE; OLIVEROS, 1991). A solução do actinômetro consiste de:

- $\quad 0,75 \mathrm{~mol} / \mathrm{L}$ de ácido oxálico $\left(\mathrm{H}_{2} \mathrm{C}_{2} \mathrm{O}_{4} \cdot 2 \mathrm{H}_{2} \mathrm{O}\right)$; 
- $\quad 0,15 \mathrm{~mol} / \mathrm{L}$ de $\mathrm{Fe}_{2}\left(\mathrm{SO}_{4}\right)_{3} .5 \mathrm{H}_{2} \mathrm{O}$.

A solução foi preparada em uma sala escura, com volume total de $5 \mathrm{~L}$. O actinômetro foi adicionado ao reator fotoquímico, previamente encoberto por papel alumínio, protegendo-o, assim, da incidência externa de fótons. Ao longo do experimento, borbulhou-se $\mathrm{N}_{2}$ no interior do tanque de mistura, evitando-se a oxidação do $\mathrm{Fe}^{2+}$ pelo $\mathrm{O}_{2}$ dissolvido. $\mathrm{O}$ experimento teve duração de 20 minutos. Coletaram-se amostras de $0,25 \mathrm{~mL}$ a cada 2 minutos, as quais foram transferidas para frascos âmbar encapados com papel alumínio, contendo $24,75 \mathrm{~mL}$ de solução complexante composta de:

- $\quad$ ácido acético $0,5 \mathrm{~mol} / \mathrm{L}$;

- $\quad$ acetato de sódio $0,5 \mathrm{~mol} / \mathrm{L}$;

- 1,10-fenantrolina 0,01 mol/L.

Após 90 minutos em repouso (tempo necessário para o actinômetro reagir com o complexante) as amostras foram analisadas para determinação de $\mathrm{Fe}^{2+}$ por espectrofotometria UV-visível no comprimento de onda $510 \mathrm{~nm}$, onde o coeficiente de absorção molar do complexo ferro(II)-fenantrolina é alto $\left(11000 \mathrm{~L} \mathrm{~mol}^{-1} \mathrm{~cm}^{-1}\right.$, conforme BRAUNet al., 1991).

\subsection{EXPERIMENTOS}

\subsubsection{Planejameto experimental}

Os experimentos foram realizados segundo um planejamento baseado na matriz uniforme Doehlert (FERREIRA et al., 2004). O número total de pontos experimentais do planejamento é calculado por $k^{2}+k+1$, em que $k$ é o número de variáveis independentes estudadas. Foram avaliados os efeitos das seguintes variáveis: 
- $\quad U_{1}$ : Concentração inicial de sulfametoxazol;

- $\quad U_{2}: \mathrm{pH}$ inicial.

As concentrações iniciais foram selecionadas com base na literatura (CRUZ et al., 2010). Para calcular os valores reais variáveis $U_{1}$ e $U_{2}$, utiliza-se a eq. (8), em que $X_{i}$ corresponde ao valor codificado da variável $i$ (entre 0 e 1):

$$
U_{i}=U_{0}+\Delta U \cdot X_{i}
$$

Em que:

$$
U_{0}=\frac{U_{\text {imáx }}+U_{\text {imin }}}{2}
$$

é o valor de Ui no centro da região experimental e

$$
\Delta U=\frac{U_{\operatorname{máx}}-U_{\min }}{2}
$$

Corresponde à variação média de Ui. O planejamento experimental Doehlert é apresentado esquematicamente na Figura 5. A Tabela 2 apresenta os valores máximos e mínimos, referentes ao planejamento, bem como $U_{0 i}$ e $\Delta U_{i}$, para cada variável independente estudada também são apresentados os valores codificados e reais. 


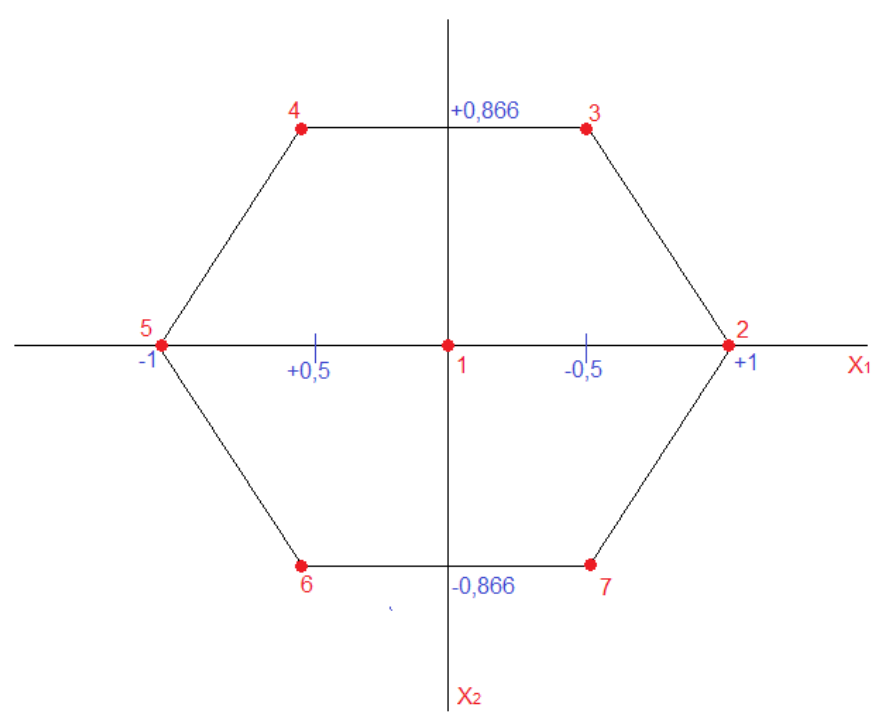

Figura 8 - Representação esquemática da distribuição dos experimentos segundo o planejamento experimental Doehlert. $X_{1}$ : valor codificado correspondente à concentração de sulfametoxazol. $X_{2}$ : $\mathrm{pH}_{0}$. Os números dos experimentos são indicados nos vértices e no centro do hexágono.

Tabela 2 - Domínio experimental dos valores nominais das variáveis estudadas.

\begin{tabular}{ccccc}
\hline \multirow{2}{*}{$\begin{array}{c}\text { No do } \\
\text { experimento }\end{array}$} & $\boldsymbol{X}_{\mathbf{1}}$ & $\begin{array}{r}\text { Valores codificados } \\
{[\mathbf{S M X}]_{0}}\end{array}$ & \multicolumn{2}{c}{ Valores reais } \\
\cline { 2 - 5 }$(\mathbf{m g} / \mathbf{L})$ & $\boldsymbol{X}_{\mathbf{2}}$ & $\mathbf{p H}$ \\
\hline 1 & 0,0 & 30 & 0,000 & 7,0 \\
2 & 1,0 & 50 & 0,000 & 7,0 \\
3 & 0,5 & 40 & 0,866 & 9,0 \\
4 & $-0,5$ & 20 & 0,866 & 9,0 \\
5 & $-1,0$ & 10 & 0,000 & 7,0 \\
6 & $-0,5$ & 20 & $-0,866$ & 5,0 \\
7 & 0,5 & 40 & $-0,866$ & 5,0 \\
\hline
\end{tabular}




\section{RESULTADOS E DISCUSSÃO}

\subsection{EXPERIMENTO ACTINOMÉTRICO}

A actinometria de ferrioxalato para o reator fotoquímico operando com a lâmpada Philips TUV de $36 \mathrm{~W}$ resultou na formação de $\mathrm{Fe}^{2+}$ à taxa de $4,35 \times 10^{-5}$ $\mathrm{mol} / \mathrm{s}$. Sabendo-se que ocorre absorção total da radiação incidente de $254 \mathrm{~nm}$ pela solução actinométrica à concentração empregada e que o rendimento quântico para formação de $\mathrm{Fe}^{2+}$ a partir de $\mathrm{Fe}^{3+}$ é igual a 1,23 íons/fóton (BRAUN et al., 1991), obteve-se taxa de emissão igual a $2,15 \times 10^{19}$ fótons/s. Em termos de potência radiante em $254 \mathrm{~nm}$, esse valor corresponde a 16,8 W, de modo que a eficiência radiante (razão entre a potência efetiva e a potência elétrica) da lâmpada empregada nos experimentos de fotólise é igual $47 \%$. Esse valor corresponde ao esperado para lâmpadas de vapor de mercúrio de baixa pressão (OPPENLÄNDER, 2003).

\subsection{ENSAIO DE HIDRÓLISE}

O ensaio de hidrólise teve duração total de 24 horas, com amostras retiradas no início e após $12 \mathrm{~h}$ e $24 \mathrm{~h}$. Analisaram-se duas concentrações (valores nominais de $20 \mathrm{mg} / \mathrm{L}$ e $40 \mathrm{mg} / \mathrm{L}$ ); os valores de $\mathrm{pH}$ foram ajustados para 3, 5, 7, 9 e controle $(5,3)$, com soluções de $\mathrm{H}_{2} \mathrm{SO}_{4}$ e $\mathrm{NaOH}$.

As Figuras 9 e 10 permitem observar que, independentemente do valor do $\mathrm{pH}$ e da concentração inicial de sulfametoxazol, tanto para meio ácido $(\mathrm{pH} 3,0)$ quanto para meios neutro $(\mathrm{pH} 7,0)$ e básico $(\mathrm{pH} 9,0)$, a solução apresenta estabilidade química, não sendo constatada reação de hidrólise do SMX no tempo total considerado. $O$ fato de não ocorrer hidrólise no período de 24 horas permite concluir que a degradação de SMX observada durante a fotólise nos experimentos realizados neste trabalho tem como único responsável a interação da radiação UVC com o antibiótico. Em relação à degradação em ambientes naturais, Lam et al.(2003) 
relatam a meia vida do SMX de 19 a 82 dias e ressaltam que sua persistência se deve ao fato de serem continuamente lançados nos ambientes aquáticos.

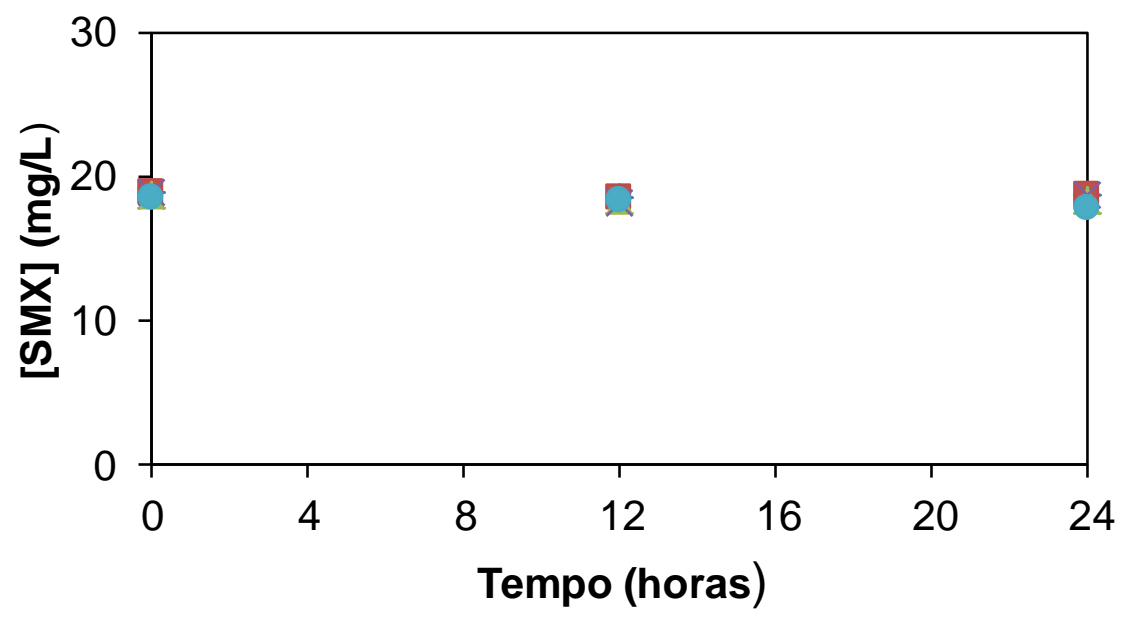

Figura 9 - Resultado dos ensaios de hidrólise com valores médios da duplicata para

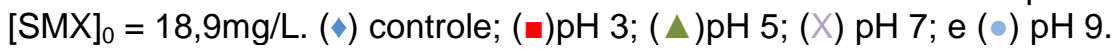

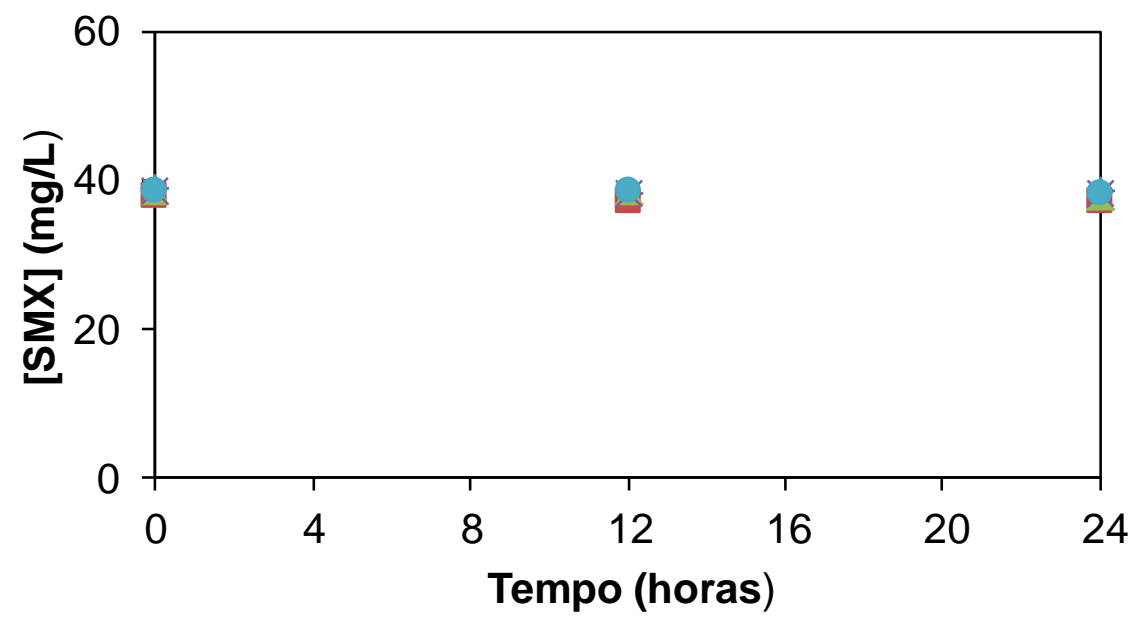

Figura 10 - Resultado dos ensaios de hidrólise com valores médios da duplicata para

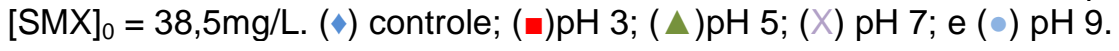


Tabela 3 - Resultados do ensaio de hidrólise.

\begin{tabular}{|c|c|c|c|c|}
\hline \multirow{2}{*}{$\begin{array}{c}{[\mathrm{SMX}]_{0}} \\
\text { nominal } \\
(\mathrm{mg} / \mathrm{L})\end{array}$} & \multirow{2}{*}{ pH } & \multicolumn{3}{|c|}{ [SMX]real (mg/L) } \\
\hline & & Oh & $12 \mathrm{~h}$ & $24 \mathrm{~h}$ \\
\hline \multirow{10}{*}{20} & \multirow{2}{*}{ Controle } & 18,9 & 18,6 & 18,9 \\
\hline & & 18,9 & 18,4 & 18,7 \\
\hline & \multirow{2}{*}{3} & 18,9 & 18,3 & 18,7 \\
\hline & & 18,9 & 18,6 & 18,9 \\
\hline & \multirow{2}{*}{5} & 18,7 & 18,7 & 18,8 \\
\hline & & 18,6 & 18,1 & 17,8 \\
\hline & \multirow{2}{*}{7} & 18,9 & 18,0 & 18,7 \\
\hline & & 18,8 & 18,4 & 18,8 \\
\hline & \multirow{2}{*}{9} & 18,5 & 18,2 & 17,9 \\
\hline & & 18,6 & 18,4 & 17,7 \\
\hline \multirow{10}{*}{40} & \multirow{2}{*}{ Controle } & 38,9 & 38,5 & 38,5 \\
\hline & & 38,9 & 38,2 & 38,3 \\
\hline & \multirow{2}{*}{3} & 37,9 & 37,1 & 37,5 \\
\hline & & 37,7 & 37,3 & 37,0 \\
\hline & \multirow{2}{*}{5} & 38,5 & 38,6 & 37,9 \\
\hline & & 38,5 & 38,4 & 38,2 \\
\hline & \multirow{2}{*}{7} & 38,7 & 38,2 & 38,3 \\
\hline & & 38,2 & 38,5 & 38,5 \\
\hline & \multirow{2}{*}{9} & 38,8 & 38,5 & 38,5 \\
\hline & & 38,7 & 38,7 & 38,3 \\
\hline
\end{tabular}

\subsection{AVALIAÇÃO ESPECTROFOTOMÉTRICA}

O comportamento dos espectros de absorção do antibiótico sulfametoxazol em solução aquosa (Figura 11), em diferentes valores de pH e de concentrações, ajuda a avaliar a eficiência do tipo de lâmpada a ser empregada na fotólise direta e também como o pH pode interferir na degradação do composto durante a fotólise

A Figura 11 mostra que a absorção de radiação UV-visível pelo SMX depende do $\mathrm{pH}$. Porém mesmo com essa variação a absorção máxima ocorre próxima ao comprimento de onda $254 \mathrm{~nm}$, que corresponde ao comprimento de onda em que a lâmpada de vapor de $\mathrm{Hg}$ de baixa pressão emite, já que pode ser considerada praticamente monocromática. Dessa forma, espera-se que as moléculas de SMX absorvam fótons nesse comprimento de onda, o que foi avaliado calculando-se o coeficiente de absorção molar do composto (Figura 12). 


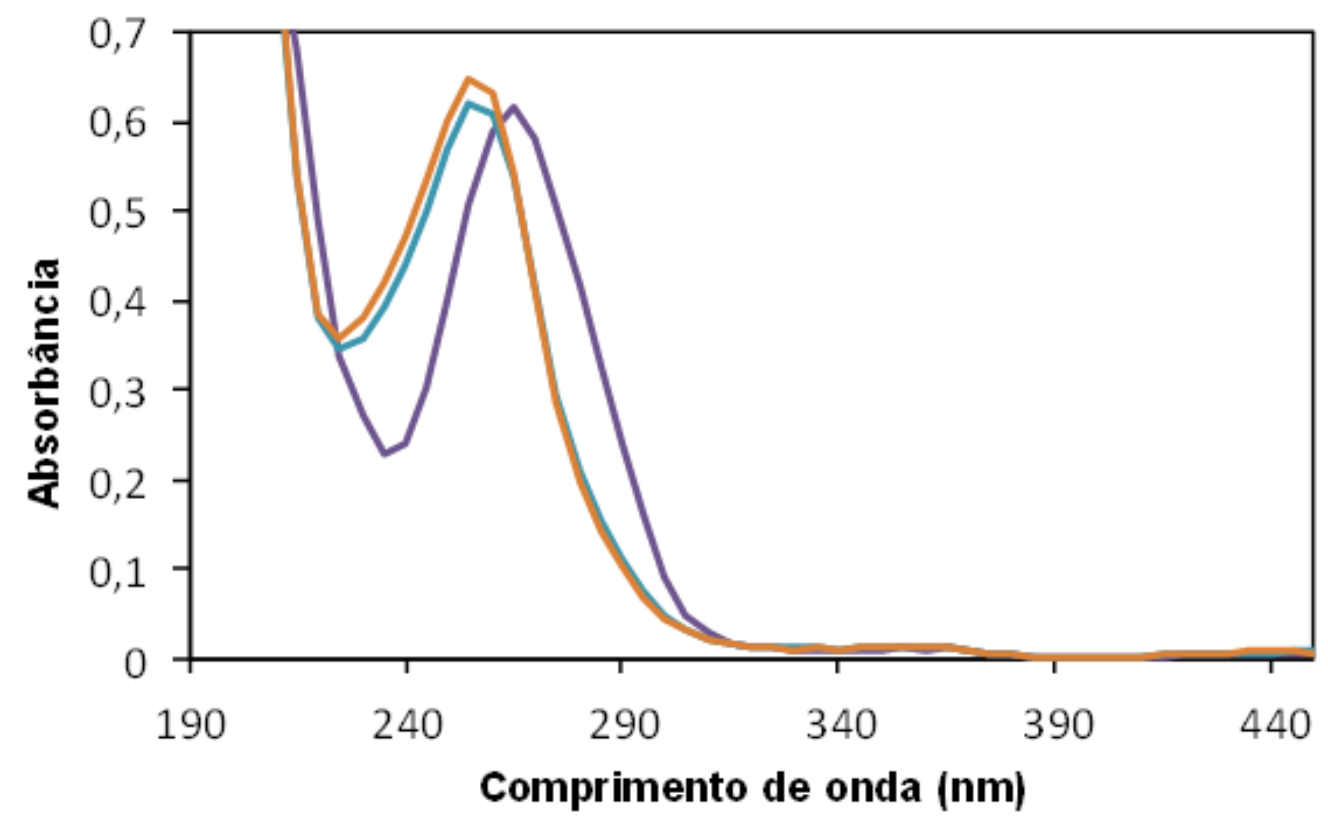

Figura 11 -Espectros de absorção UV-visível do sulfametoxazol em solução aquosa à concentração de $10 \mathrm{mg} / \mathrm{L} \mathrm{e} \mathrm{(-)pH} \mathrm{5;} \mathrm{(-)pH} \mathrm{7;} \mathrm{e(-)pH} \mathrm{9.} \mathrm{Resolução} \mathrm{de} \mathrm{5nm} \mathrm{e} \mathrm{caminho} \mathrm{ótico} \mathrm{de} 1 \mathrm{~cm}$.

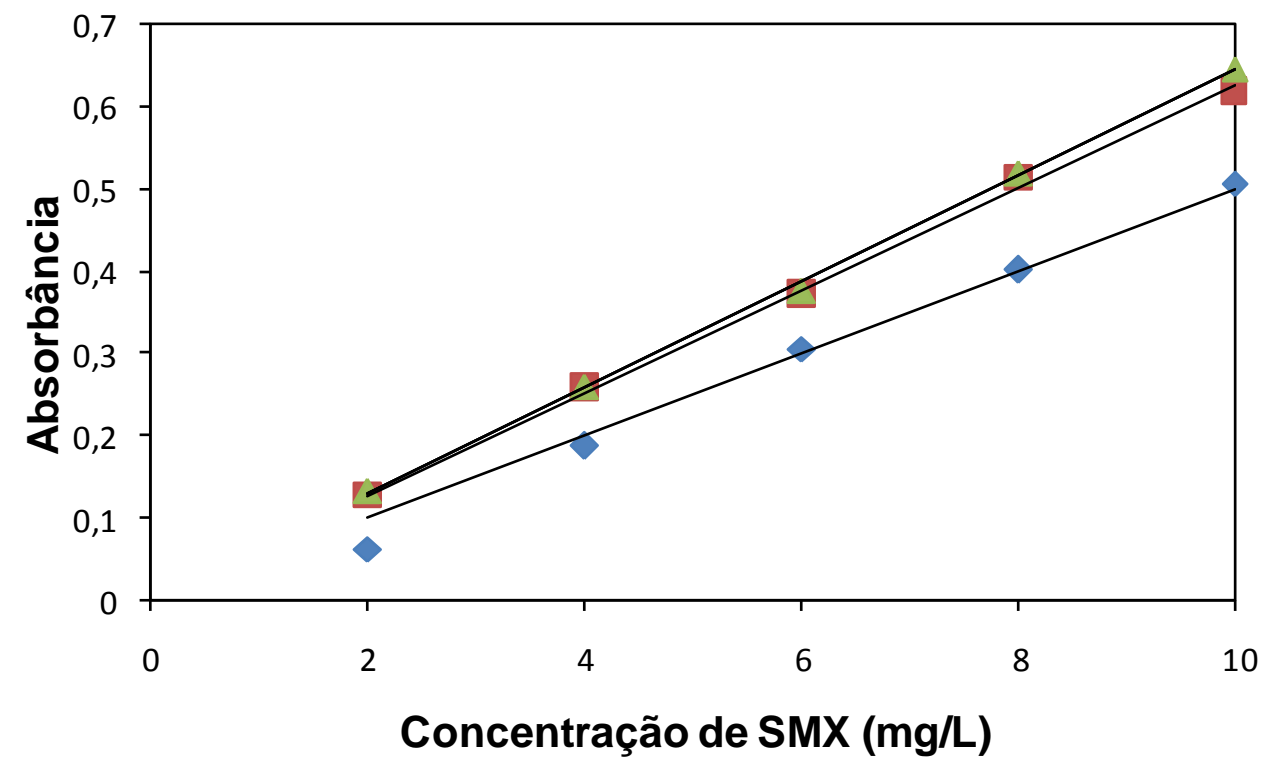

Figura 12 -Absorbância do sulfametoxazol em solução aquosa em $254 \mathrm{~nm}$ a diferentes

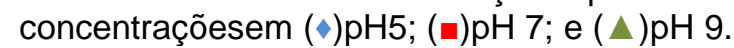

As equações das retas ajustadas aos pontos da Figura 12 e os valores dos coeficientes de determinação $R^{2}$ estão apresentados na Tabela 4. 
Tabela 4 - Equações dos ajustes lineares de absorbância (abs) em função da concentração de SMX ([SMX]) a diferentes $\mathrm{pH}$ e valores de $R^{2}$ correspondentes.

\begin{tabular}{ccc}
\hline pH & Equação da reta & $\boldsymbol{R}^{2}$ \\
\hline 5 & $a b s=0,0499 \times[\mathrm{SMX}]$ & 0,9852 \\
7 & $a b s=0,0627 \times[\mathrm{SMX}]$ & 0,9958 \\
9 & $a b s=0,0645 \times[\mathrm{SMX}]$ & 0,9991 \\
\hline
\end{tabular}

O valor do coeficiente de absorção molar do SMX em $254 \mathrm{~nm}$ é calculado pela equação 11, conforme a Lei de Beer-Lambert:

$$
a b s_{254}=\varepsilon_{254 \times[S M X] \times I}
$$

Conforme a Figura 12, a absorção do antibiótico depende do pH. Obtiveramse $\varepsilon_{254}=11568 \mathrm{~L} / \mathrm{mol} \mathrm{cm}$ para pH $5, \varepsilon_{254}=15951 \mathrm{~L} / \mathrm{molcm}$ para pH 7 e $\varepsilon_{254}=16372 \mathrm{~L} /$ mol cm para pH 9. Em meio básico e neutro os valores de $\varepsilon_{254}$ foram similares, porém em meio ácido a absorção de radiação UV em $254 \mathrm{~nm}$ é menor em relação ao meio básico e ácido. Esses valores estão de acordo com a literatura; Baeza e

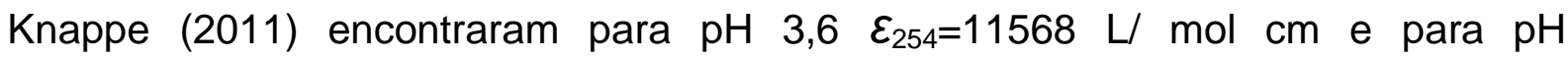
$7,85 \varepsilon_{254}=16580 \mathrm{~L} / \mathrm{mol} \mathrm{cm}$ Esse comportamento é relacionado ao estado de ionização do SMX em meio aquoso, que será discutido em detalhes no item 5.4.

\subsection{OBTENÇÃO DO pKA DE SOLUÇÕES AQUOSAS DE SMX}

Em solução aquosa, o SMX apresenta um equilíbrio ácido-base característico (Figura 13) e sua foto-degradação está fortemente relacionada ao seu estado de ionização (ZHOU; MOORE,1994). As formas mais estáveis são o ânion sulfametoxazol em meio básico e a forma protonada em meio ácido (BOREEN; ARNOLD; MC NEILL, 2004). 
<smiles>[R]NS(=O)(=O)c1ccc(N)cc1</smiles>

$\mathrm{SH}_{2}^{+}$

$\mathrm{SH}$<smiles>[R]N([O-])S(=O)(=O)c1ccc(N)cc1</smiles>

$\mathrm{S}^{-}$

Figura 13 - Equilíbrios ácido-base de sulfas em solução aquosa. $\mathrm{SH}_{2}{ }^{+}=$forma catiônica, protonada; $\mathrm{SH}$ =forma neutra; e $\mathrm{S}^{-}$forma aniônica, desprotonada. Valores de $\mathrm{pK}_{\mathrm{a}, 1}=1,6$ e pK $\mathrm{pK}_{\mathrm{a}, 2}=5,7$ (BOREEN; ARNOLD; MC NEILL, 2004).

A obtenção experimental de $\mathrm{pK}_{\mathrm{a}}$ foi realizado a partir de soluções aquosas a 10 valores de $\mathrm{pH}$ diferentes, entre 3 e 12, os valores de $\mathrm{pH}$ foram baseados nos experimentos realizados anteriormente. Na Figura 14 é possível observar que em meio ácido, há uma banda de absorção no UV-visível com o máximo em 268 nm. À medida que $\mathrm{opH}$ aumenta, a banda se desloca para comprimentos de ondas menores (blue shift), como resultado da desprotonação da molécula. Dessa forma, em meio básico, o máximo da banda da absorção no UV-visível é verificado em cerca de $256 \mathrm{~nm}$. Observa-se que o sistema possui dois isosbésticos bem característicos, em 220nm e 262nm.

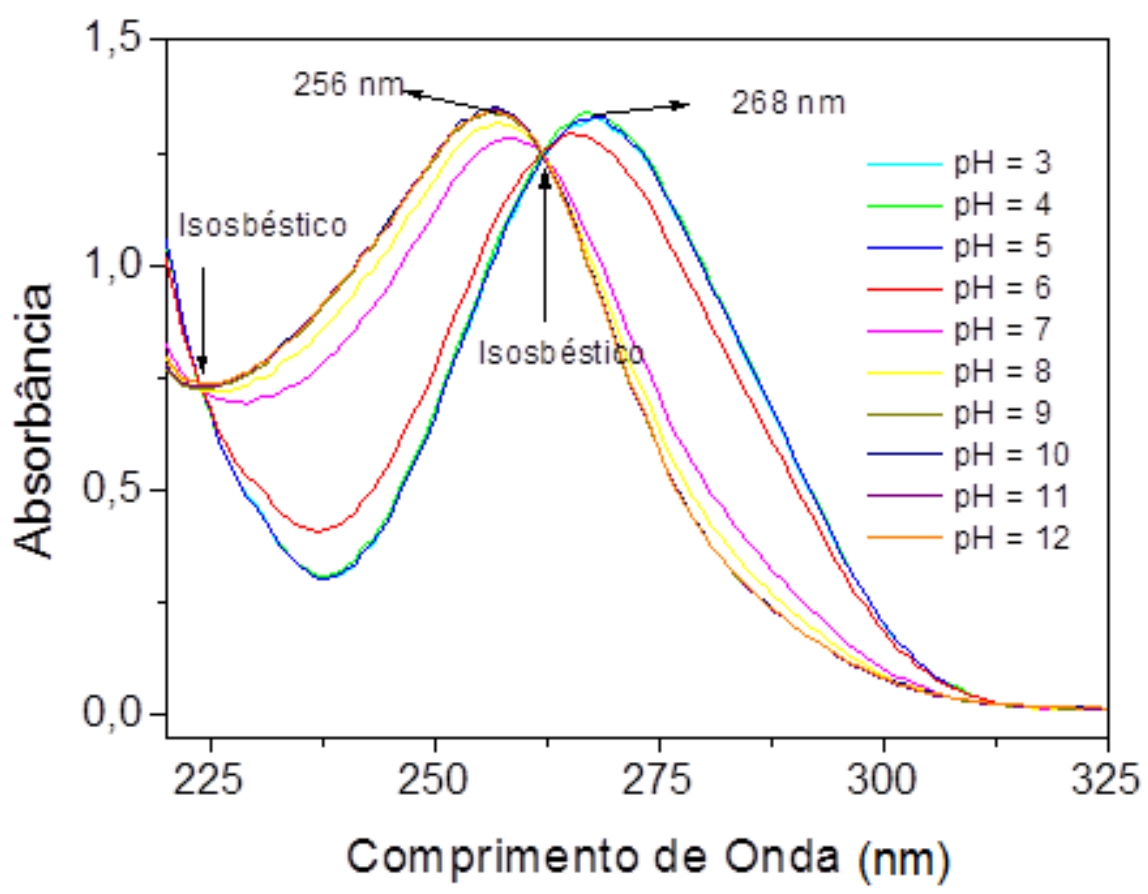

Figura 14 - Obtenção experimental do pKa do sulfametoxazol em solução aquosa. 
Para estimar os valores de $\mathrm{pKa}$, foi feito um gráfico da absorbância para os comprimentos de onda em que se verificaram os máximos correspondentes às formas protonada (meio ácido, $268 \mathrm{~nm}$ ) e desprotonada (meio básico, $257 \mathrm{~nm}$ ). Obtiveram-se os ajustes dos dados experimentai os em termos de curvas sigmoidais utilizando o programa Origin 8.0(Figura 15). O pKa pode ser estimado como o valor de $\mathrm{pH}$ onde se observa a intersecção entre as duas sigmoidais, sendo $\mathrm{pK}_{\mathrm{a}}=6,5$.

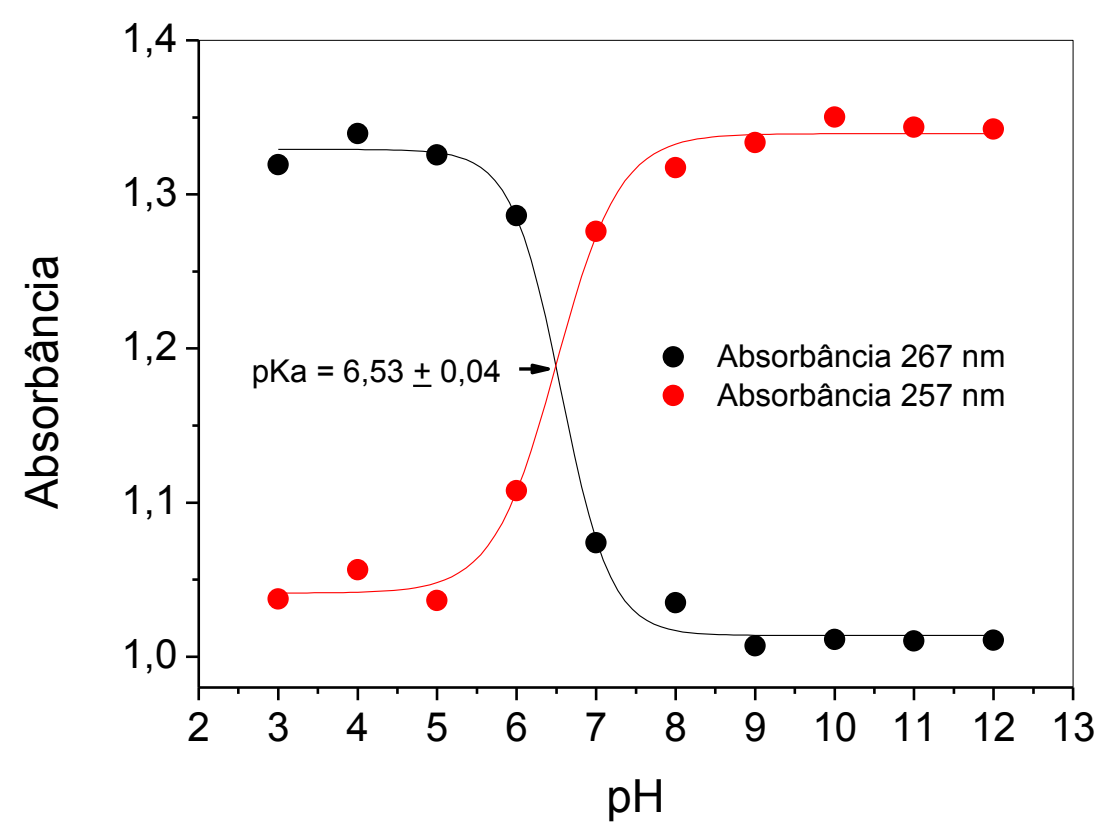

Figura 15 - Estimativa do pKa.

Boreen, Arnold e Mc Neill (2004) comentam sobre como o pKa permite entender melhor o comportamento fotoquímico do SMX em ambientes naturais, pois o valor do pH em ambientes aquáticos varia entre 6 e 9, alterando a absorção de radiação UV pelo SMX; como essas mudanças ocorrem abaixo de $300 \mathrm{~nm}$, sua degradação no meio ambiente não está relacionada à fotólise direta, mas sim à decomposição intermediada pela fotodecomposição de nitratos e nitritos em solução aquosa, gerando espécies radicalares que atacam o antibiótico. 


\subsection{ESTUDO DA DEGRADAÇÃO DO SULFAMETOXAZOL POR FOTÓLISE DIRETA EM SOLUÇÃO AQUOSA}

Os experimentos de fotodegradação do sulfametoxazol por fotólise direta em $254 \mathrm{~nm}$ em solução aquosa foram realizados conforme o planejamento apresentado na Tabela 2, utilizando uma lâmpada de vapor de mercúrio de baixa pressão de 36 W. A Tabela 5 indica que em todos os experimentos obteve-se degradação do composto SMX superior a 99\% em relação à concentração inicial, em cerca de 60 minutos. Porém a concentração de carbono orgânico total (COT) manteve-se estável em todos os experimentos.

Durante os experimentos a solução tornou-se alaranjada, mantendo-se límpida, sendo essa coloração provavelmente proveniente dos subprodutos formados. Quanto maior a concentração inicial do antibiótico, mais intenso foi o tom alaranjado observado.

Tabela 5 - Resultados dos experimentos de fotólise de SMX em solução aquosa.

\begin{tabular}{|c|c|c|c|c|c|c|c|}
\hline Exp. & $\mathrm{pH}_{0}^{(\mathrm{a})}$ & $\begin{array}{c}{[\mathrm{SMX}]_{0}} \\
(\mathrm{mg} / \mathrm{L})^{(\mathbf{b})}\end{array}$ & $\begin{array}{c}\mathrm{COT}_{0} \\
(\mathrm{mgC} / \mathrm{L})\end{array}$ & $\begin{array}{l}\text { Remoção } \\
\text { de SMX (c) } \\
(\%)\end{array}$ & $\begin{array}{c}\text { Remoção } \\
\text { de COT } \\
\text { (c) }(\%)\end{array}$ & $\begin{array}{c}\text { Tempo } \\
\text { para } \\
\text { remoção } \\
\text { de } 50 \% \text { do } \\
\text { total inicial } \\
\text { de } \\
\text { SMX(min) }\end{array}$ & $\begin{array}{c}\text { Taxa de } \\
\text { inicial de } \\
\text { remoção de } \\
\text { SMX } \\
\text { (mg/L.min) }\end{array}$ \\
\hline $1 \mathrm{~A}$ & 7,0 & 21,3 & 15,3 & 99,9 & 5,3 & 10,8 & 1,29 \\
\hline $1 \mathrm{~B}$ & 7,0 & 22,8 & 14,6 & 99,2 & 2,7 & 9,46 & 1,15 \\
\hline $1 \mathrm{C}$ & 7,0 & 22,6 & 15,8 & 99,4 & 1,9 & 10,7 & 1,46 \\
\hline 2 & 7,1 & 35,6 & 24,9 & 99,2 & 1,4 & 18,8 & 1,30 \\
\hline 3 & 8,9 & 29,8 & 19,5 & 99,4 & 3,0 & 18,9 & 0,94 \\
\hline 4 & 9,1 & 15,7 & 8,5 & 99,5 & 6,9 & 5,3 & 1,27 \\
\hline 5 & 6,8 & 7,2 & 5,6 & 99,9 & 7,8 & 4,8 & 0,86 \\
\hline 6 & 4,9 & 14,1 & 8,2 & 99,9 & 1,6 & 4,6 & 2,28 \\
\hline 7 & 4,9 & 29,9 & 19,7 & 99,9 & 0,4 & 5,0 & 3,91 \\
\hline
\end{tabular}


A Figura 16 apresenta a comparação dos experimentos 1A, 1B e 1C, repetições na condição do ponto central do planejamento Doehlert. Pode-se dizer que a reprodutibilidade é adequada, com desvio-padrão médio de 0,46 mg/L.
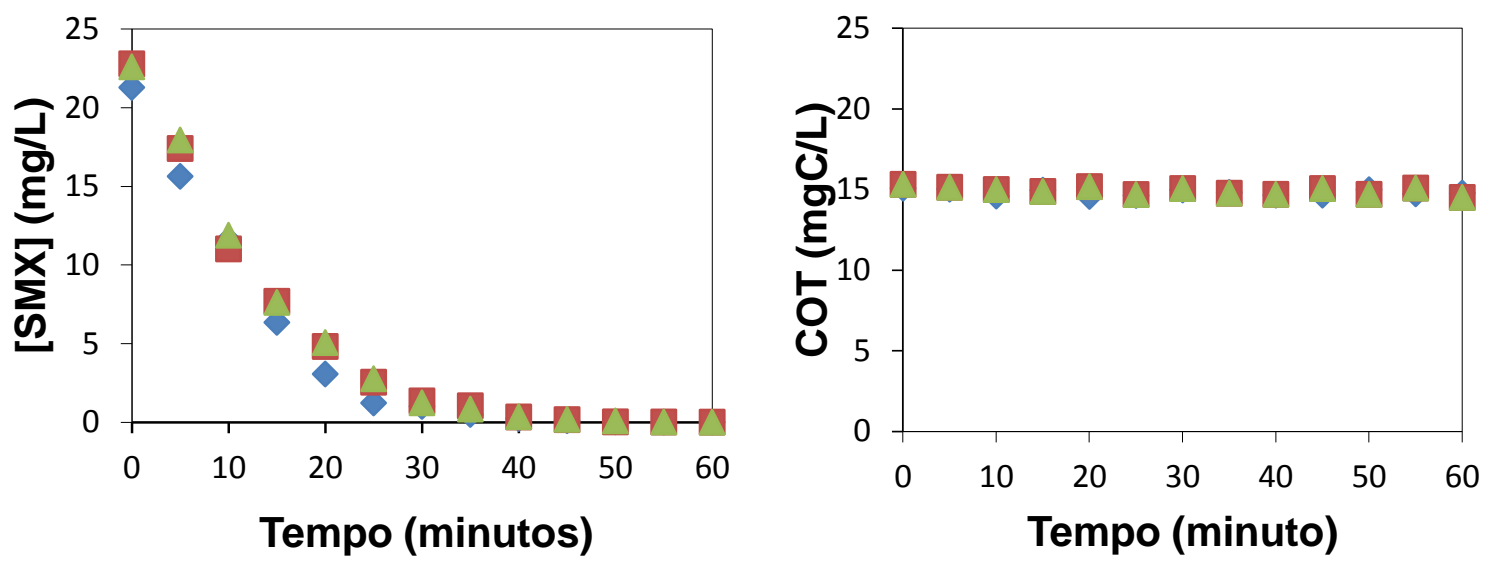

Figura 16 -Resultados do experimento 1 realizado em triplicata.

(४) $1 \mathrm{~A} ;(\bullet) 1 \mathrm{~B} ; \mathrm{e}(\Delta) 1 \mathrm{C}$. $[\mathrm{SMX}]_{0}=22,6 \mathrm{mg} / \mathrm{L} ; \mathrm{pH}_{0}=7$.
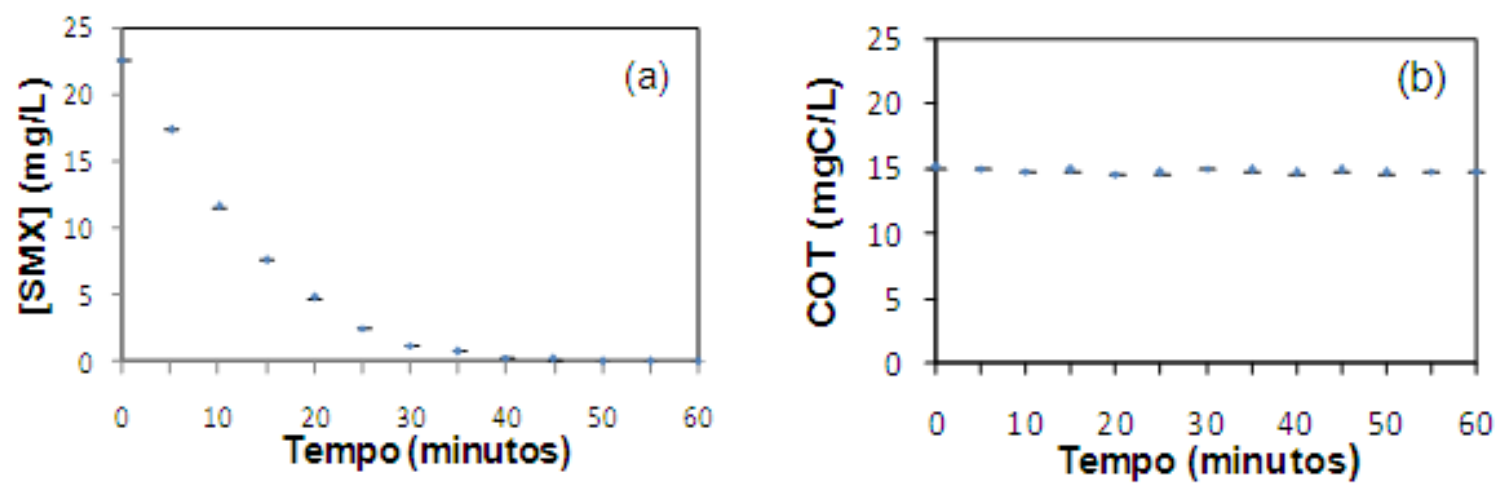

Figura 17 - Resultados do experimento 1, em termos de valores médios e barras de desvio-padrão. $[S M X]_{0}=22,6 \mathrm{mg} / \mathrm{L} ; \mathrm{pH}_{0}=7$.

Pode-se dizer, a partir das Figuras 16 e 17, que a reprodutibilidade é adequada, com desvios-padrões médios de apenas $0,27 \mathrm{mg} / \mathrm{L}$ para [SMX] e de 0,20 $\mathrm{mgC} / \mathrm{L}$ para COT. As remoções de COT ao final de 60 minutos para os experimentos $1 \mathrm{~A}, 1 \mathrm{~B}$ e $1 \mathrm{C}$ foram iguais a $5,3 \%, 2,7 \%$ e $1,9 \%$, respectivamente, dentro do erro de leitura do equipamento. Pode-se afirmar que praticamente não ocorre mineralização do sulfametoxazol, apenas sua transformação em produtos. 
As Figuras 18 e 19 apresentam o conjunto de resultados de remoção de concentração de SMX e COT em função do tempo para todos os experimentos. Os experimentos possuem comportamento similar, em que a concentração de SMX cai rapidamente e o carbono orgânico total mantém-se praticamente constante até o final para todos os experimentos realizados. Trovó et al. (2009) também observaram esse comportamento, por se tratar da fotólise direta com radiação ultravioleta (UV); em comparação com processos envolvendo geração de radicais hidroxila, a fotólise direta apresenta, geralmente, eficiência menor quanto à mineralização.

É possível observar que os experimentos que começaram em meio básico e neutro permitem observar a queda do $\mathrm{pH}$, comportamento provavelmente relacionado ao subproduto formado pela fotólise do $\mathrm{SMX}$, o ácido sulfanilíco, como reportam Borenn, Arnold e McNeill (2004).
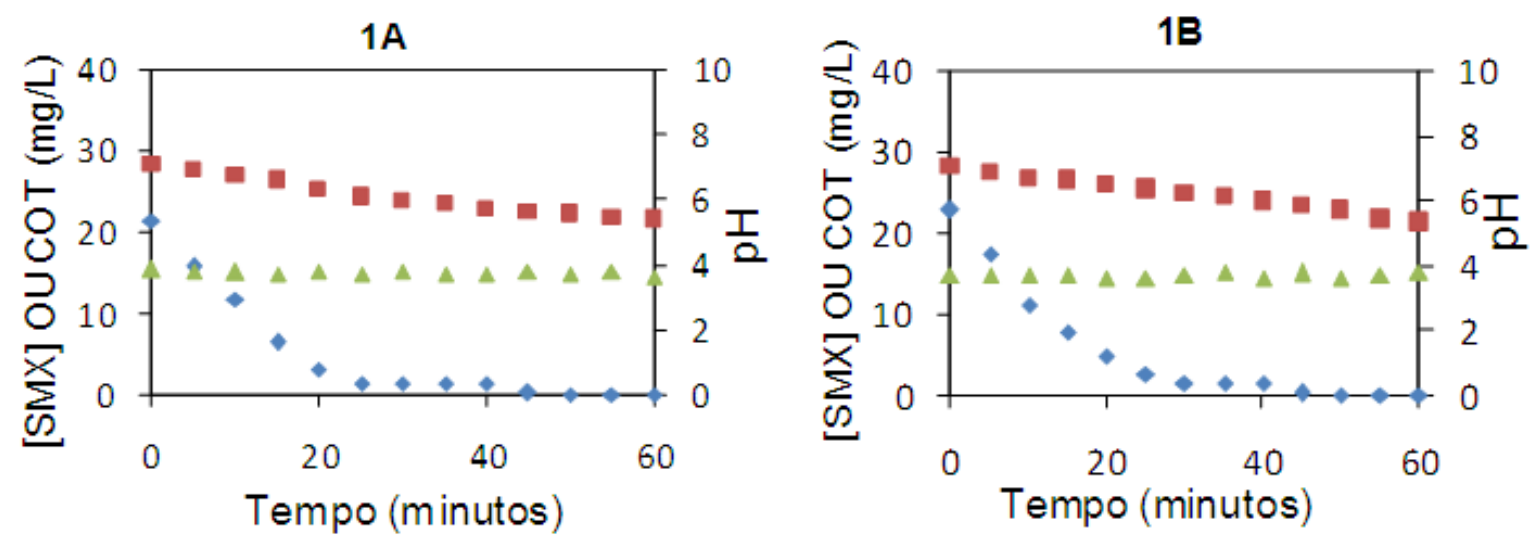

Figura 18 - Resultados dos experimentos de fotólise direta em $254 \mathrm{~nm}$ de sulfametoxazol e (SMX) em solução aquosa. (»)[SMX]; (₫) pH; e ( $\Delta$ ) COT. Condições: $1 \mathrm{~A}\left([\mathrm{SMX}]_{0}=21,3 \quad \mathrm{mg} / \mathrm{L} ; \mathrm{pH}_{0}=7\right) ; 1 \mathrm{~B}$ $\left([\mathrm{SMX}]_{0}=22,8 \mathrm{mg} / \mathrm{L} ; \mathrm{pH}_{0}=7\right)$; 

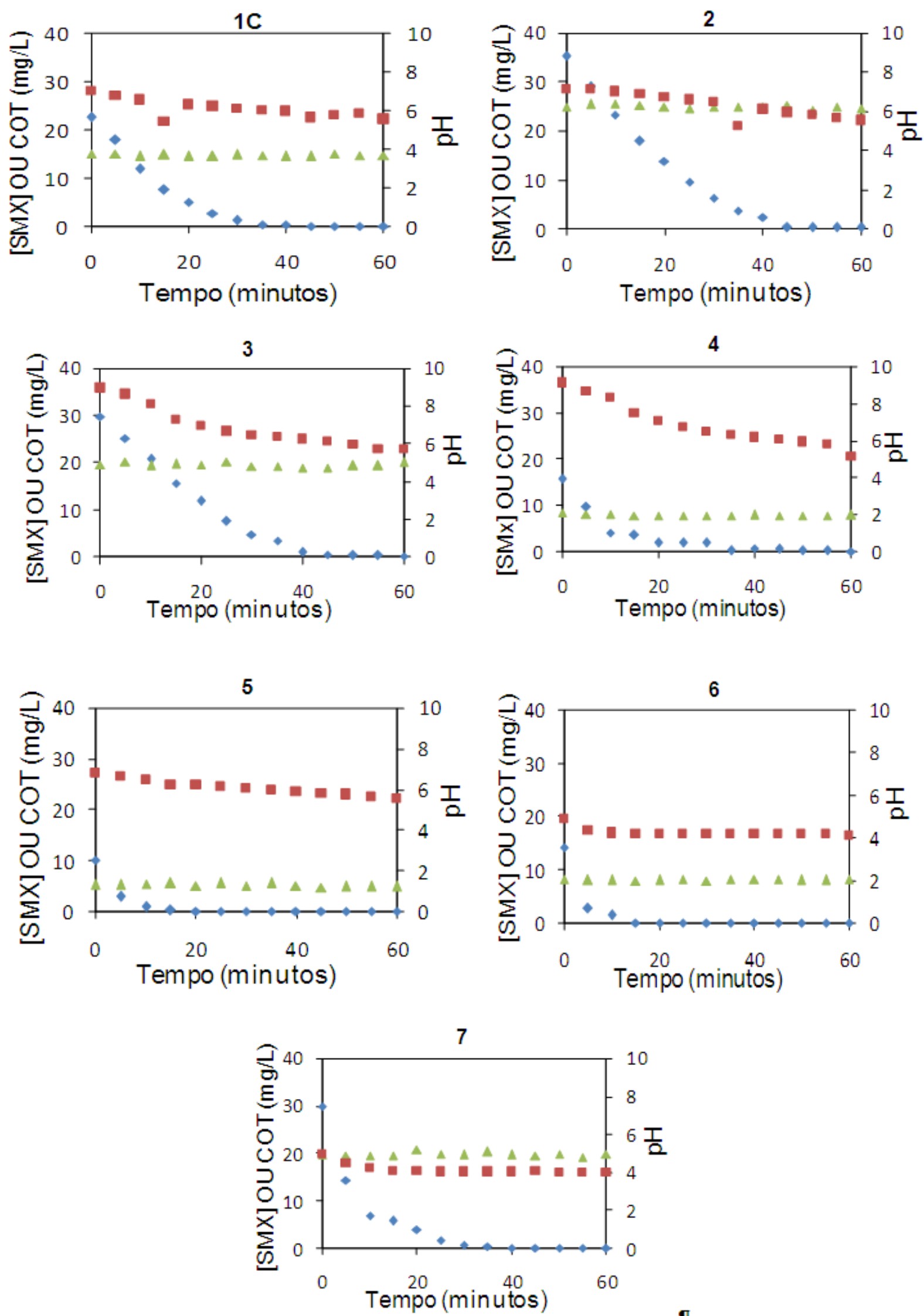

Figura 19 - Resultados dos experimentos de fotólise direta em $254 \mathrm{~nm}$ de sulfametoxazol e (SMX) em solução aquosa. (४)[SMX]; (₫) pH; e ( $\Delta$ ) COT. Condições: 1C ([SMX] $\left.]_{0}=22,6 \mathrm{mg} / \mathrm{L} ; \mathrm{pH}_{0}=7\right) ; 2$ $\left([S M X]_{0}=35,6 \mathrm{mg} / \mathrm{L} ; \mathrm{pH}_{0}=7,1\right) .3\left([\mathrm{SMX}]_{0}=29,8 \mathrm{mg} / \mathrm{L} ; \mathrm{pH}_{0}=8,9\right) ; 4$ ([SMX $\left.]_{0}=15,7 \mathrm{mg} / \mathrm{L} ; \mathrm{pH}_{0}=9,1\right) ; 5$ $\left([S M X]_{0}=7,2 \mathrm{mg} / \mathrm{L} ; \mathrm{pH}_{0}=6,8\right) ; 6\left([S M X]_{0}=14,1 \mathrm{mg} / \mathrm{L} ; \mathrm{pH}_{0} 4,9\right) ; 7\left([\mathrm{SMX}]_{0}=29,9 \mathrm{mg} / \mathrm{L} ; \mathrm{pH}_{0}=4,9\right)$. 
A Figura 20 apresenta a comparação dos experimentos 4 e 6, realizados com concentrações iniciais de SMX similares (15,7 mg/L e 14,1 mg/L, respectivamente), porém em meios diferentes, meio básico $(\mathrm{pH}$ 9,0) e meio ácido (pH5).Independentemente do $\mathrm{pH}$ adotado para o experimento, a degradação de SMX foi superior a $99 \%$ após 60 minutos de tratamento. Apesar de se obter remoção quase completa do antibiótico, comparando-se os experimentos 4 e 6 é possível verificar comportamentos diferentes no primeiros 30 minutos de fotólise. Em meio ácido a taxa inicial de remoção de SMX foi maior em relação à observada em meio neutro (2,28 mg/L.min e 1,27 mg/L.min, respectivamente).

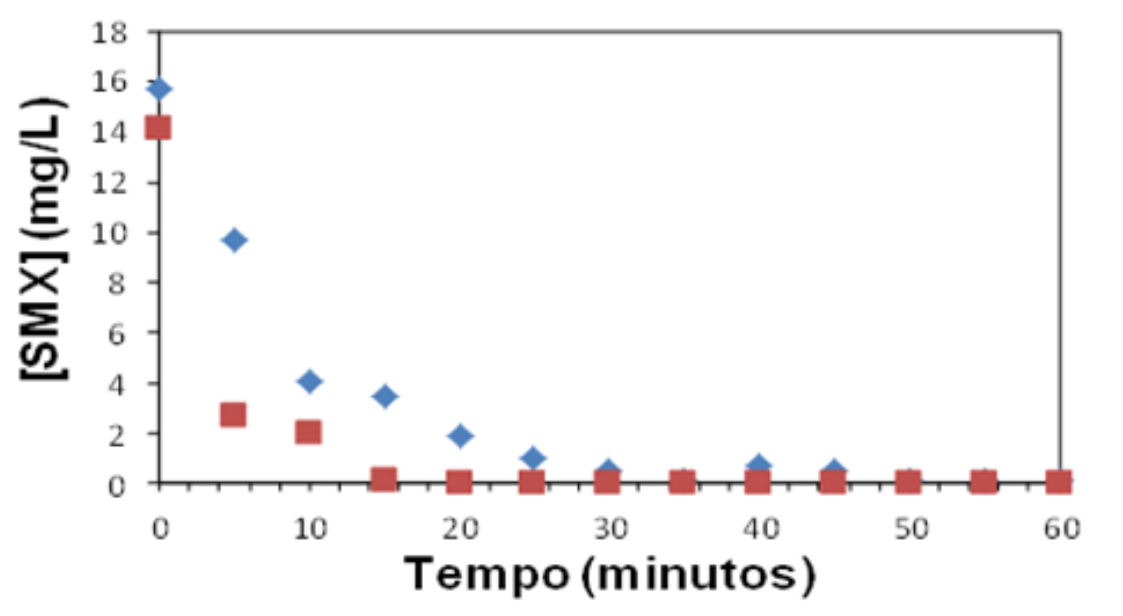

Figura 20 -Evolução de [SMX] em função do tempo para os experimentos $4(\diamond)\left([S M X]_{0}=15,7 \mathrm{mg} / \mathrm{L}\right.$ e pH 9,1) e $6(\varpi)\left([S M X]_{0}=14,1 \mathrm{mg} / \mathrm{L}\right.$ e pH$\left.H_{0}=4,9\right)$.

$\mathrm{Na}$ Figura 21 comparam-se os resultados dos experimentos 3 e 7 . Nesse caso também se discute o efeito do aumento do $\mathrm{pH}$ para uma mesma concentração inicial de SMX. Observa-se novamente que a remoção de SMX é favorecida em meio ácido, com taxa inicial de degradação do antibiótico maior no experimento 7 (3,91 mg/L.min) que no experimento 3 (0,94 mg/L.min). 


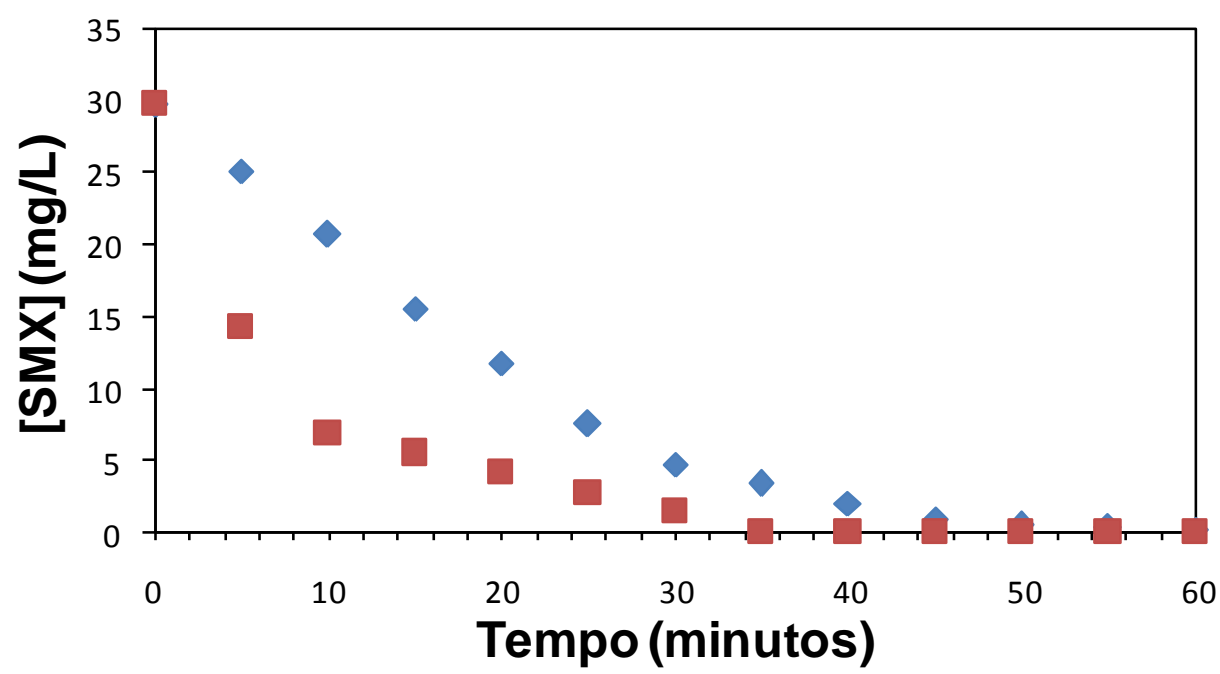

Figura 21 - Evolução de [SMX] em função do tempo para os experimentos $3(\triangleleft)\left([S M X]_{0}=29,8 \mathrm{mg} / \mathrm{L} \text { e pH 8,9) e } 7 \text { (๘) ([SMX }\right]_{0}=29,9 \mathrm{mg} / \mathrm{L}$ e $\left.\mathrm{pH}_{0}=4,9\right)$.

\subsubsection{Análise estatística}

Os valores de $X_{i}$ foram recalculados considerando os valores medidos (isto é, reais, não nominais) das variáveis independentes. Dessa forma, os novos valores mínimo, máximo, $U_{0}$ e $\Delta U$ são apresentados na Tabela 6.

Tabela 6 - Domínio experimental dos novos valores das variáveis estudadas.

\begin{tabular}{cccccc}
\hline Variáveis & Identificação & $\boldsymbol{U}_{\min }$ & $\boldsymbol{U}_{\text {máx }}$ & $\boldsymbol{U}_{\mathbf{0}}$ & $\boldsymbol{\Delta} \boldsymbol{U}$ \\
\hline$U_{1}$ & {$[\mathrm{SMX}](\mathrm{mg} / \mathrm{L})$} & 7,2 & 35,6 & 21,4 & 7 \\
$U_{2}$ & $\mathrm{pH}$ & 4,9 & 9,1 & 7,0 & 2,1 \\
\hline
\end{tabular}

Os resultados dos experimentos foram analisados estatisticamente a partir de um modelo de superfície de resposta, com o propósito de avaliar o efeito das variáveis envolvidas na degradação do antibiótico sulfametoxazol. Como a remoção de SMX ao final de 60 minutos em todos os experimentos foi praticamente a mesma (superior a 99\%), a análise foi realizada quanto ao tempo necessário para remoção de 50\%da quantidade inicial de $\operatorname{SMX}\left(Y_{1}\right)$ e taxa de remoção $\left(Y_{2}\right)$ utilizando o software Statgraphics Plus 3.0. 
A análise de variância (ANOVA) para a resposta $Y_{1}$ apresentada na Tabela 7separa a variabilidade da resposta, conforme as contribuições de cada efeito, sendo a significância estatística avaliada comparando-se os quadrados médios da variável $X_{1}$. A variável $X_{1}$ corresponde à concentração inicial de SMX e a variável $X_{2}$, ao valor de $\mathrm{pH}$ inicial.

Tabela 7 - Análise de variância (ANOVA) para a resposta $Y_{1}$ (tempo necessário para remoção de $50 \%$ da quantidade inicial de SMX). Consideram-se 95\% de confiança e 3 graus de liberdade $(t=3,1825) . X_{1}$ : variável codificada correspondente a $[S M X]_{0} ; X_{2}$ : variável codificada correspondente

\begin{tabular}{|c|c|c|c|c|c|c|c|}
\hline $\begin{array}{c}\text { Variáveis } \\
\text { e } \\
\text { interações } \\
\end{array}$ & $\begin{array}{l}\text { Soma dos } \\
\text { quadrados }\end{array}$ & $\begin{array}{l}\text { Graus de } \\
\text { liberdade }\end{array}$ & $\begin{array}{l}\text { Quadrado } \\
\text { médio }\end{array}$ & $F$ & $p$ & Efeito & $\begin{array}{c}\text { Intervalo } \\
\text { de } \\
\text { confiança }\end{array}$ \\
\hline$x_{1}$ & 145,985 & 1 & 145,985 & 196,13 & 0,0008 & 10,97 & $\pm 1,59$ \\
\hline$X_{2}$ & 36,0968 & 1 & 36,0968 & 48,59 & 0,0061 & 8,34 & $\pm 3,13$ \\
\hline$x_{1}^{2}$ & 2,67391 & 1 & 2,67391 & 3,59 & 0,1543 & $-2,30$ & $\pm 2,89$ \\
\hline$X_{1} X_{2}$ & 46,5289 & 1 & 46,5289 & 62,51 & 0,0042 & 8,89 & $\pm 5,03$ \\
\hline$x_{2}^{2}$ & 12,0774 & 1 & 12,0774 & 16,23 & 0,0275 & $-8,10$ & $\pm 5,38$ \\
\hline Erro Total & 2,23298 & 3 & 0,0744328 & & & & \\
\hline $\begin{array}{l}\text { Total } \\
\text { Corrigido }\end{array}$ & 261,063 & 8 & & & & & \\
\hline$R^{2}$ & 0,9914 & & & & & & \\
\hline
\end{tabular}

Para a resposta $Y_{1}$ (tempo necessário para remoção de $50 \%$ da quantidade inicial de SMX), o coeficiente de determinação $R^{2}=0,9914$ indica que o modelo ajustado, eq.(12), explica bem a variabilidade dos resultados experimentais em termos de resposta, considerados o erro e o domínio experimental.

$Y_{1}=9,91+6,89 X_{1}+3,11 X_{2}-3,1 X_{1}^{2}+1,50 X_{1} X_{2}-6,69 X_{1}^{2}$

A Figura 22compara os valores experimentais e calculados da resposta.A Figura 23 mostra que os resíduos estão distribuídos aleatoriamente com média zero em torno da linha de resíduo zero. 


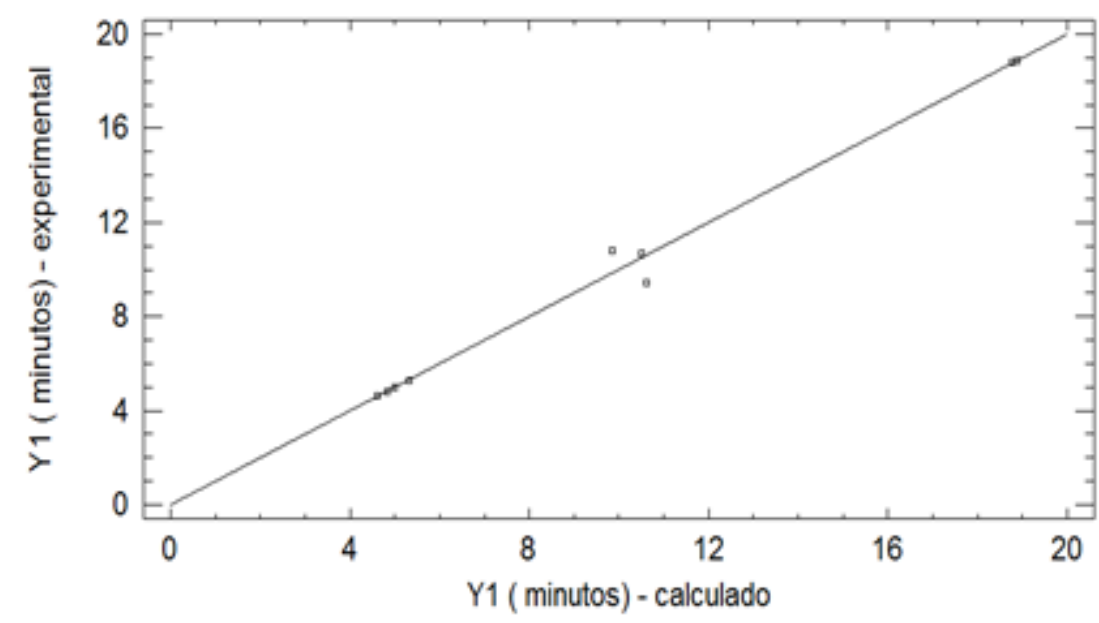

Figura 22 - Comparação entre valores experimentais e calculados da resposta $Y_{1}$ (tempo necessário para remoção de $50 \%$ da quantidade inicial de SMX).

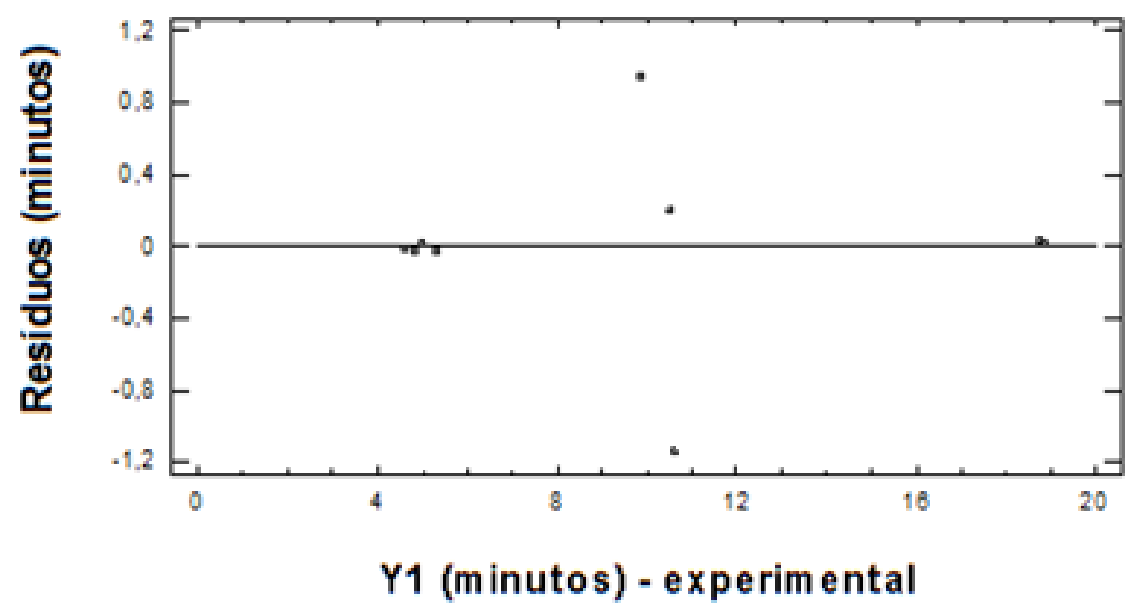

Figura 23 - Distribuição dos resíduos em função dos valores experimentais da resposta $Y_{1}$ (tempo necessário para remoção de $50 \%$ da quantidade inicial de SMX).

O resultado da ANOVA (Tabela 6) e o diagrama de Pareto (Figura 24) indicam efeitos positivos significativos das variáveis $X_{1}(p=0,0008 ; F=196,132)$ e $X_{2}$ $(p=0,031 ; F=48,59)$ quanto a resposta $Y_{1}$. Além disso, os termos $X_{1}^{2} \mathrm{e}$ de $X_{2}^{2}(p=0,1543 ; F=3,59 ; \quad p=0,0275 ; F=16,23$, respectivamente) mostram efeitos negativos, sendo o efeito de $X_{2}^{2}$ significativo, o que sugere efeito adverso sobre a resposta $Y_{1}$ para concentrações iniciais mais altas de SMX e valores mais altos de $\mathrm{pH}$ inicial. 


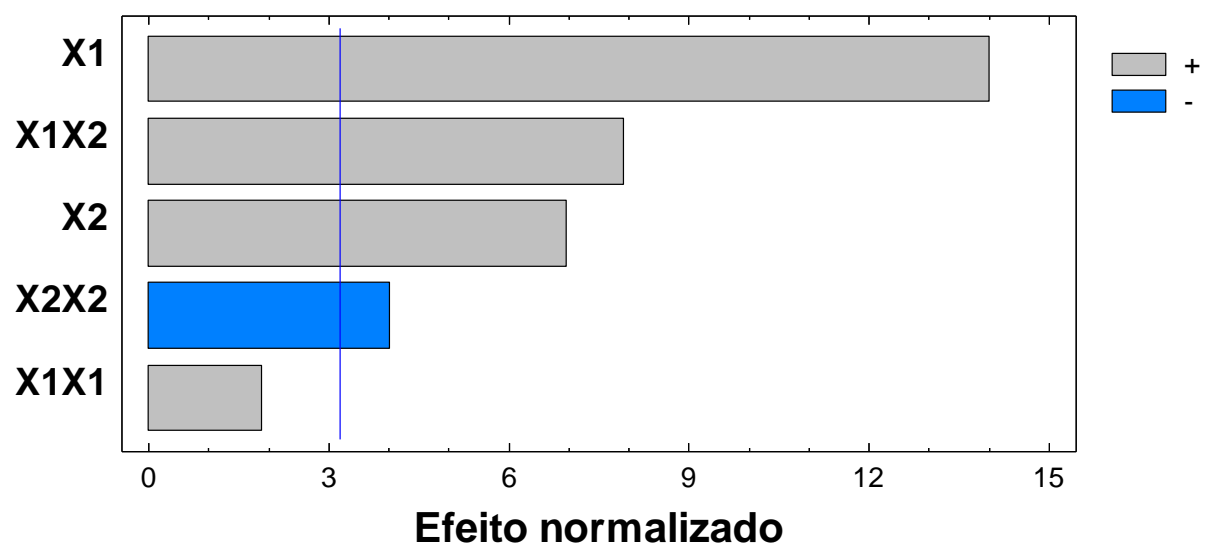

Figura 24 - Diagrama de Pareto para a resposta $Y_{1}$ (tempo necessário para remoção de $50 \%$ da quantidade inicial de SMX). $X_{1}$ : variável codificada correspondente a $[\mathrm{SMX}]_{0}(\mathrm{mg} / \mathrm{L}) ; X_{2}:$ variável codificada correspondente ao $\mathrm{pH}_{0}$.

A Figura 25 apresenta a superfície de resposta correspondente ao modelo dado pela Equação 12 e a Figura 26 apresenta as curvas de contorno correspondentes. De acordo com os resultados da ANOVA, observa-se que quando a variável $X_{2}(\mathrm{pH})$ está em seu valor mínimo, a concentração inicial de sulfametoxazol $\left(X_{1}\right)$ praticamente não apresenta efeito sobre a resposta $Y_{1}$. Porém, o efeito positivo do aumento do $\mathrm{pH}$ sobre a resposta é facilmente observado para a variável $X_{1}$ fixada em seu valor máximo. Esse comportamento está associado à rapidez com que o SMX é consumido, assim, para baixas concentrações iniciais de SMX não é possível observar a interferência do $\mathrm{pH}$, já que em qualquer caso sua degradação por meio da fotólise em 254 nm é muito rápida. 


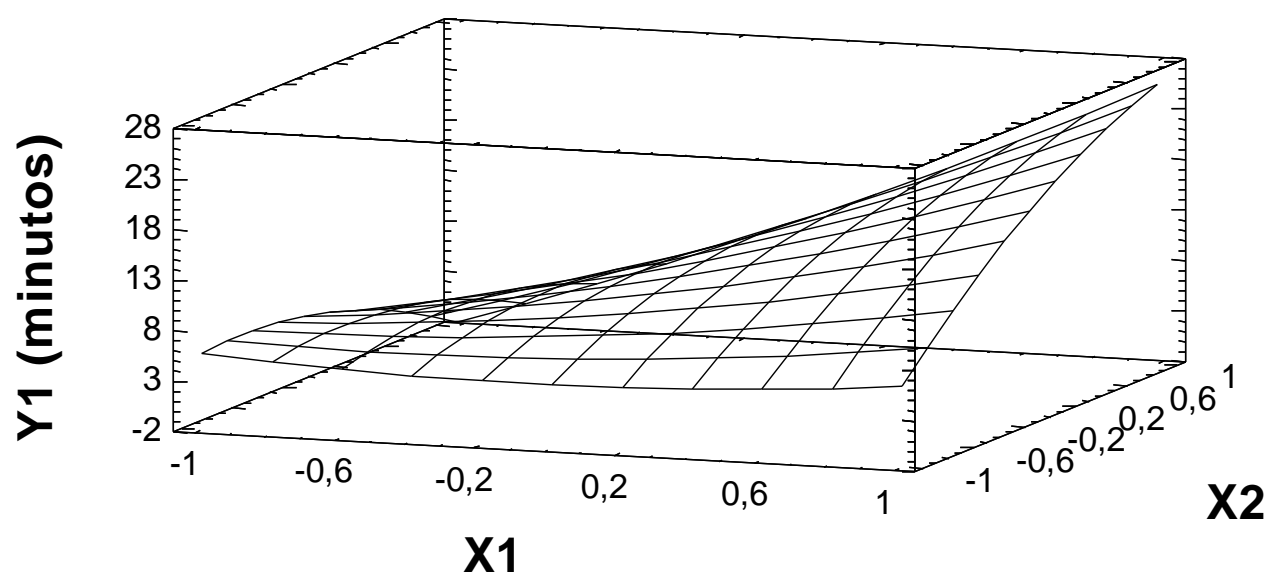

Figura 25 - Superfície de resposta descrita pela eq.(12) para a variável dependente $Y_{1}$ (tempo necessário para remoção de $50 \%$ da quantidade inicial de SMX). $X_{1}$ : variável codificada correspondente a $[\mathrm{SMX}]_{0}(\mathrm{mg} / \mathrm{L}) ; X_{2}$ : variável codificada correspondente ao $\mathrm{pH}_{0}$.

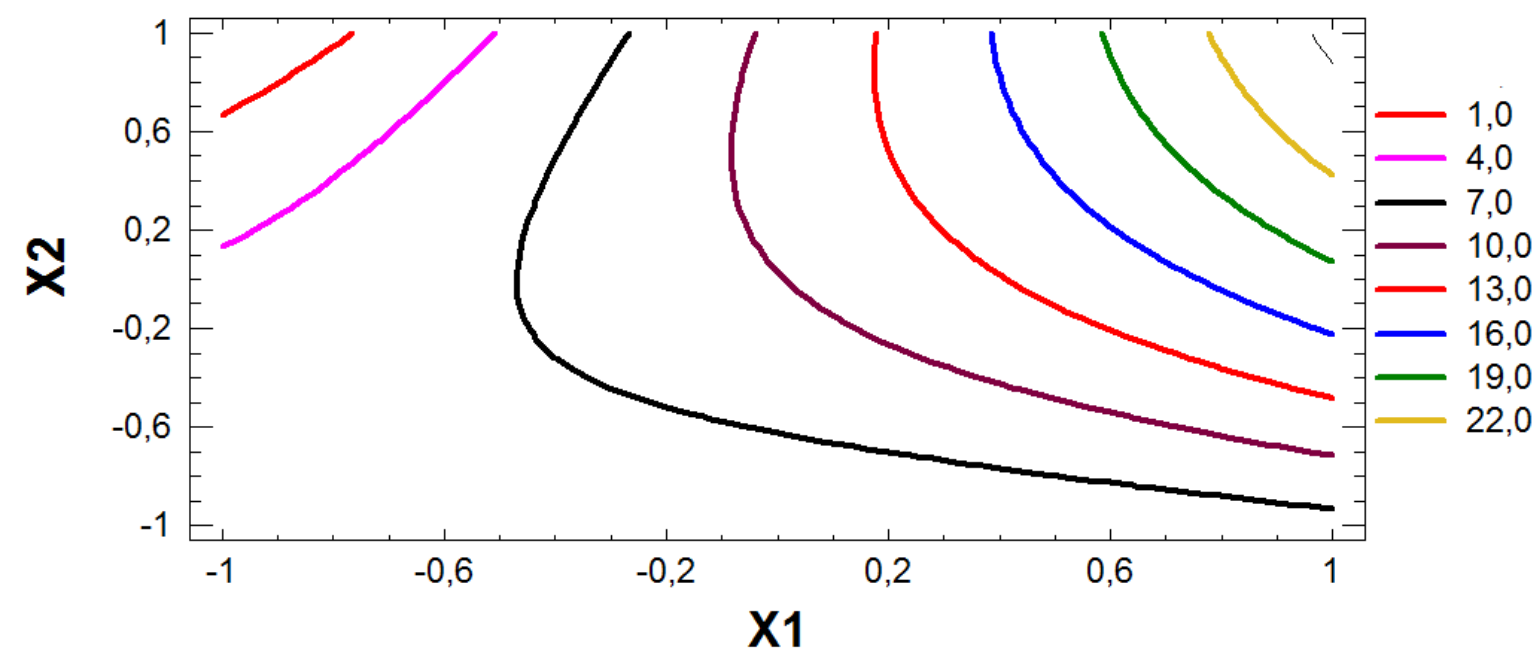

Figura 26 - Curvas de contorno para a superfície de resposta descrita pela eq. (12) para a variável dependente $Y_{1}$ (tempo necessário para remoção de $50 \%$ da quantidade inicial de SMX). $X_{1}$ : variável codificada correspondente a $[\mathrm{SMX}]_{0}(\mathrm{mg} / \mathrm{L}) ; X_{2}$ : variável codificada correspondente ao $\mathrm{pH}_{0}$.

A interação entre a quantidade inicial de SMX e o pH está representada na Figura 27, a partir da qual pode-se observar que para maior quantidade inicial do antibiótico o pH interfere na resposta; nesse caso, o valor de $Y_{1}$ é apreciavelmente maior, indicando que degradação do SMX durante a fotólise é mais lenta em meio básico, como foi constatado pela comparação direta dos experimentos. Por outro 
lado, no caso da menor quantidade inicial, o valor de $Y_{1}$ foi baixo, não sendo possível observar o efeito do $\mathrm{pH}$, já que a degradação ocorre rapidamente.

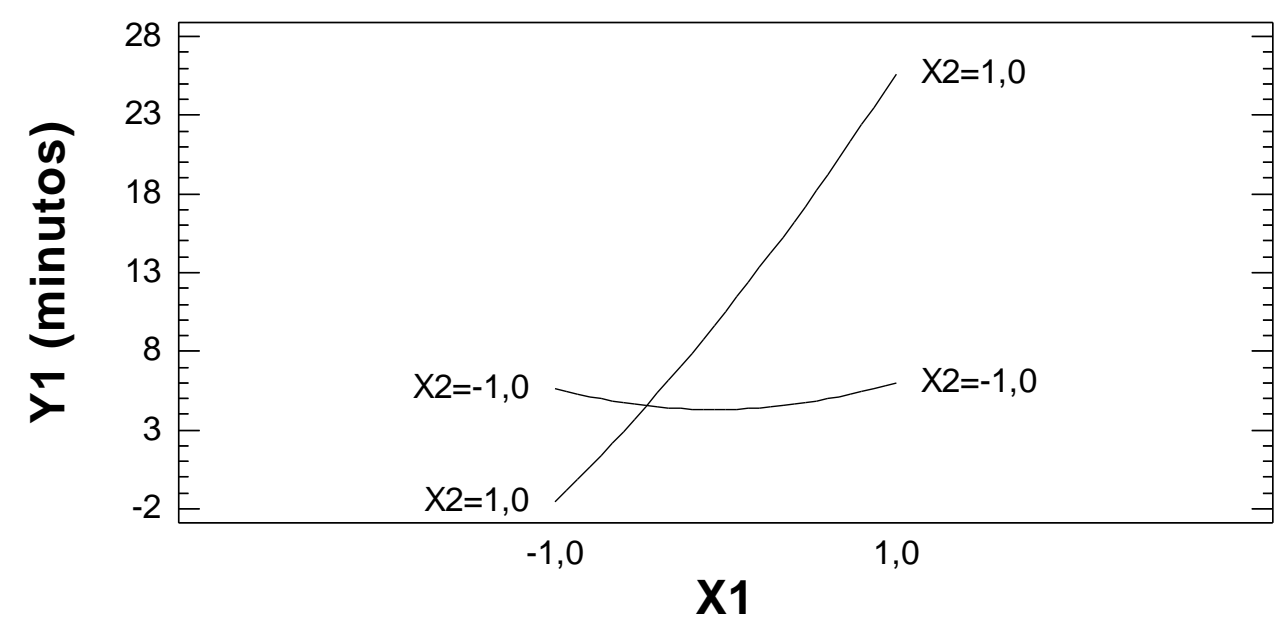

Figura 27 - Comportamento da resposta $Y_{1}$ (tempo necessário para remoção de $50 \%$ da quantidade inicial de SMX). $X_{1}$ : variável codificada correspondente a $[\mathrm{SMX}]_{0}(\mathrm{mg} / \mathrm{L}) ; X_{2}:$ variável codificada correspondente ao $\mathrm{pH}_{0}$.

A taxa inicial de degradação de $\operatorname{SMX}\left(Y_{2}, \mathrm{mg} / \mathrm{L} \mathrm{min}\right)$ foi aproximada por $\Delta[\mathrm{SMX}] / \Delta t$, considerando $\mathrm{o}$ intervalo de tempo entre 0 e 10 minutos. A Tabela 8 apresenta a análise de variância (ANOVA) para essa resposta.

Tabela 8 - Análise de variância (ANOVA) para a resposta $Y_{2}$ (taxa inicial de degradação de SMX em $\mathrm{mg} / \mathrm{L}$.min). Consideram-se $95 \%$ de confiança e 3 graus de liberdade $(t=3,1825) . X_{1}$ : variável codificada correspondente a $[\mathrm{SMX}]_{0} ; X_{2}$ : variável codificada correspondente ao $\mathrm{pH}_{0}$.

\begin{tabular}{|c|c|c|c|c|c|c|c|}
\hline $\begin{array}{c}\text { Variáveis } \\
\text { e } \\
\text { interações } \\
\end{array}$ & $\begin{array}{l}\text { Soma dos } \\
\text { quadrados }\end{array}$ & $\begin{array}{l}\text { Graus de } \\
\text { liberdade }\end{array}$ & $\begin{array}{l}\text { Quadrado } \\
\text { médio }\end{array}$ & $F$ & $p$ & Efeito & $\begin{array}{c}\text { Intervalo } \\
\text { de } \\
\text { confiança }\end{array}$ \\
\hline$x_{1}$ & 0,451195 & 1 & 0,451195 & 10,82 & 0.0461 & 0,76 & $\pm 0,37$ \\
\hline$x_{2}$ & 3,37498 & 1 & 3,37498 & 80,92 & 0,0029 & $-1,89$ & $\pm 0,74$ \\
\hline$x_{1}^{2}$ & 0,0225617 & 1 & 0,0225617 & 0,54 & 0,5153 & $-0,21$ & $\pm 0,67$ \\
\hline$X_{1} X_{2}$ & 0,8586643 & 1 & 0,8586643 & 20,59 & 0,0200 & $-1,81$ & $\pm 1,19$ \\
\hline $\begin{array}{l}X_{2}^{2} \\
\text { Erro Total }\end{array}$ & $\begin{array}{c}1,4562 \\
0,12513\end{array}$ & $\begin{array}{l}1 \\
3\end{array}$ & $\begin{array}{c}1,4562 \\
0,0417099\end{array}$ & 34,91 & 0,0097 & 1,72 & $\pm 0,92$ \\
\hline $\begin{array}{l}\text { Total } \\
\text { Corrigido }\end{array}$ & 7,2984 & 8 & & & & & \\
\hline$R^{2}$ & 0,9828 & & & & & & \\
\hline
\end{tabular}


No caso da resposta $Y_{2}$, o coeficiente de determinação $R^{2}=0,9283$ indica que o modelo ajustado, eq.(13), explica satisfatoriamente a variabilidade dos resultados experimentais em termos de resposta, considerados o erro e o domínio experimental associados.

$Y_{2}=1,27+0,38 X_{1}-0,95 X_{2}-0,14 X_{1}^{2}+0,91 X_{1} X_{2}-0,86 X_{2}^{2}$

A Figura 28 compara valores experimentais e calculados pela eq.(13) da taxa inicial de degradação de SMX. O valor médio dos resíduos absolutos é igual a 0,11, com desvio-padrão de $0,20 \mathrm{mg} / \mathrm{L}$ min. O gráfico dos resíduos, Figura 29, mostra a diferença entre os valores experimentais e os calculados da variável dependente, em função dos valores experimentais. Os resíduos estão aleatoriamente distribuídos com média zero em torno da linha de resíduo zero.

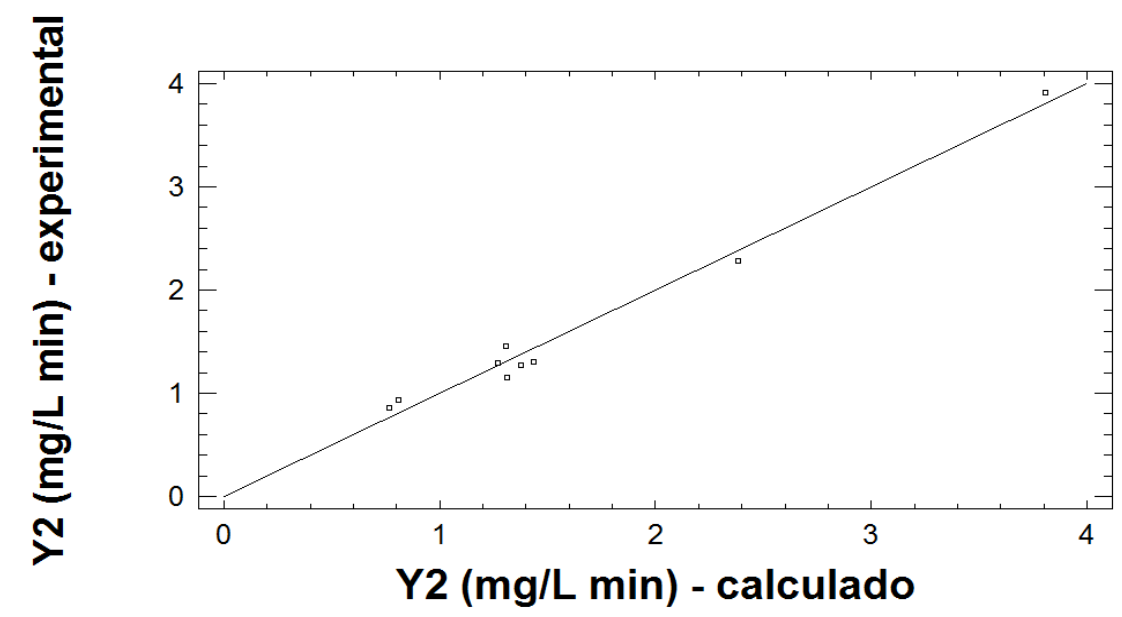

Figura 28 - Comparação entre valores experimentais e calculados da resposta $Y_{2}$ (taxa inicial da degradação do SMX). 


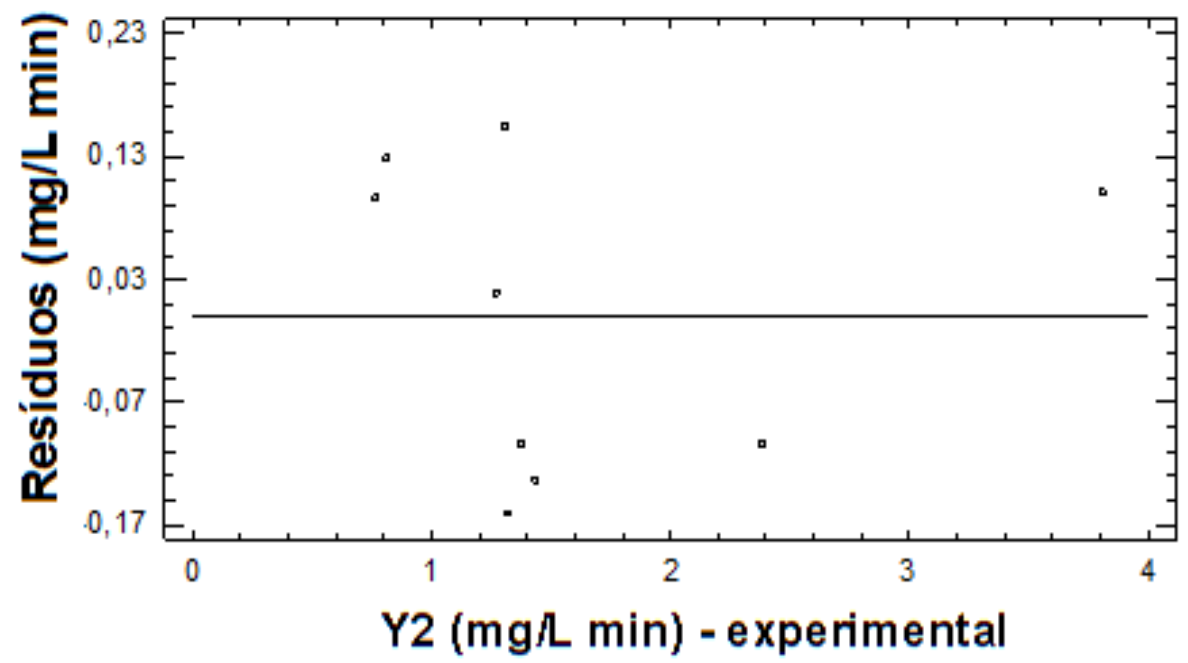

Figura 29 - Distribuição dos resíduos em função dos valores experimentais da resposta $Y_{2}$ (taxa inicial da degradação do SMX)

A ANOVA (Tabela 8 ) permite identificar o efeito significativo negativo das variáveis $X_{2}(F=80,92 ; p=0,029)$ e o efeito positivo de $X_{1}(F=10,82 ; p=0,0461)$, como mostra o diagrama de Pareto (Figura 30).

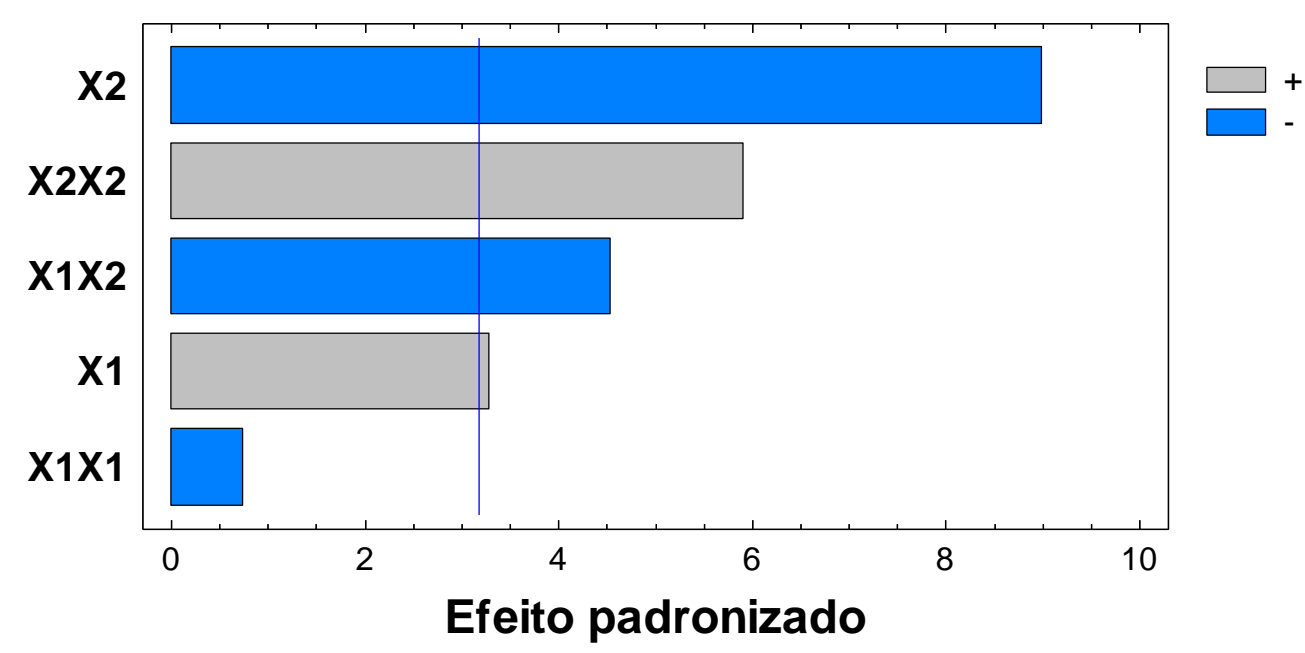

Figura 30 - Diagrama de Pareto para a resposta $Y_{2}$ (taxa inicial da degradação doSMX). $X_{1}$ : variável codificada correspondente a $[\mathrm{SMX}]_{0}(\mathrm{mg} / \mathrm{L}) ; X_{2}$ : variável codificada correspondente ao $\mathrm{pH}_{0}$.

A Figura 31 apresenta a superfície de resposta correspondente ao modelo dado pela eq. (13) e a Figura 32 apresenta as curvas de contorno correspondentes. 
Os resultados mostram que a taxa inicial de remoção de SMX aumenta para maiores valores da variável $X_{1}$ e menores valores da variável $X_{2}$. O efeito do $\mathrm{pH}$ sobre esta resposta é mais evidente para a maior quantidade inicial de SMX; o tempo necessário para remoção de SMX em meio ácido foi menor, porque apesar do menor valor do coeficiente de absorção molar em 254 nm, o rendimento quântico é maior em pH baixo (BAEZA; KNAPPE, 2011). Hatchard e Parker (1956) definem o rendimento quântico como a medida da eficiência fotônica de uma reação fotoquímica, ou seja, o número de mols de um produto formado, ou reagente consumido, por número de mols de fótons absorvidos.

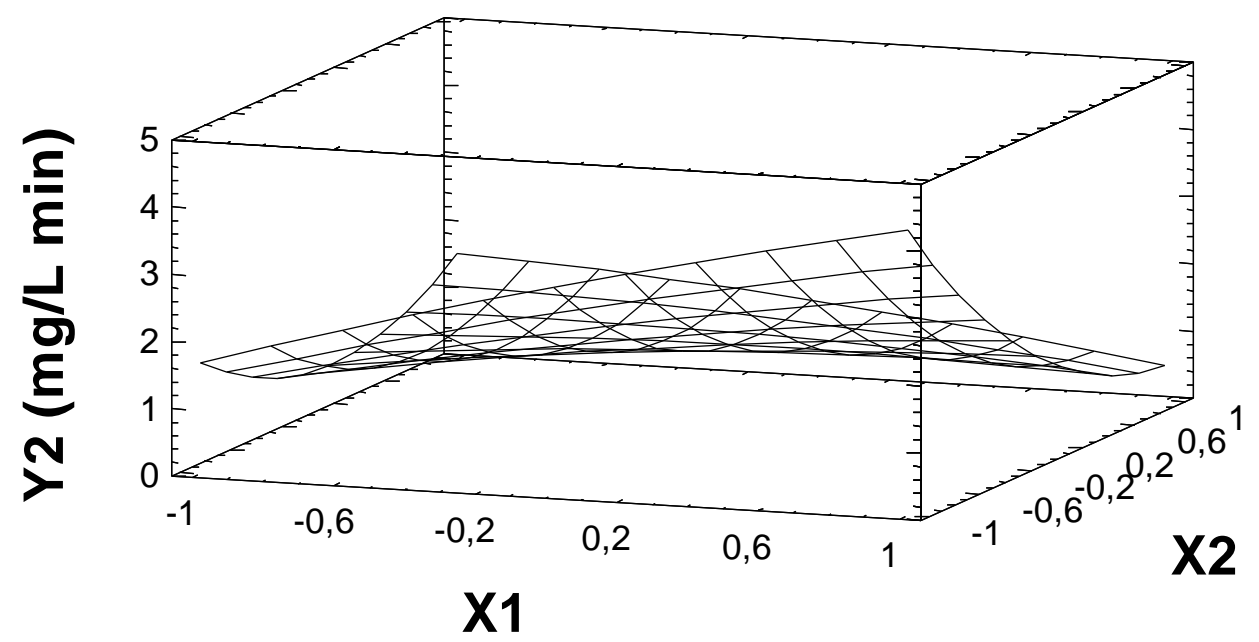

Figura 31 - Superfície de resposta descrita pela eq. (13) para a variável dependente $Y_{2}$ (taxa da degradação inicial do SMX). $X_{1}$ : variável codificada correspondente a $[\mathrm{SMX}]_{0}(\mathrm{mg} / \mathrm{L}) ; X_{2}$ : variável codificada correspondente ao $\mathrm{pH}$.

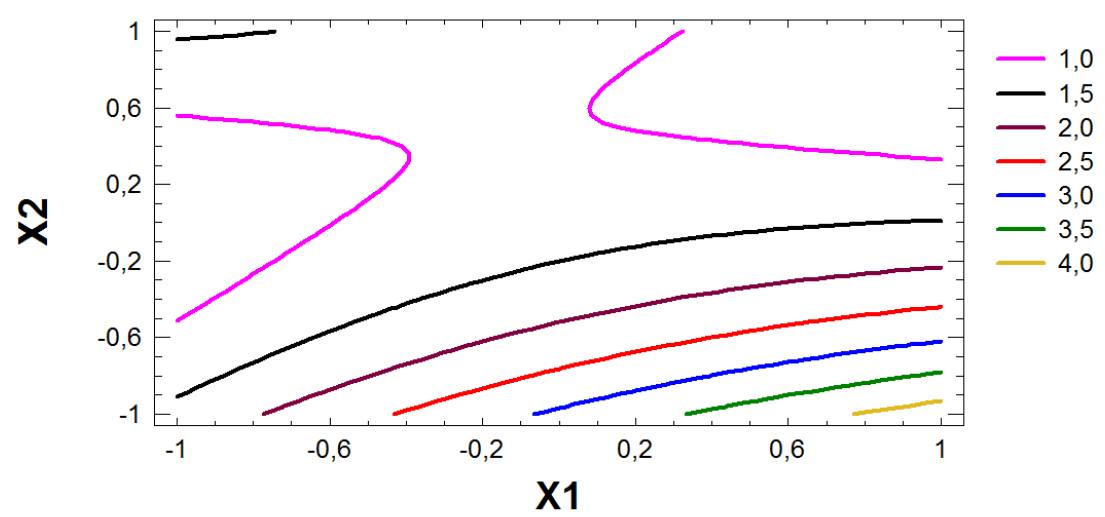

Figura 32 - Curvas de contorno para a superfície de resposta descrita pela eq. (13) para a variável dependente $Y_{2}$ (taxa inicial da degradação do de SMX). $X_{1}$ : variável codificada

correspondente a $[\mathrm{SMX}]_{0}(\mathrm{mg} / \mathrm{L}) ; X_{2}$ : variável codificada correspondente ao $\mathrm{pH}_{0}$. 


\subsubsection{Análise da degradação do sulfametoxazol em 180 minutos}

Utilizando-se as condições do ponto central do planejamento Doehlert, realizou-se um experimento prolongado, com duração de 180 minutos. A Figura 33 mostra que o COT se manteve constante, não ocorrendo mineralização durante esse intervalo de tempo. A coloração da solução não se alterou após 60 minutos de tratamento.

A Figura 34 apresenta as leituras de temperatura, concentração de oxigênio dissolvido $(\mathrm{OD})$ e $\mathrm{pH}$. A concentração de oxigênio dissolvido no meio cai ao longo do experimento, o que leva a crer que tenha havido consumo do $\mathrm{O}_{2}$ durantes as reações de fotólise.

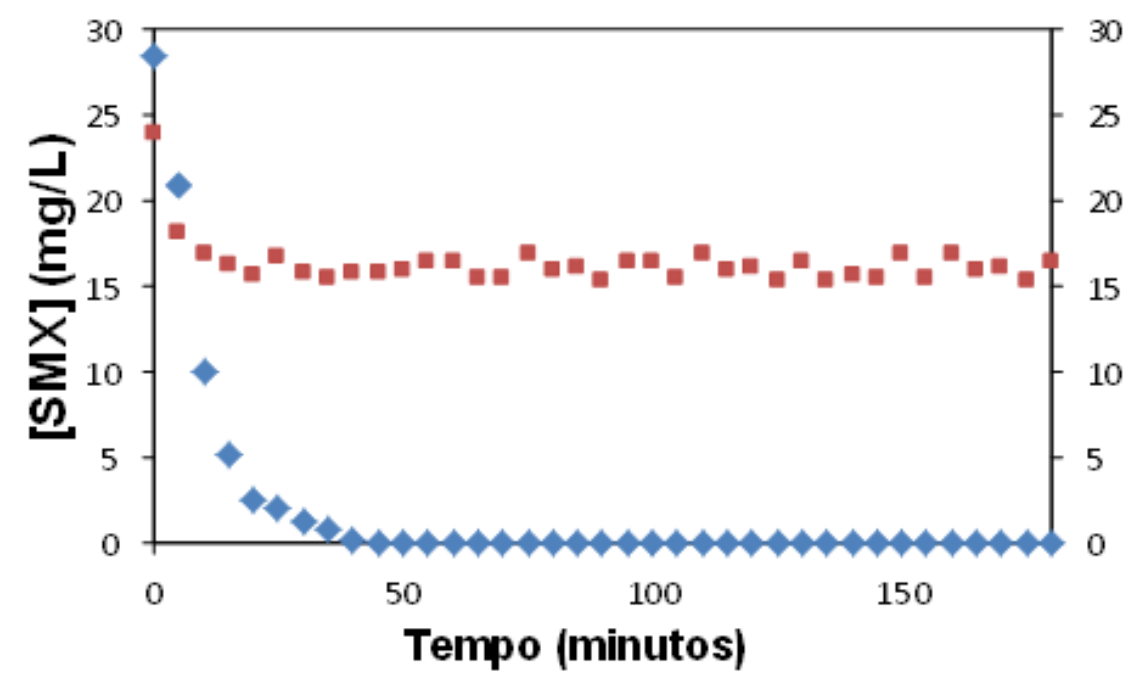

Figura 33 - Evolução da concentração de SMX e do COT durante o experimento de fotólise prolongado. (४) [SMX]; (₫)COT. Condições: $[\mathrm{SMX}]_{0}=27,9 \mathrm{mg} / \mathrm{L}$ e p $\mathrm{H}_{0}=7,2$. 


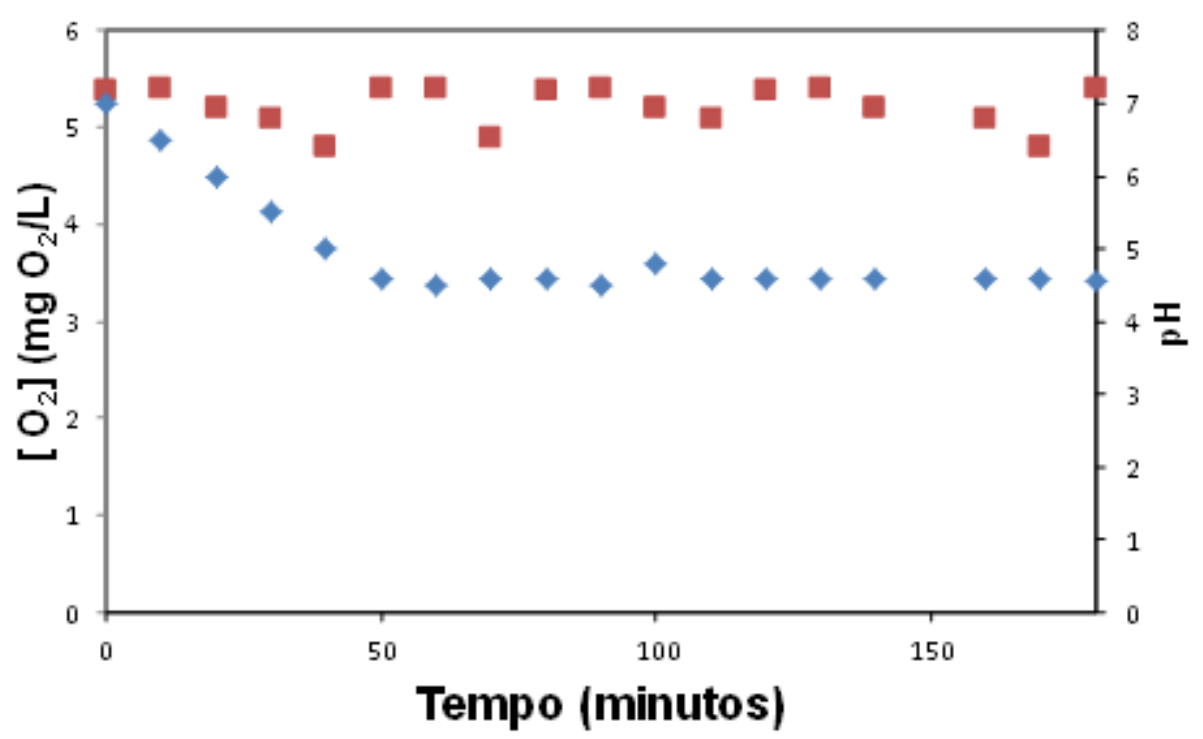

Figura 34 - Evolução da concentração de oxigênio dissolvido (OD) e pH ao longo do tempo durante o experimento de fotólise prolongado.(») pH]; (₫) $\left[\mathrm{O}_{2}\right]$. Condições: $[S M X]_{0}=27,9 \mathrm{mg} / \mathrm{L} \mathrm{e}$ $\mathrm{pH}_{0}=7,2$.

\subsubsection{Análise da influência do pH na degradação de sulfametoxazol}

Foram realizados mais três experimentos, mantendo $\mathrm{o} p \mathrm{pH}$ constante (controlado manualmente) durante os 60 minutos de reação. Repetiu-se o ponto central do experimento Doehlert(experimento 1) e os experimentos 3 e 7 por possuírem concentrações iniciais nominais iguais e pH iniciais diferentes.

A Figura 35 compara resultados de dois experimentos realizados com concentrações e pH iniciais similares. Em um deles o pH foi ajustado inicialmente em 7 e deixado livre durante todo o experimento, enquanto no outro manteve-se $\mathrm{opH}$ controlado manualmente em 7 ao longo do tempo; praticamente não se observa diferença na evolução de [SMX]. Na Figura 36 , as diferenças nos valores de pH em função do tempo também não foram significativas: no experimento em que o pH foi deixado livre, o pH final foi de 5,56, próximo ao valor final do experimento realizado com pH controlado, 6,70. Em consequência disso, possivelmente, não se observa efeito quanto ao comportamento da fotólise. 


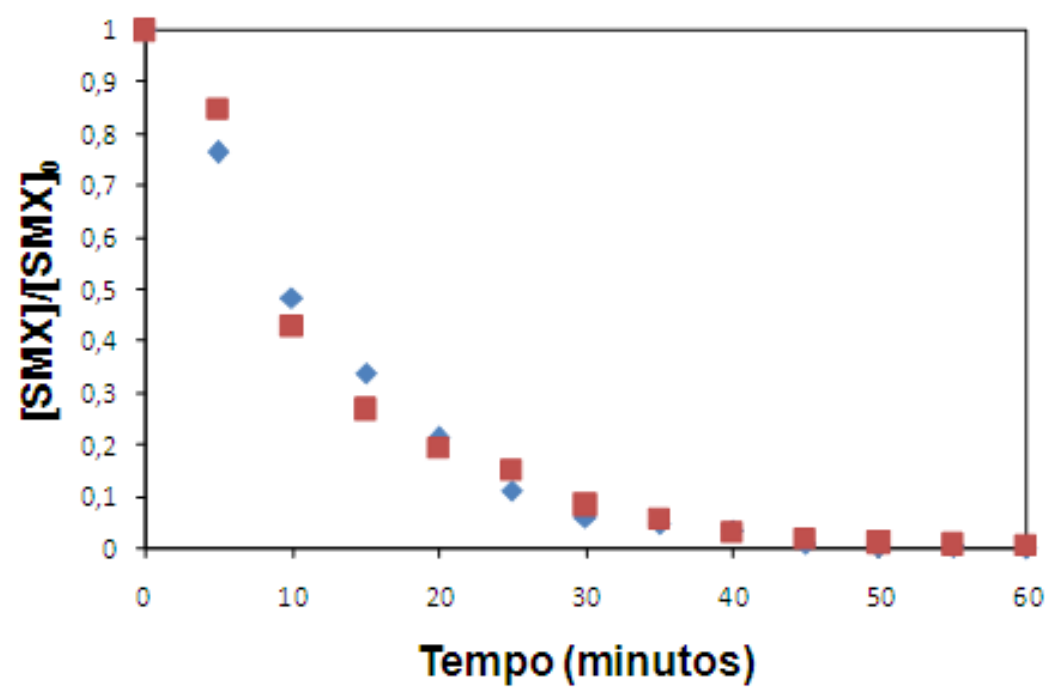

Figura 35 - Evolução de [SMX]/[SMX] em função do tempo para experimentos de fotólise realizados com $(\star) \mathrm{pH}$ livre e $(\varpi) \mathrm{pH}$ controlado. Condições do experimento 1: [SMX $]_{0}=28,6 \mathrm{mg} / \mathrm{L} \mathrm{e}$ $\mathrm{pH}_{0}=7$.

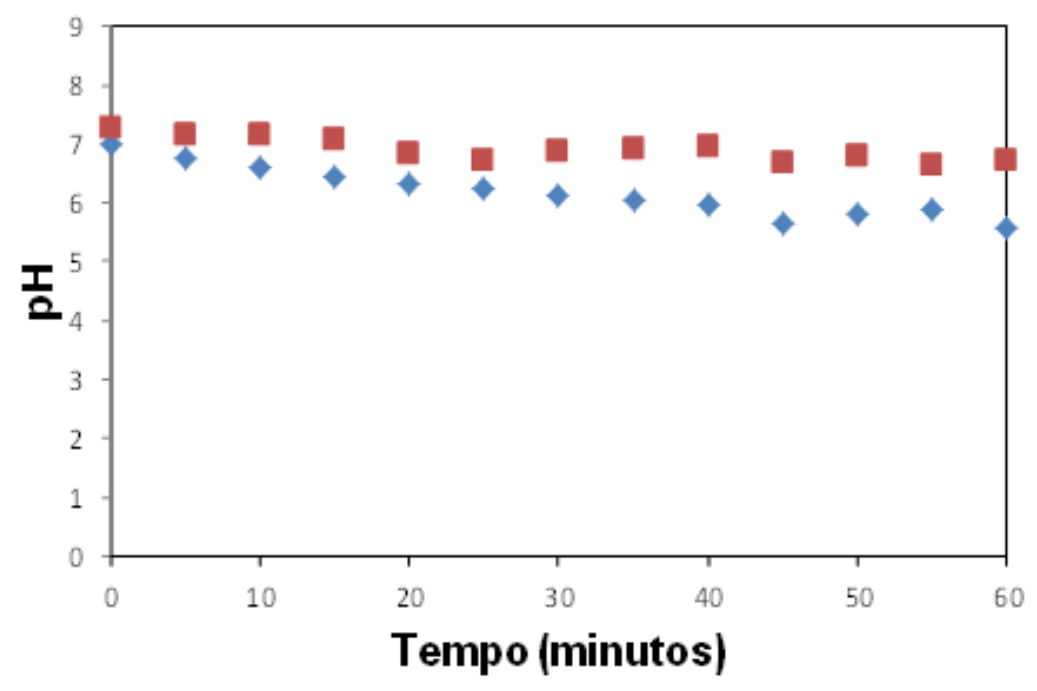

Figura 36 - Evolução do pH em função do tempo para experimentos de fotólise realizados com (^) pH livre e ( $\bullet) \mathrm{pH}$ controlado. Condições do experimento 1: $[\mathrm{SMX}]_{0}=28,6 \mathrm{mg} / \mathrm{L} \mathrm{e} \mathrm{pH}=7$.

Na Figura 37 a comparação entres os experimentos realizados com pH livre e $\mathrm{pH}$ controlado mostra uma diferença nos valores de $[\mathrm{SMX}] /[\mathrm{SMX}]_{0}$ no intervalo de tempo de 10 a 20 minutos; exatamente nesse intervalo a Figura 38 mostra importante diferença na evolução do $\mathrm{pH}$. Quando não controlado, o pH tende a diminuir com o tempo, o que provavelmente deve-se à formação de produtos de caráter ácido a partir da quebra do SMX. Nesse caso, como o meio foi se tornando ácido, houve alteração do SMX da forma aniônica para a forma neutra, menos 
estável e provavelmente mais suscetível à quebra por fotólise direta (BOREEN; ARNOLD; MC NEILL, 2004)

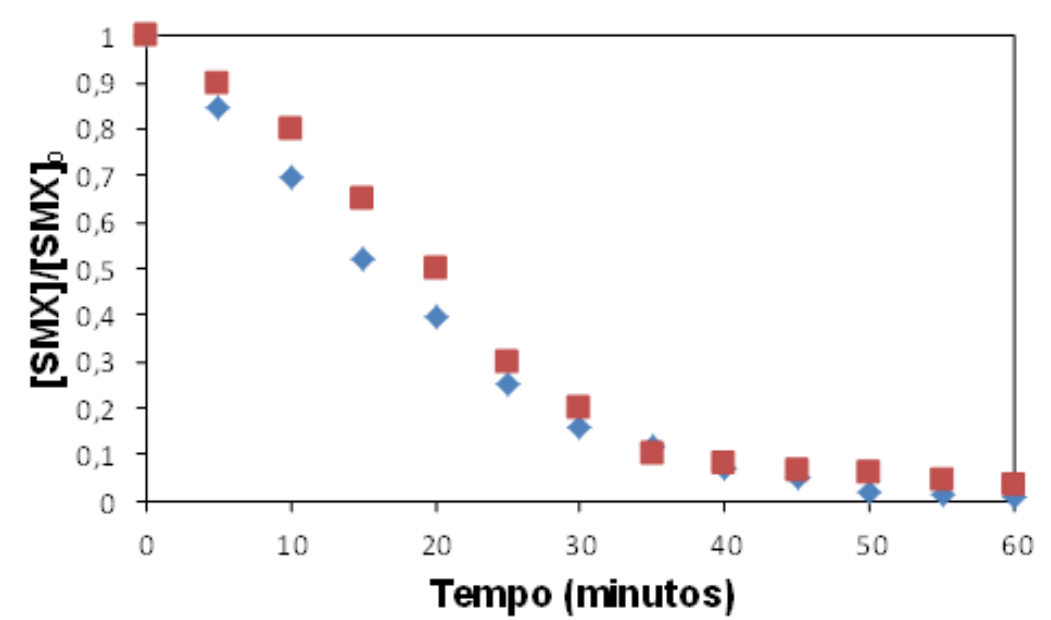

Figura 37 - Evolução de [SMX]/[SMX $]_{0}$ em função do tempo para experimentos de fotólise realizados com ( $\bullet) \mathrm{pH}$ livre e $(\varpi) \mathrm{pH}$ controlado. Condições do experimento $3:[S M X]_{0}=38,6 \mathrm{mg} / \mathrm{L}$ e $\mathrm{pH}_{0}=8,9$.

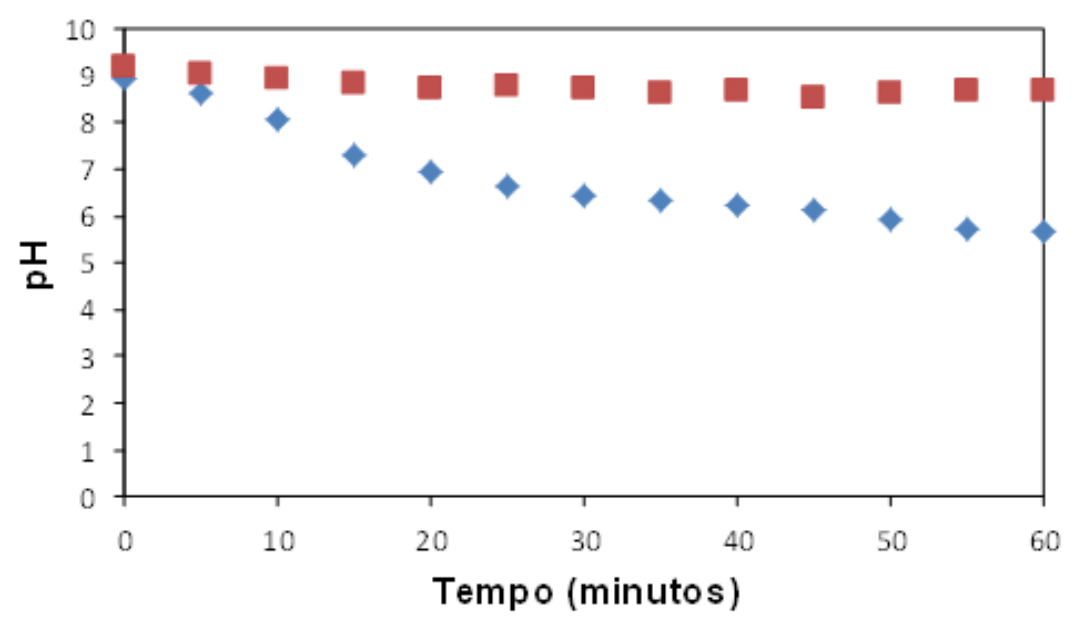

Figura 38 - Evolução do pH em função do tempo para experimentos de fotólise realizados com (४)pH livre e ( $₫) \mathrm{pH}$ controlado. Condições do experimento 3: $[\mathrm{SMX}]_{0}=38,6 \mathrm{mg} / \mathrm{L}$ e $\mathrm{pH}_{0}=8,9$.

No caso do experimento 7, percebe-se que, como o ensaio foi executado em meio ácido, houve variação do $\mathrm{pH}$ de 5 para 4 quando o $\mathrm{pH}$ foi ajustado inicialmente e deixado livre. Trata-se de uma ligeira alteração, assim como a mudança na degradação do SMX também foi ligeiramente diferente no intervalo entre 5 e 
20minutos, reforçando o argumento de que o SMX é degradado mais rapidamente em menores valores de $\mathrm{pH}$ (Figura 39).

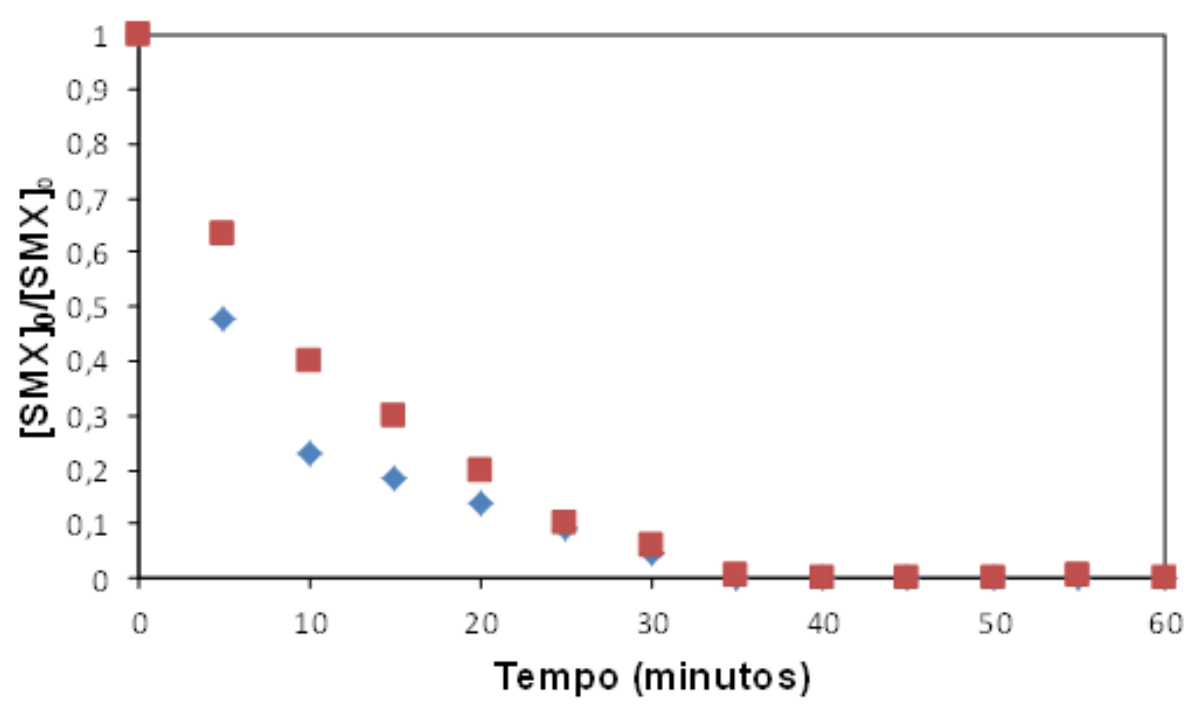

Figura 39 - Evolução de $[S M X] /[S M X]_{0}$ em função do tempo para experimentos de fotólise realizados com ( $\bullet$ pH livre e $(\varpi) p H$ controlado. Condições do experimento 7: [SMX $]_{0}=37,9 \mathrm{mg} / \mathrm{L} \mathrm{e}$ $\mathrm{pH}_{0}=4,7$.

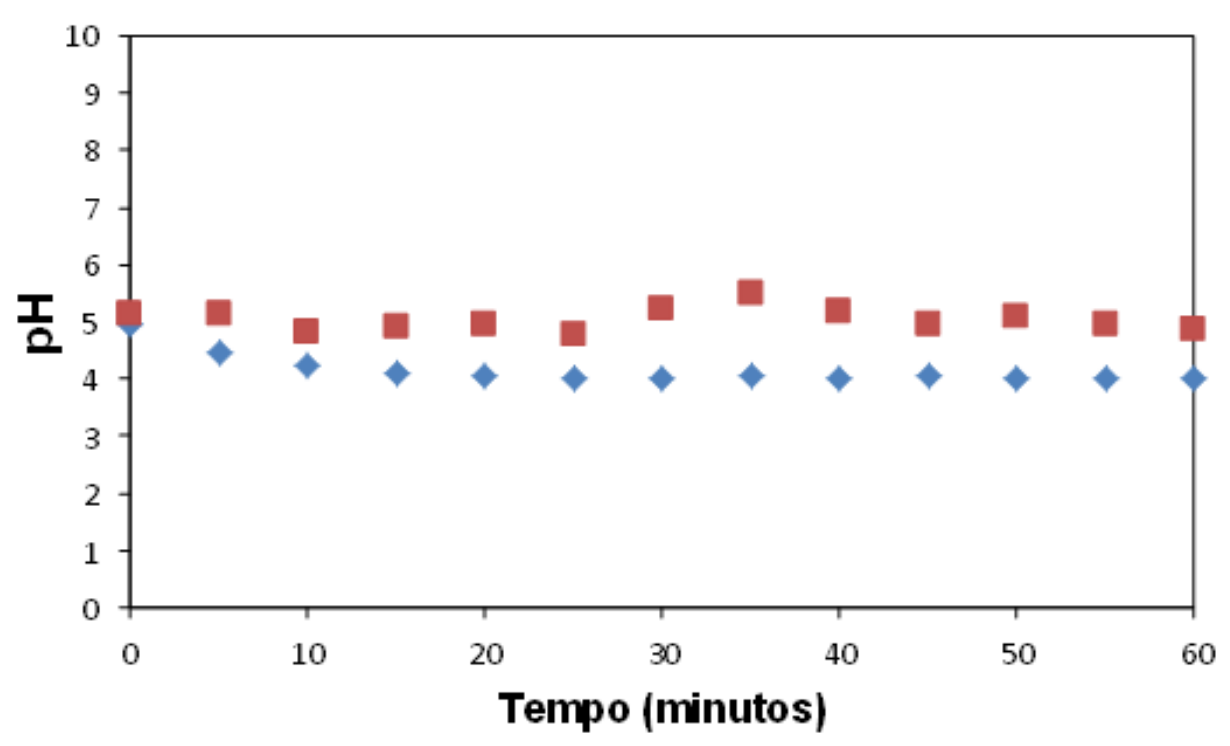

Figura 40 - Evolução do pH em função do tempo para experimentos de fotólise realizados com (४)pH livre e (₫)pH controlado. Condições do experimento 7: $[\mathrm{SMX}]_{0}=37,9 \mathrm{mg} / \mathrm{L}$ e $\mathrm{pH}_{0}=4,7$. 


\subsubsection{Experimentos em meio anóxico}

O efeito da presença de oxigênio dissolvido foi investigado comparando-se três condições: com o reator aberto à atmosfera, borbulhando-se argônio grau técnico na solução contida no tanque de mistura e borbulhando- $\mathrm{seO}_{2}$ na solução contida no tanque de mistura. A concentração de OD foi medida ao longo do tempo em todos esses experimentos.

Ao se borbulhar argônio durante o experimento, o meio se torna pobre em oxigênio, inibindo as reações dependentes de oxigênio, como as dadas pelas eq. (5) e (6) que, normalmente, ocorrem durante a fotólise direta.

$$
\begin{aligned}
& \mathrm{AB}^{\star}+\mathrm{O}_{2} \rightarrow \mathrm{AB}^{+\bullet}+\mathrm{O}_{2}^{-\bullet} \\
& \mathrm{AB}^{*}+{ }^{3} \mathrm{O}_{2} \rightarrow \mathrm{AB}+{ }^{1} \mathrm{O}_{2}
\end{aligned}
$$

A Figura 41 compara experimentos com concentrações inicias de SMX similares, sendo que em ambos os experimentos o pHfoi mantido controlado próximo de 7. Observa-se que as curvas de degradação do antibiótico possuem comportamento similar, o que permite deduzir que nessas condiçõesa fotólise do SMX não depende do oxigênio presente no meio. 


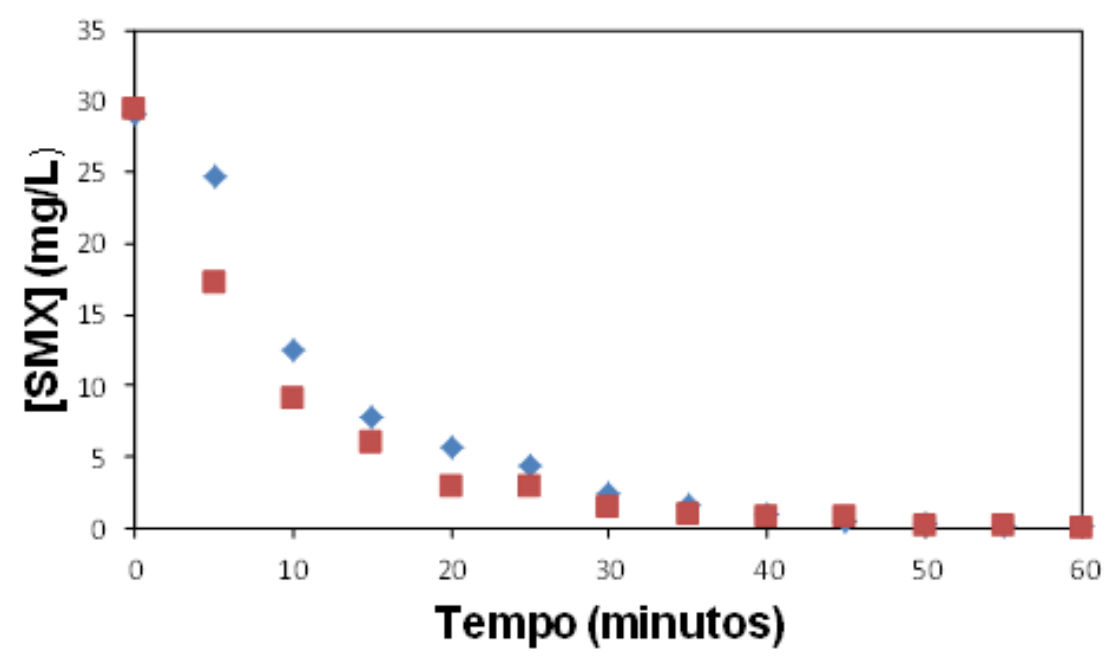

Figura 41 - Evolução de [SMX] em função do tempo para experimentos de fotólise realizados em ( $\downarrow$ ) sistema aberto à atmosfera e ( $\bullet$ condições anóxicas. Condições do experimento 1:

$[\mathrm{SMX}]_{0}=29,3 \mathrm{mg} / \mathrm{L}$ e $\mathrm{pH}_{0}=6,8$.

$\mathrm{Na}$ Figura 42a mesma comparação é feita para experimentos realizados nas condições do experimento 3. Também não houve alteração significativa na evolução da concentração de SMX ao longo do tempo para os diferentes meios utilizados. Zhou e Moore (1997) utilizaram $\mathrm{NaN}_{2}$ como sequestrador de oxigênio singlete e concluíram que a falta deste também não altera a taxa de fotodegradação do sulfametoxazol.

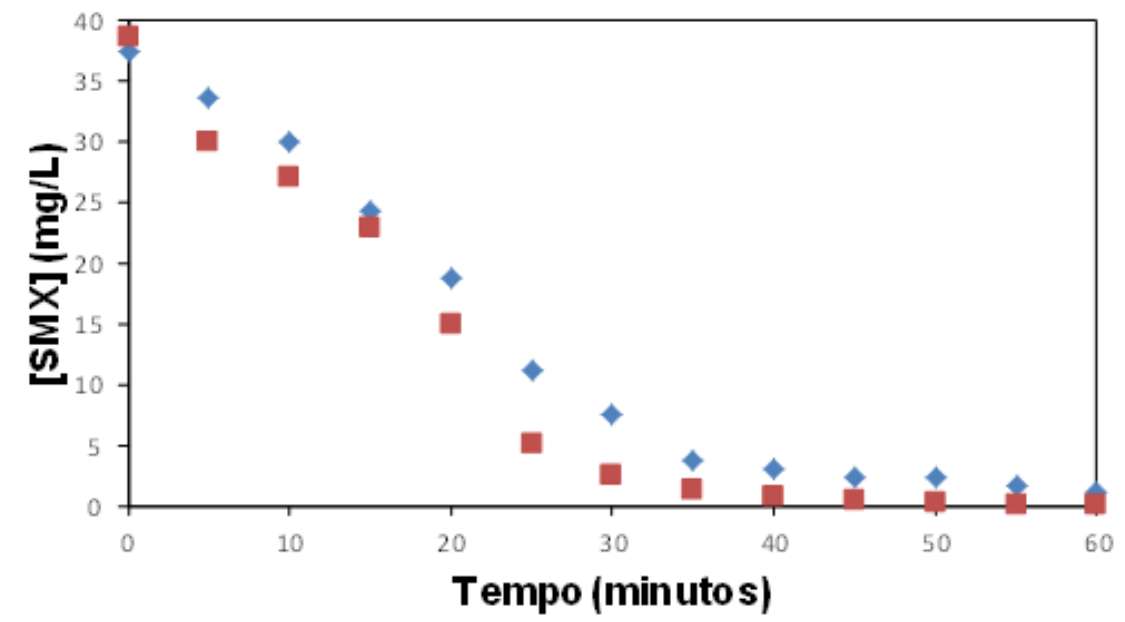

Figura 42 - Evolução de [SMX] em função do tempo para experimentos de fotólise realizados em ( $\downarrow$ ) sistema aberto à atmosfera e ( $\square)$ condições anóxicas. Condições do experimento 3:

$[S M X]_{0}=37,9 \mathrm{mg} / \mathrm{L}$ e $\mathrm{pH}_{0}=8,6$. 
$\mathrm{Na}$ Figura 43 comparam-se três condições de experimento, com o reator aberto à atmosfera e borbulhando-se argônio grau técnico ou $\mathrm{O}_{2}$ na solução contida no tanque de mistura. O comportamento é o mesmo observado nas Figuras 41 e 42. Para confirmar que $0 \mathrm{O}_{2}$ não promove a reação fotodegradação do antibiótico, realizou-se um experimento saturando a solução com oxigênio. A evolução das concentrações de SMX nesses três experimentos foi parecida, permitindo concluir que a principal rota de degradação do antibiótico ocorre a partir da fotólise do SMX, sem participação do oxigênio dissolvido.

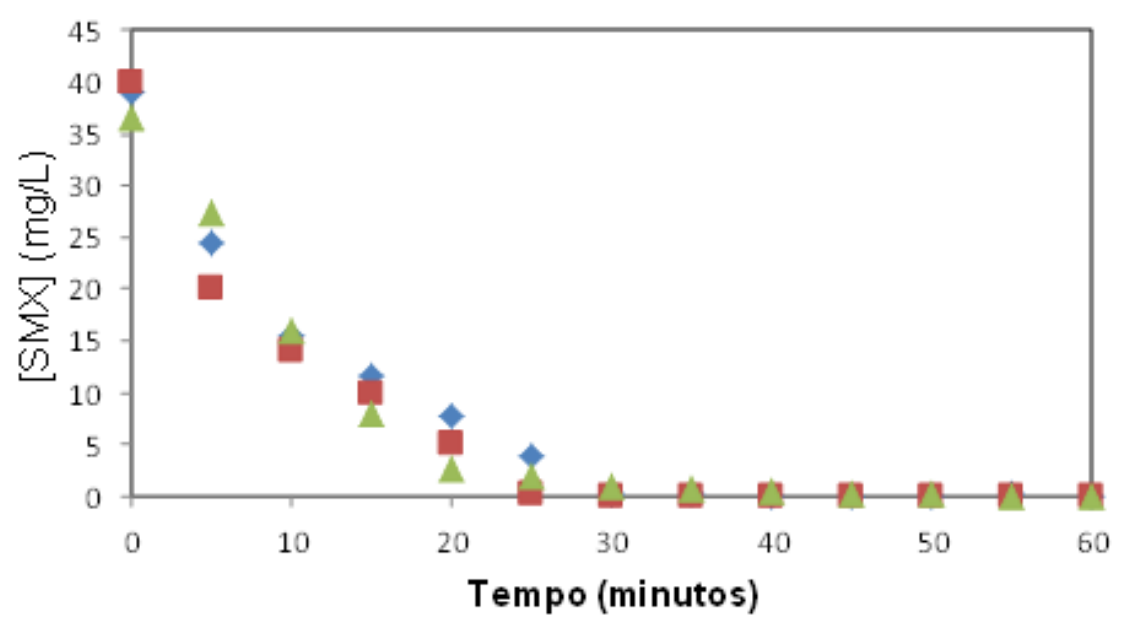

Figura 43 - Evolução de [SMX] em função do tempo para experimentos de fotólise realizados em ( sistema aberto à atmosfera; $(\boldsymbol{\square})$ condições anóxicas; e $(\Delta)$ meio saturado $c o m \mathrm{O}_{2}$. Condições do experimento 7: $[\mathrm{SMX}]_{0}=38,6 \mathrm{mg} / \mathrm{L}$ e $\mathrm{pH}_{0}=4,9$.

\subsubsection{Experimento com intervalos de irradiação/não-irradiação alternados}

Em buscar de entender melhor as reações que ocorrem na fotólise do SMX em solução aquosa, realizou-se um experimento ligando-se e desligando-se a lâmpada do reator. $O$ ensaio durou 60 minutos, sendo que nos primeiros 5 minutos a lâmpada ficou acesa e foram retiradas amostras de 1 em 1 minuto; após a coleta da amostra em 5 minutos, desligou-se a lâmpada e as amostras foram retiradas de 5 em 5 minutos e assim por diante, até o final do experimento. A Tabela 9 apresenta os valores de concentração de SMX ao longo do tempo e os intervalos de tempo que a lâmpada permaneceu ligada ou desligada. 
Tabela 9 - Experimento com intervalos de irradiação/não-irradiação alternados ("liga-desliga").

\begin{tabular}{ccc}
\hline Tempo (minutos) & [SMX] $(\mathrm{mg} / \mathrm{L})$ & Condição da lâmpada \\
\hline 0 & 36,9 & Ligada \\
1 & 34,2 & Ligada \\
2 & 30,1 & Ligada \\
3 & 26,4 & Ligada \\
4 & 23,2 & Ligada \\
5 & 19,9 & Apaga-se a lâmpada \\
10 & 18,8 & Liga-se a lâmpada \\
15 & 16,4 & Ligada \\
20 & 13,8 & Apaga-se a lâmpada \\
25 & 13,6 & Desligada \\
30 & 12,9 & Liga-se a lâmpada \\
35 & 6,0 & Ligada \\
40 & 2,0 & Apaga-se a lâmpada \\
45 & 2,0 & Desligada \\
50 & 2,0 & Liga-se a lâmpada \\
55 & 0,2 & Ligada \\
60 & 0,1 & Ligada \\
\hline
\end{tabular}

A Figura 44 apresenta a evolução da concentração de SMX durante o experimento, é visível a formação de patamares nos períodos em que não há emissão de radiação UVC pela lâmpada. Como os valores de concentração do antibiótico são similares quando não há fotólise, pode-se supor que a degradação do SMX está diretamente ligada à absorção da radiação emitida pela lâmpada, sem interferência da concentração de oxigênio dissolvido, como também discutido anteriormente. 


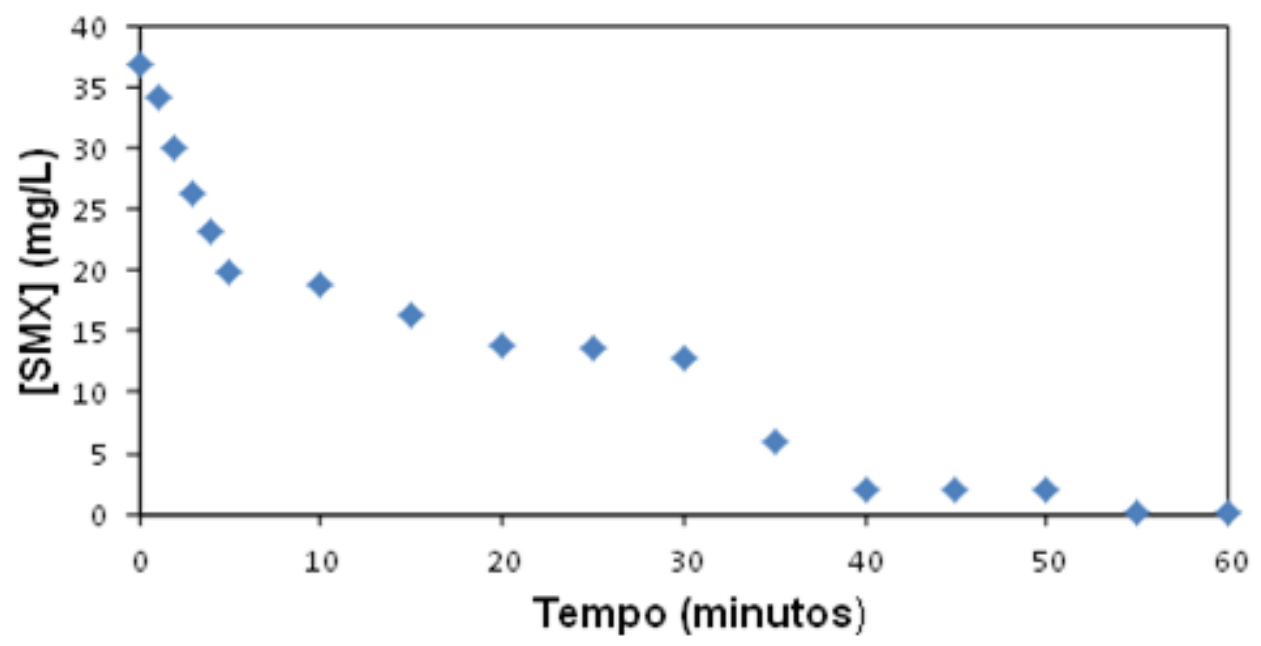

Figura 44 - Evolução de [SMX] em função do tempo para o experimento realizado com intervalos de irradiação/não-irradiação alternados ("liga-desliga"). Condições do experimento 7: $[\mathrm{SMX}]_{0}=38,5 \mathrm{mg} / \mathrm{L}$ e $\mathrm{pH}_{0}=4,9$.

\subsection{PRODUTOS FORMADOS NA FOTÓLISE DO SULFAMETOXAZOL}

Os produtos formados na fotólise são persistentes, o que está relacionado ao fato da concentração de carbono orgânico total (COT) manter-se praticamente estável após 60 minutos de tratamento. Nazuhoglu et al. (2011) realizaram um experimento de 6 horas, alcançando 24\% de remoção de COT, o que evidencia que os produtos formados a partir da fotólise do SMX são mais resistentes à fotólise.

A Figura 45 apresenta o cromatograma correspondente a um experimento de fotólise do SMX realizado com $[S M X]_{0}=14,1 \mathrm{mg} / \mathrm{L}$ e $\mathrm{pH}_{0} 4,9$. O pico com tempo de retenção de 16 minutos corresponde ao SMX, o qual é rapidamente degradado, formando picos à esquerda que representam os produtos de degradação. A Figura 46 mostra que após 40 minutos de irradiação observa-se redução da área dos picos distribuídos em torno do tempo de retenção de 3 minutos, o que indica degradação dos produtos formados na fotólise do antibiótico. 


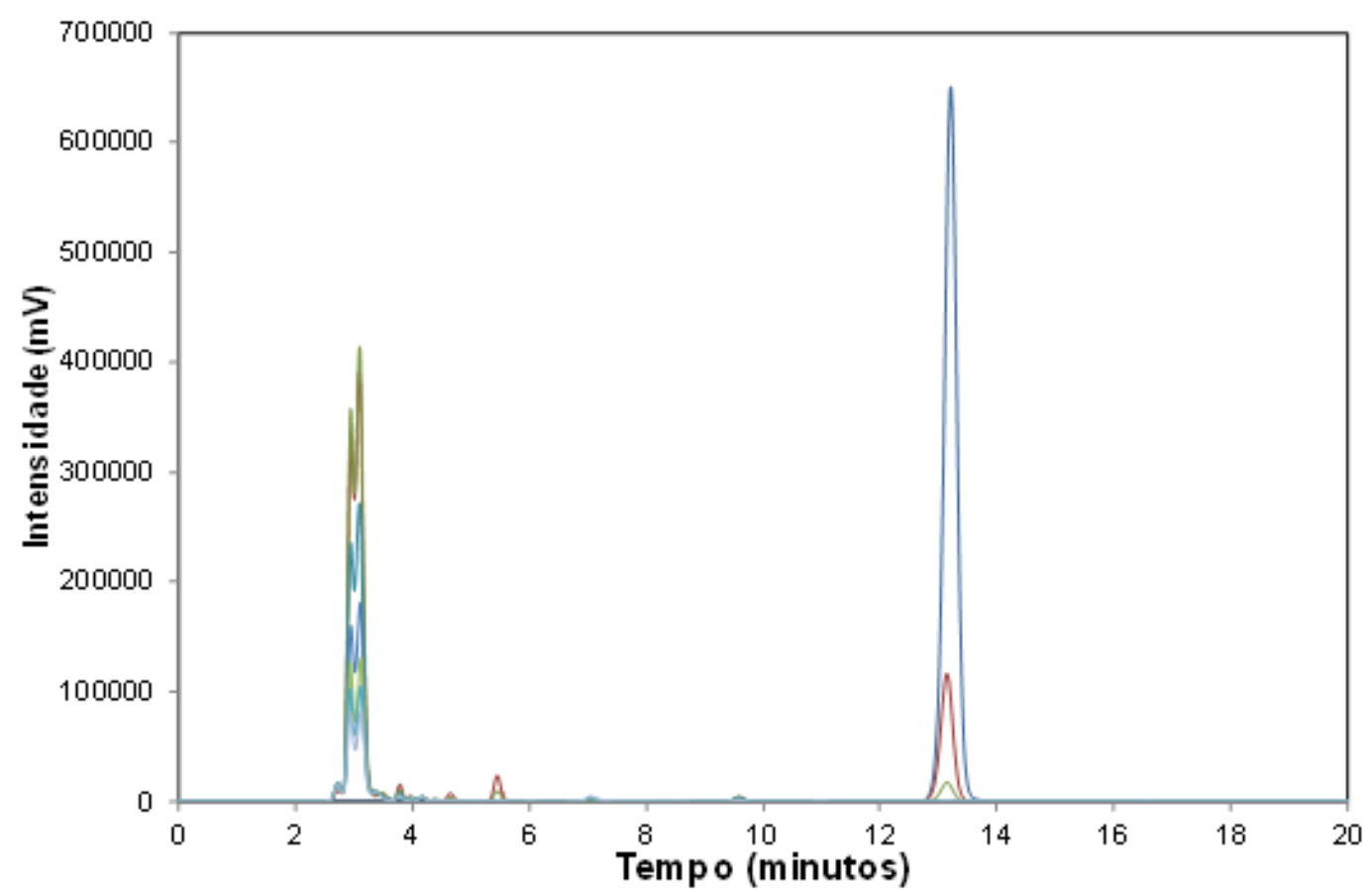

Figura 45 - Cromatogramas obtidos na fotólise do SMX. (-) 0 min; (-) $5 \mathrm{~min} ;(-) 10 \mathrm{~min} ;(-) 20 \mathrm{~min}$;

$(-) 30 \mathrm{~min} ;(-) 40 \mathrm{~min} ;(-) 50 \mathrm{~min}$; e $(-) 60 \mathrm{~min}$. Condições: $[\mathrm{SMX}]_{0}=14,1 \mathrm{mg} / \mathrm{L}$ e pH $\mathrm{H}_{0}=4,9$.

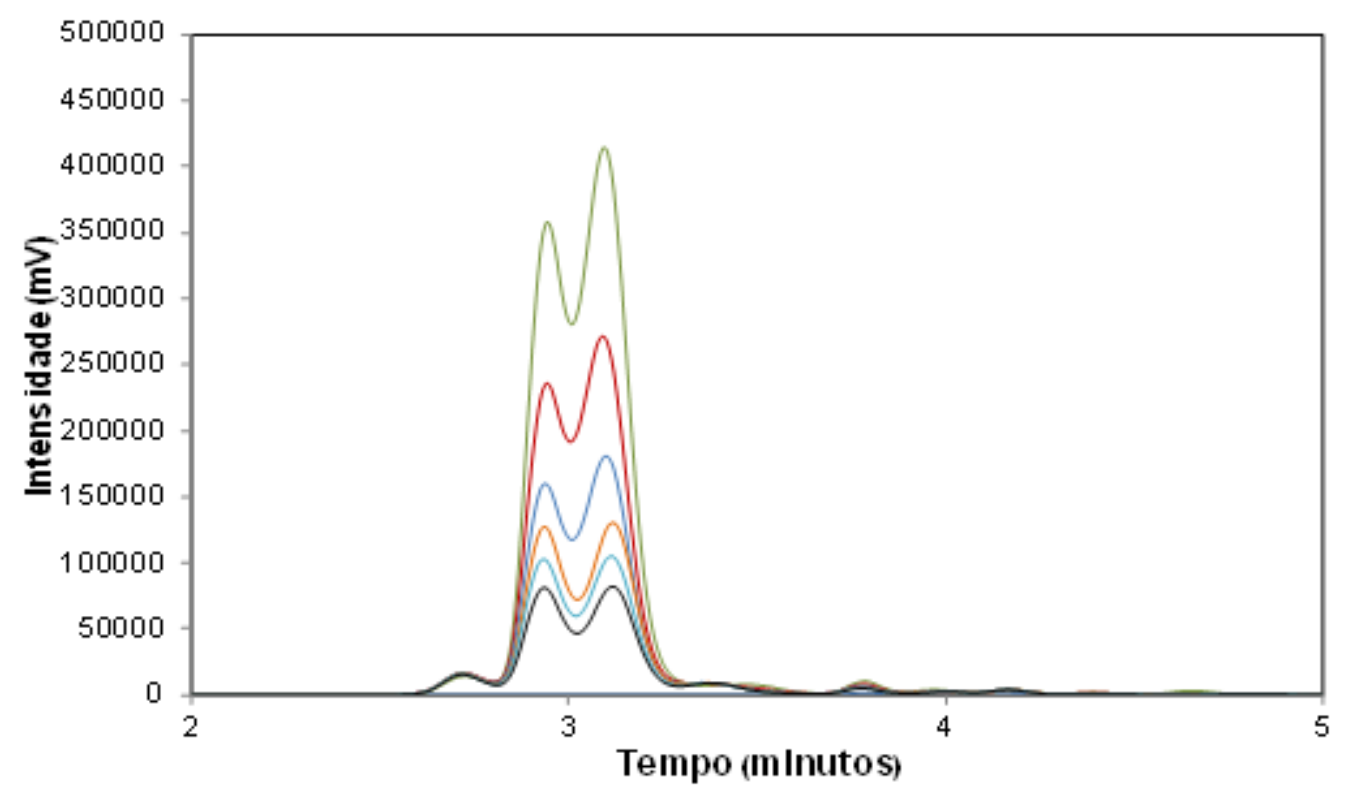

Figura 46 - Cromatogramas obtidos na fotólise do SMX. (-) $10 \mathrm{~min} ;(-) 20 \mathrm{~min} ;(-) 30 \mathrm{~min}$; (-) $40 \mathrm{~min} ;(-) 50 \mathrm{~min}$; e (一) 60min. Condições: $[\mathrm{SMX}]_{0}=14,1 \mathrm{mg} / \mathrm{L}$ e $\mathrm{pH}_{0}=4,9$.

Zhou e Moore (1994) identificaram dois dos cinco principais produtos formados, utilizando padrões e comparando o tempo de retenção; os produtos identificados foram o ácido sulfanílico e o 3-amino-5-metil-isoxazol. Dessa forma, o pico com menor tempo de retenção e maior intensidade foi identificado utilizando um padrão de ácido sulfanilíco. Ao se injetar esse padrão, o tempo de retenção foi o 
mesmo que o tempo de retenção do produto formado a partir da fotólise do SMX, como mostra a Figura 39.

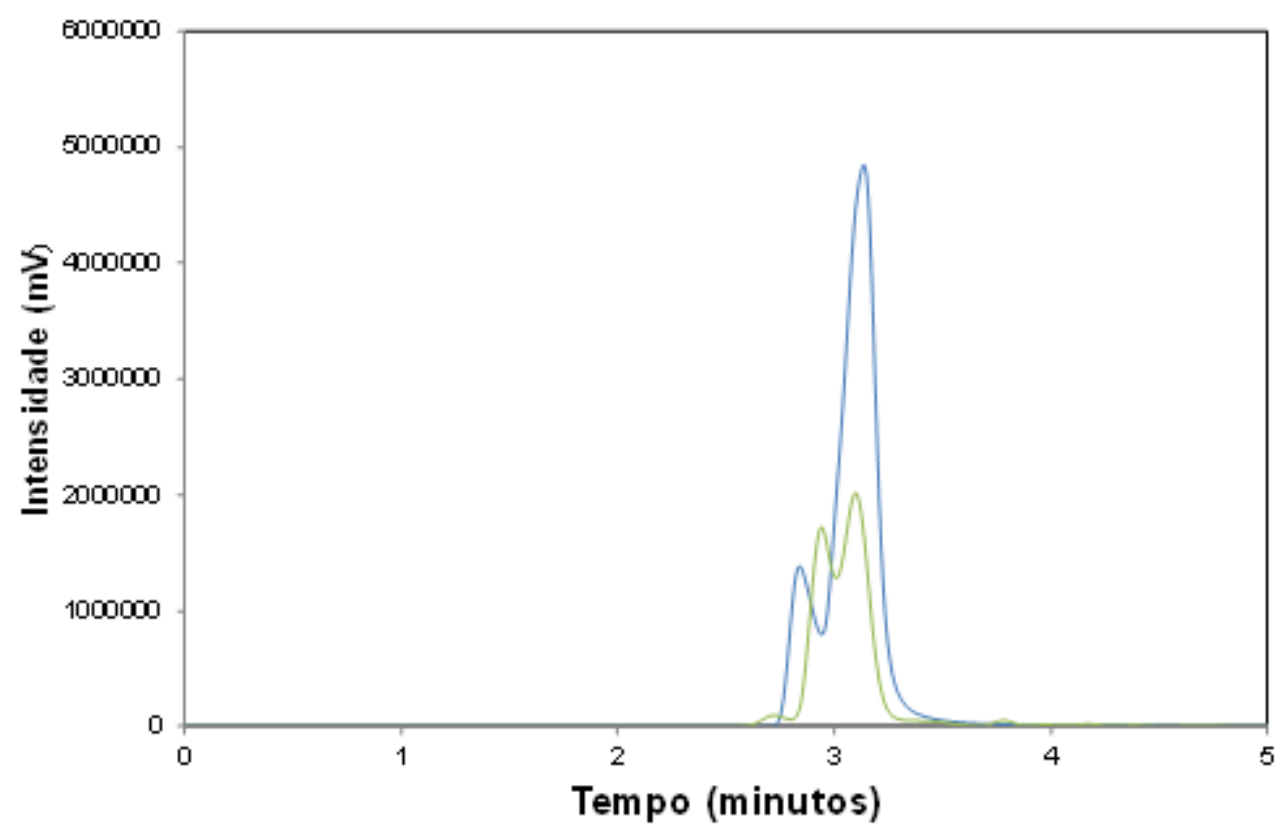

Figura 47 - Cromatogramas correspondentes ao $(-)$ produto de degradação do SMX e ao $(-)$ padrão ácido sulfanílico.

Estudos mostram que as sulfonamidas são transformadas na fotólise por quebra das ligações mostradas na Figura 48. Para o SMX, o principal caminho de degradação é a quebra da ligação $\delta$ (BOREEN; ARNOLD; MCNEILL, 2004).

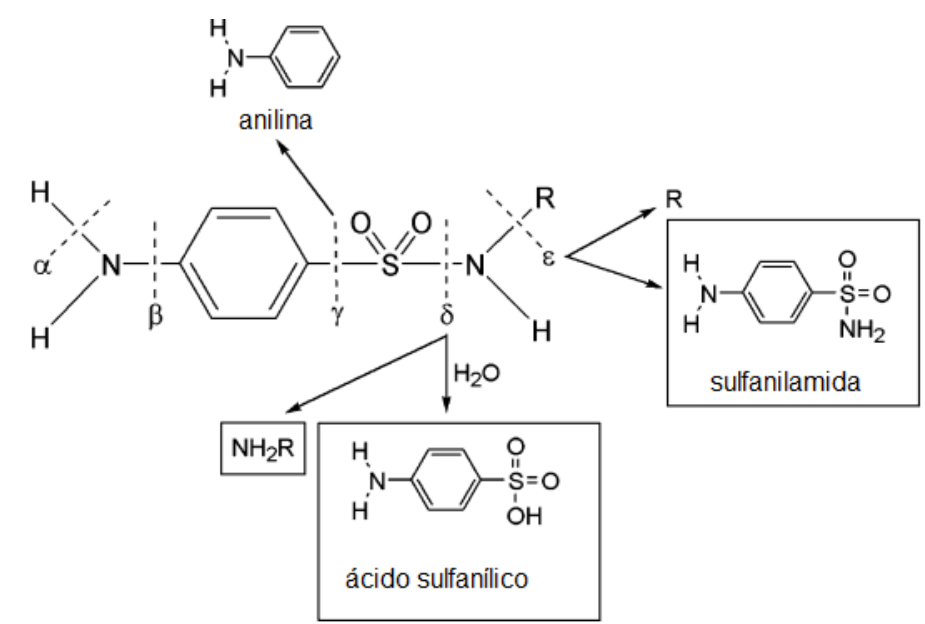

Figura 48 - Possíveis quebras de ligações devido à fotólise de sulfonamidas (BOREEN; ARNOLD; MCNEILL K., 2004). 


\subsection{ENSAIOS DE RESPIROMETRIA}

Os ensaios de respirometria foram realizados em triplicata. Avaliaram-se os experimentos em que se obtiveram maior e menor taxa de degradação nos 10 minutos iniciais (experimento 7 e 5 , respectivamente). Nesses experimentos, avaliou-se a inibição da atividade microbiana, através da medida do oxigênio utilizado para a degradação biológica de material orgânico presente em soluções aquosas de glicose-ácido glutâmico contendo soluções de SMX, antes e após tratamento por fotólise, ao longo de cinco dias de incubação a $20^{\circ} \mathrm{C}$. Essa medida foi expressa como demanda bioquímica de oxigênio média $\left(\mathrm{DBO}_{5}, \mathrm{mgO}_{2} / \mathrm{L}\right)$.

Os resultados da Figura 49 mostram que somente após o terceiro dia os microorganismos conseguiram metabolizar o carbono disponível no padrão contendo solução de SMX não irradiada, enquanto a degradação biológica do padrão e do padrão contendo solução de SMX irradiada foi possível desde o segundo dia. Ao final de cinco dias, o consumo de $\mathrm{O}_{2}$ pelos micro-organismos no padrão contendo solução tratada foi próximo ao observado para a solução padrão de glicose-ácido glutâmico; já o padrão contendo solução de SMX não irradiada apresentou menor consumo de $\mathrm{O}_{2}$. Dessa forma, esses resultados sugerem que a degradação do sulfametoxazol permite obter subprodutos mais favoráveis à oxidação biológica, apesar de não ocorrer remoção significativa de COT. 


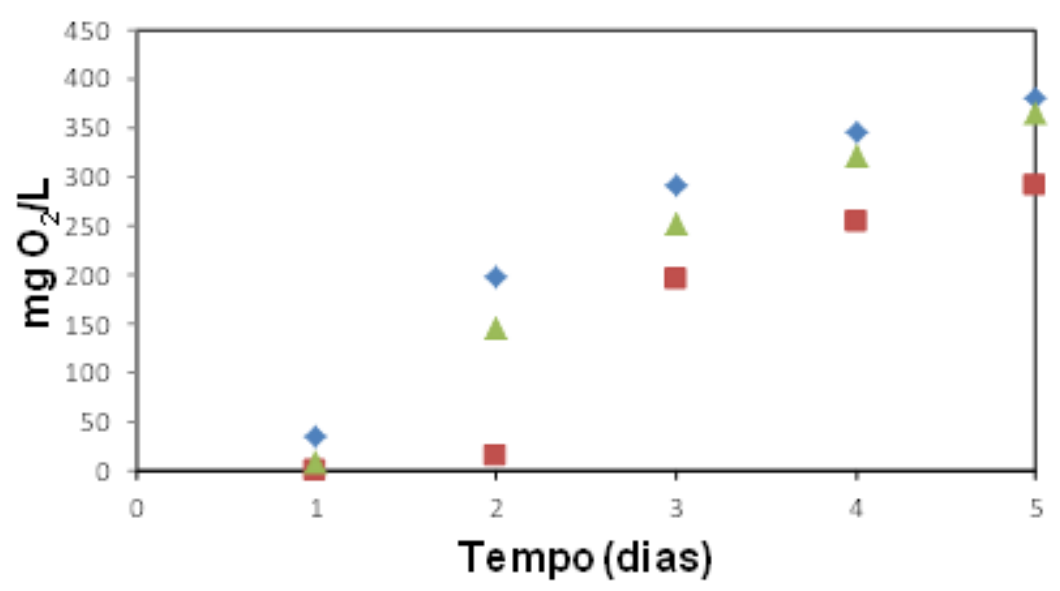

Figura 49 - Resultados dos ensaios respirométricos (médias de resultados em triplicata). (४) $\mathrm{DBO}_{\mathrm{P}}$ : demanda bioquímica de oxigênio da solução padrão glicose-ácido glutâmico;( $\Delta$ ) $\mathrm{DBO}_{\mathrm{T}}$ : demanda bioquímica de oxigênio dopadrão glicose-ácido glutâmico contendo solução de SMXapós

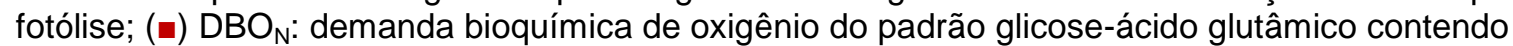
solução de SMX não irradiada. Condições do experimento 7: [SMX $]_{0}=39,6 \mathrm{mg} / \mathrm{L} ; \mathrm{pH}_{0}=5$.

A Figura 50 mostra que independente da concentração do antibiótico, somente após o terceiro dia os micro-organismos conseguiram metabolizar o carbono disponível no padrão contendo a solução de SMX não irradiada.

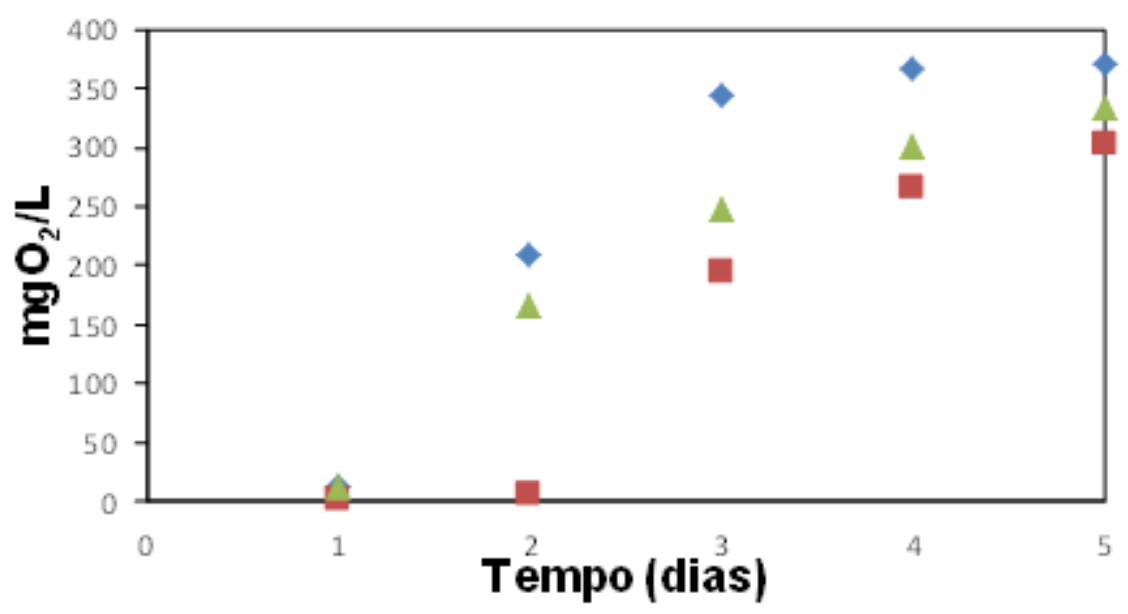

Figura 50 - Resultados dos ensaios respirométricos (médias de resultados em triplicata). (४) $\mathrm{DBO}_{\mathrm{P}}$ : demanda bioquímica de oxigênio da solução padrão glicose-ácido glutâmico;( $\Delta$ ) DBO : demanda bioquímica de oxigênio do padrão glicose-ácido glutâmico contendo solução de SMX após fotólise; ( $)^{2} \mathrm{DBO}_{\mathrm{N}}$ : demanda bioquímica de oxigênio do padrão glicose-ácido glutâmico contendo solução de SMX não irradiada. Condições do experimento 5: $[S M X]_{0}=8,6$ mg/L; $\mathrm{pH}_{0}=7$.

O cálculo da porcentagem de inibição (inb\%) se obtém ao longo dos cinco dias, relacionando o valor da $\mathrm{DBO}_{5}$ do padrão glicose-ácido glutâmico ( $\mathrm{DBO} P$ ), com 
a medida da $\mathrm{DBO}_{5}$ das amostras avaliadas que contêm o padrão glicose-ácido glutâmico mais soluções de $S M X$ irradiada e não irradiada $\left(\mathrm{DBO}_{\mathrm{T}}\right.$ ou $\mathrm{DBO}_{\mathrm{N}}$, respectivamente). Assim, pode-se calcular inibição microbiana em porcentagem utilizando a eq. (13) (Vicente et al., 2009).O valor experimental médio da demanda bioquímica de oxigênio do inóculo $\left(\mathrm{DBO}_{\mathrm{S}}\right)$, na ausência de substrato orgânico, foi de apenas $2 \mathrm{mg} \mathrm{O}_{2} / \mathrm{L}$.

$$
\begin{gathered}
\mathrm{inb} \%=\left(\frac{(\mathrm{DBO} p-\mathrm{DBOs})-(\mathrm{DBOt}-\mathrm{DBOs})}{(\mathrm{DBOp}-\mathrm{DBOs})}\right) \\
\times 100
\end{gathered}
$$

As Figuras 51 e 52 confirmam que a solução de SMX não irradiada inibiu a atividade microbiana frente ao padrão glicose-ácido glutâmico até o segundo dia de incubação e que as porcentagens de inibição associadas são superiores ao longo dos cinco dias quando comparadas às porcentagens de inibição obtidas no ensaio realizado com solução de SMX tratada por fotólise.

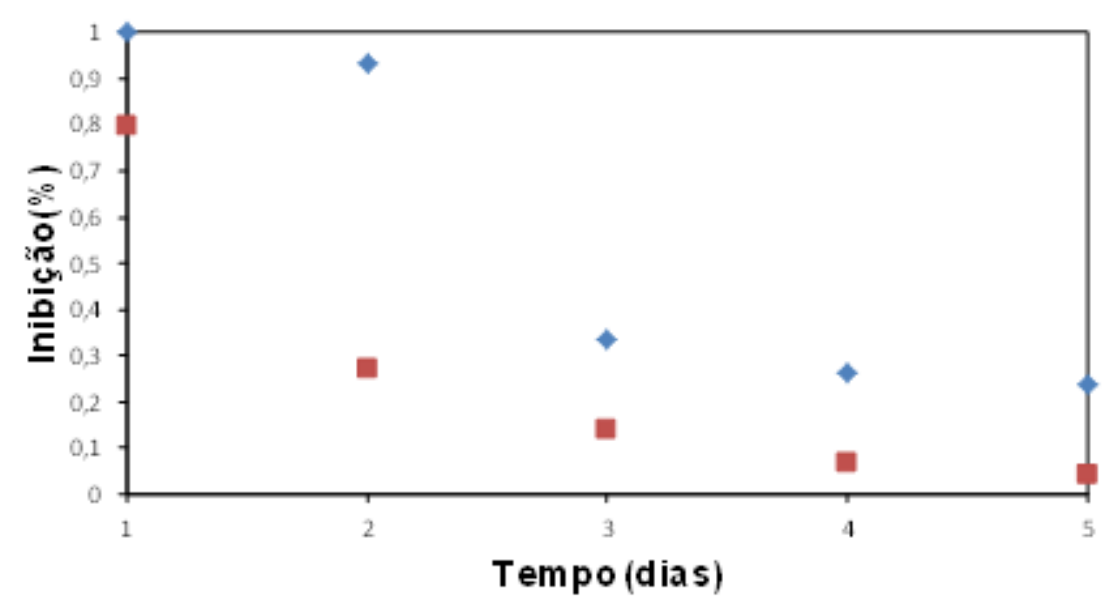

Figura 51 - Curvas de inibição da atividade microbiana frente ao padrão glicose-ácido glutâmico para

( $\bullet$ ) sistema contendo solução de SMX irradiada e ( $\downarrow$ ) sistema contendo solução de SMX não irradiada. Condições do experimento $7:[S M X]_{0}=38,7 \mathrm{mg} / \mathrm{L}$ e $\mathrm{pH}_{0}=7$. 


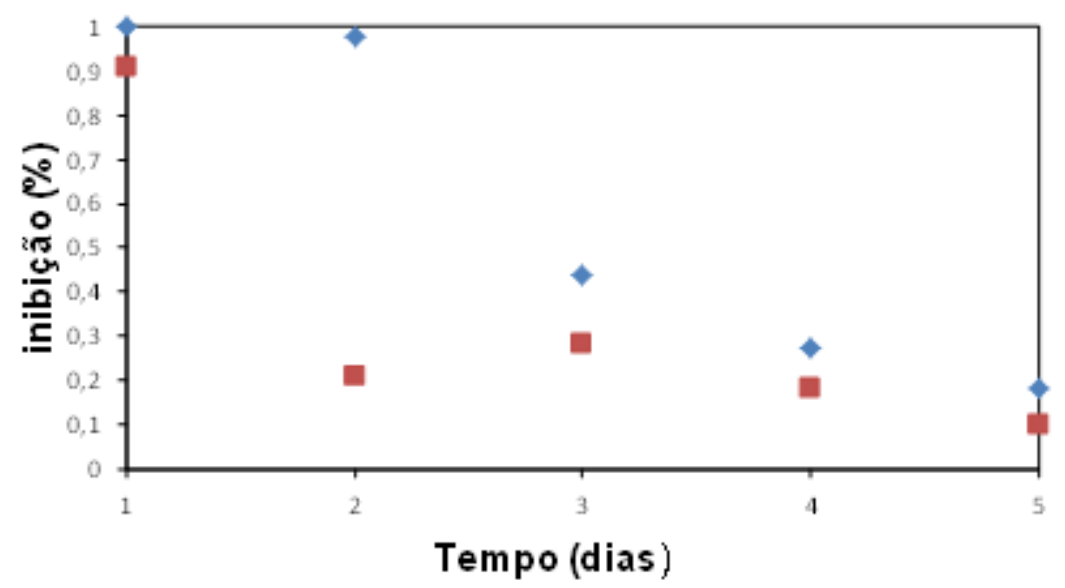

Figura 52 - Curvas de inibição da atividade microbiana frente ao padrão glicose-ácido glutâmico para (•) sistema contendo solução de SMX irradiada e (४) sistema contendo solução de SMX não irradiada. Condições do experimento5: $[\mathrm{SMX}]_{0}=8,5 \mathrm{mg} / \mathrm{L}$ e $\mathrm{pH}_{0}=5$.

Li e Zhang (2010) verificaram que a remoção de SMX por meio de adsorção em lodo ativado é desprezível, enquanto constataram degradação moderada do composto (máximo de $40 \%$ ) após 48 horas em sistemas biológicos, tanto em meio salino como não salino, embora segundo esses autores a degradação esperada em ETEs não seja maior que $20 \%$ devido aos tempos de retenção hidráulica envolvidos.

\subsection{ENSAIO DE TOXICIDADE}

Foram realizados ensaios de toxicidade aguda com a bactéria marinha Vibrio fischeri; os organismos-teste foram expostos, durante 15 minutos,àssoluções aquosas de SMX, antes e após tratamento por fotólise.

As análises de toxicidade foram baseadas no efeito gama $(\Gamma)$, razão entre 0 decréscimo na quantidade de luz emitida pelo organismo teste, após sua exposição a um agente tóxico durante um determinado período $\left(\mathrm{I}_{\mathrm{t}}\right)$ e a quantidade de luz emitida pelo organismo antes da sua exposição $\left(\mathrm{I}_{0}\right)$.

Os resultados da Figura 53 mostram que após o tratamento a solução irradiada causou um decréscimo maior na quantidade de luz emitida pela bactéria Vibrio fischeri em relação à observada no caso do teste realizado com a solução não irradiada. Dessa forma, esses resultados sugerem que a degradação do sulfametoxazol produz subprodutos mais tóxicos à bactéria marinha. Trovó et al. 
(2009) realizaram ensaios similares e também observaram o aumento da toxicidade para as soluções de SMX irradiadas com UVC para o organismo-teste.

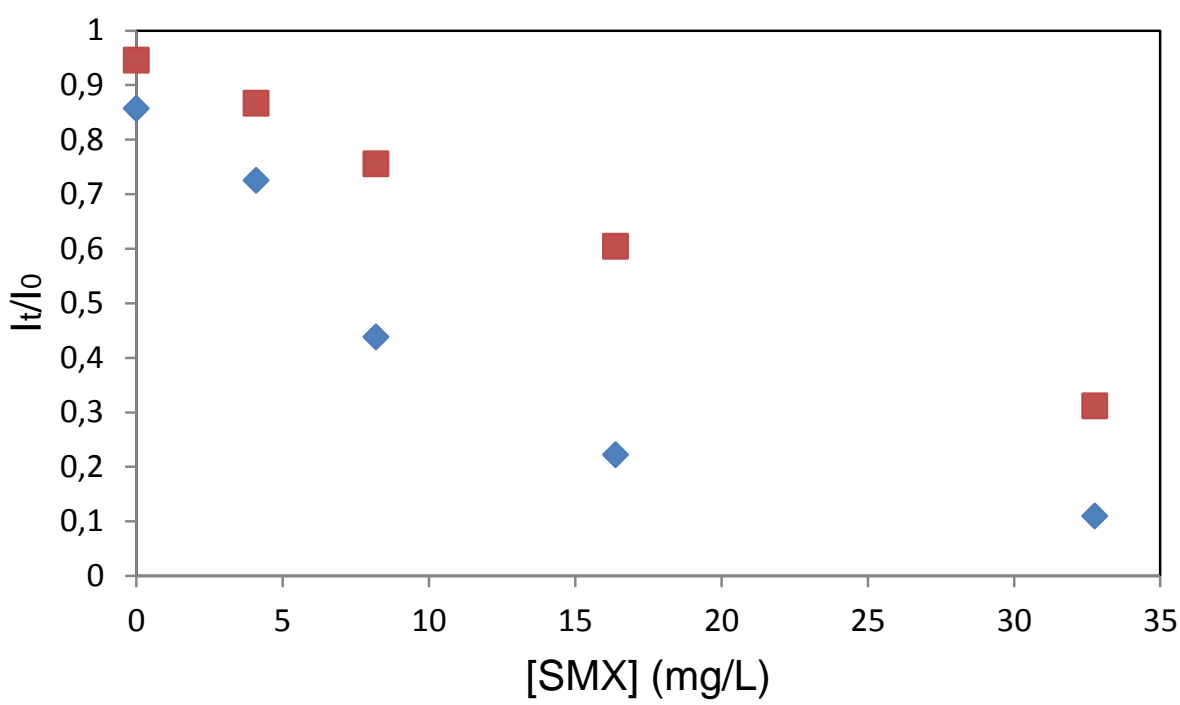

Figura 53 - Efeito gama $\left(\mathrm{I}_{0} / \mathrm{I}_{\mathrm{t}}\right)$.(๓) Solução de SMX irradiada; (४) Solução de SMX não irradiada. Condições do experimento $7:[S M X]_{0}=38,6 \mathrm{mg} / \mathrm{L}$ e $\mathrm{pH}=7$. 


\section{CONCLUSÕES E SUGESTÕES}

O presente trabalho mostra a viabilidade da aplicação da fotólise direta para o tratamento de soluções aquosas contaminadas com o antibiótico sulfametoxazol (SMX), no domínio das condições experimentais estudadas. O planejamento experimental Doehlert permitiu avaliar as diferentes condições experimentais, em termos da concentração inicial de SMX e do pH inicial, para degradar este poluente.

O antibiótico sulfametoxazol apresenta como característica importante máxima absorção UVC entre 250 e 270 nm, variando de acordo como pH. Apresenta também estabilidade química em meios ácido, neutro e básico, observada nos ensaios de hidrólise de 24 horas.

Os resultados apresentados, com altas remoções (maiores que 99\%) em curtos intervalos de tempo (30 minutos), indicam que a degradação do SMX via fotólise direta ocorre rapidamente. Em todos os experimentos obtiveram-se remoções de $99 \%$ de SMX ao final de 60 minutos de irradiação, porém sem mineralização total do composto em nenhum $\mathrm{pH}$ estudado, com formação de subprodutos persistentes. Apesar de não ocorrer mineralização do composto, os ensaios respirométricos, mostram que após dois dias de incubação os microorganismos de um consórcio bacteriano metabolizaram o carbono disponível na solução irradiada de SMX, com resultados superiores de oxigênio consumido quando comparados aos obtidos para o ensaio realizado com a solução de SMX não irradiada. Esta apresentou forte capacidade de inibição do metabolismo microbiano até o segundo dia e porcentagens de inibição ao longo de cindo dias de incubação superiores às observadas no caso da solução irradiada. Em outras palavras, apesar de não ocorrer remoção de COT, a solução obtida após tratamento por fotólisep ode ser pós-tratada por meio de processos biológicos, podendo reduzir os custos relacionados à energia e material em escala comercial. Porém para o microorganismo Vibrio fischeri os produtos formados foram mais tóxicos, logo outros bioensaios com diferentes organismos-teste são necessários para se ter uma avaliação melhor da toxicidade, tanto do antibiótico sulfametoxazol, quanto dos produtos formados. 
Tanto a variável quantidade inicial de SMX como a variável pH apresentaram efeitos estatisticamente significativos quanto ao tempo necessário para remoção de $50 \%$ da quantidade inicial de SMX e da taxa inicial de degradação do antibiótico, sendo o efeito do $\mathrm{pH}$ sobre estas respostas mais evidente para a maior quantidade inicial de SMX; o tempo necessário para remoção de SMX em meio ácido foi menor, porque apesar do menor valor do coeficiente de absorção molar em 254 nm, o rendimento quântico é maior em $\mathrm{pH}$ baixo.

Os experimentos em meio anóxico sugeriram que a fotólise do SMX ocorre independentemente se o meio possui altas ou baixas concentração de $\mathrm{O}_{2}$ dissolvido, levando a supor que a degradação do antibiótico está unicamente ligada à absorção da radiação UVC emitida pela lâmpada. 


\section{REFERÊNCIAS BIBLIOGRÁFICAS}

ALMEIDA, A. G; WEBER, R. R. Fármacos na Represa Billings, Universidade de São Paulo - Instituto Oceonográfico, 2005.

ALMEIDAI, E.; ASSALINI, M. R.; ROSAI, M. A.; DURÁN, N. Tratamento de efluentes industriais por processos oxidativos na presença de ozônio. Química Nova, v. 27, n.5, 2004.

ANIPSITAKIS, G.P. Chemical and microbial decontamination of pool water using activated potassium peroxymonosulfate. Water Research, v. 42, n. 12, p.160-188, 2008.

ANIPSITAKIS, G.P. Cobalt/Peroxymonosulfate and Related Oxidizing reagents for Water Treatment. 2005. 219p., Tese (doutorado)-Department of Civil and Environmental Engineering, University of Cincinnati, Cincinnati, 2005.

ANISPITAKIS, G.P.; DIONYSIOU, D. D. Transition metal/UV-based advanced oxidation technologies for water decontamination. Applied Catalysis B: Environmental, v. 54, n. 3, p.155-163, 2004.

ANTONIOU, M. G.; CRUZ, A. A.; DIONYSIOU, D. D. Degradation of microcystin-LR using sulfate radicals generated through photolysis, thermolysis and e-transfer mechanisms. Applied Catalysis B: Environmental, v. 96, p. 290-298, 2010.

AQUINO, S.F.; CHERNICHARO, C. A. L.; FORESTI, E.; SANTOS M. L.F. S. Metodologia para determinação da atividade metanogênica específica (AME) em Logos anaeróbios. Engenharia Sanitária e Ambiental, v. 2, n. 2, p. 192-201, 2007.

ANVISA Disponível em <anvisa.gov.br> acesso em>6 dez. 2011

AVISAR D,; LESTER, Y.; RONEN D. Sulfamethoxazole contamination of a deep phreatic aquifer.Science of theTotal Environment,v. 407, n.14, p.4278-4282, 2009.

ABREU, L. F.; FARIA, J. A. F. Evaluation of a system for chemical sterilization of packages.Packaging Technology and Science, v.17, p.37-42, 2004 
AGUIAR, A.M.S. Avaliação do emprego da radiação ultravioleta na descontaminação de águas com turbidez e cor moderadas. 2000. 111p. Dissertação (mestrado) Saneamento, Meio ambiente e Recurso Hídricos - Escola de Engenharia da Universidade Federal de Minas Gerais, Belo Horizonte, 2000

BAEZAA C; KNAPPEB D. R. U.Transformation kinetics of biochemically active compounds in low-pressure UV Photolysis and $\mathrm{UV} / \mathrm{H}_{2} \mathrm{O}_{2}$ advanced oxidationprocesses. Water Research, v.45, p.4531-4543, 2011.

BALL, D.W. The electromagnetic spectrum: a history. Spectroscopy, v.3, n.22, p.1417, 2007.

BELLONA, C.; DREWES, J. E.; XU, P.; AMY, G. Factors affecting the rejection of organic solutes during NF/RO treatment - a literature review. Water Research, v. 38, n.12, p.2795-2809, 2004.

BILA, D. M.; DEZOTTI, M.. Fármacos no meio ambiente. Química Nova, v.26, n.4,p 523-530, 2003.

BINTSIS, T.; LITOPOULOU-TZANETAKI, E.; ROBINSON, R. Existing and potential applications of ultraviolet light in the food industry - a critical review. Journal of the Science of Food and Agriculture, v.80, n. 6, p.637-645, 2000.

BOREEN, A. L.; ARNOLD, W.; MC NEIL, K. Photochemical fate of sulfa drugs in the aquatic environment: sulfa drugs containing five-membered heterocyclic groups. Environmental Science \& Technology, v.38, p.3933-3940, 2004.

BRAUN, A. M.; MAURETTE, M. T.; OLIVEROS, E. Photochemical Technology. Chischester, ed. John Wiley, 1991.

BRENNER, C.G.B. Antimicrobiais sulfametoxazol e trimetoprima em efluente hospitalar: determinação, degradação através de eletrocoagulação e identificação de subprodutos e metabólicos. 2009. 93p., Dissertação (mestrado) Centro de Ciências naturais e exatas, Universidade Federal de Santa Maria, Santa Maria, 2009.

CARBALLA, M.; OMIL, F.; LEMA, J. M. Removal of cosmetic ingredients and pharmaceuticals in sewage primary treatment. Water Research, v.39, n.19, p. 47904796, 2005. 
CALIARI, P.C; MACHADO, A.M.; SALARO, A.L.; GONÇALVES, R.F.; JUNGER, D.L.; GATTI, G.M.; NATI, T. A Radiação UV como auxiliar no tratamento de efluente de psicultura. In: $2^{\circ}$ Encontro Nacional de Tecnologia Química, Bahia, 2009.

CARDEÑA, U. M. J. Tratamento de efluentes aquosos contendo clorofenóis por meio de processo oxidativo avançado foto-Fenton. 2009 125p. Dissertação (mestrado) - Engenharia - Escola Politécnica da Universidade de São Paulo, São Paulo, 2009.

CARDOSO, C. F. Avaliação da esterilização de filme de polietileno com peróxido de hidrogênio e radiação ultravioleta. 2007. 58p. Dissertação (mestrado) - Tecnologia de Alimentos-Universidade Estadual de Campinas, Campinas, 2007.

CHIEN, Y.H.; LAI, H.T.; LIU, S.M.Modeling the effects of sodium chloride on degradation of chloramphenicol in aquaculture pond sediment. .Science of theTotal Environment, v.239, p.81-87, 1999.

CLARA, M.; KREUZINGER, N.; STERNN, B.; GANSB, O.; KROISSA, H. The solids retention time - a suitable design parameter to evaluate the capacity of wastewater treatment plants

to remove micropolluants. Water Research, v.39, n. 1, p.97-106, 2005.

CRESTANA, G. B.; SILVA, J. H. Fármacos residuais: panorama de um cenário negligenciado. Revista Internacional de Direito e Cidadania, n. 9, p.55-65, 2011.

CRISTINO, W. Tratamento de efluentes têxtil contendo corante reativo violeta 5: comparação entre os processos oxidativos avançados irradiados e não irradiados. 2006. 136p. Dissertação (mestrado) - Engenharia de Processos Químicos - Escola de Engenharia Mauá do Centro Universitário do Instituo Mauá de Tecnologia, São Caetano do Sul, 2006.

CRUZ, L. H.; HENNING, F. G.; SANTOS, A. B.; PERALTA-ZAMORA, P. Degradação fotocatalítica de sulfametoxazol, trimetoprima e diclofenaco em solução aquosa. Química Nova, v. 33, n.6, 2010.

COMPANHIA DE TECNOLOGIA DE SANEAMENTO AMBIENTAL L.5.227: Teste de toxicidade com a bactéria luminescente Vibrio fischeri(Método de Ensaio). São Paulo, 2001.11p. 
DRILLIA, P.; DOKIANAKIS, S. N.; FOUNTOULAKIS, M. S.;et al., On the occasional biodegradation of pharmaceuticals in the activated sludge process: the example of the antibiotic sulfamethoxazole. Journal of Hazardous Materials, v. 122, n.3, p. 259-26, 2005.

FENT, K.; WESTON, A.A.; CAMINADA, D.Ecotoxicologyofhumanpharmaceuticals. Aquatic Toxicology, v.76, p.122-159, 2006.

FERREIRA, I.V.L. Fotocatálise heterogênea com $\mathrm{TiO}_{2}$ aplicada ao tratamento de esgoto sanitário secundário. 2005. 187p. Tese (doutorado). Escola de Engenharia de São Carlos, Universidade de São Paulo, São Paulo, 2005.

FERREIRA, S. L. C.; SANTOS W. N. L.; QUINTELLA C. M.; NETO B. N.; BOSQUESENDRA J.Doehlertmatrix: a chemometric tool for analyticalchemistry - review. Talanta, v.63, p.1061-1067, 2004.

GENNADIOS, A.; RHIM, J. W.; HANDA, A.; WELLER, C. L.; HANNA, M. A. Ultraviolet radiations Effects physical and molecular properties of soy protein films. Journal of Food Science, v.63, n.2, p.1-4, 1998.

GOleT, E. M.; ALDER, A. C.; HARTMANN, A.; TERNES, T. A.; GIGER W. Trace determination of fluoroquinolone antibacterial agents in solid-phase extraction urban wastewater byliquid chromatography with fluorescence detection. Analytical Chemistry, v. 73, n. 15,p. 3632-363, 2002.

GÓMEZ-RAMOS, M. M.; MEZCUA, M.; AGUERA, A.; FERNÁNDEZ-ALBA, A. R.; GONZALO, S.; RODRIGUEZ, A.; ROSAL, R. Chemical and toxicological evouluntion of the antibiotic sulfamethoxazole under ozone treatment in water solution. Journal of Hazardous Materials, v.192, p.18-25, 2011.

HALLING-S $\varnothing R E N S E N, \quad B . ; \quad N I E L S E N, \quad$ S.N., LANZKY, P.F.; INGERSLEV, F.; LÜTZHØFT, H.C.H.; JØRGENSEN, S.E. Occurrence, fate and effects of pharmaceutical substances in the environment-a review. Chemosphere, v.36, n.2, p.357-394, 1998.

HARTIG, C.; STORM, T.; JEKEL, M. Detection and identification of sulphonamide drugs in municipal waste water by liquid chromatography coupled with electrospray ionization tandem mass spectrometry. Journal of Chromatography, v. 854, n.1, p.163-17, 1999. 
HEBERER, T. Occurrence, fate, and removal of pharmaceutical residues in the aquatic environment: a review of recent research data. Toxicology Letters, v.131, n.1, p. 5-17, 2002.

HENSCHEL, K.P; WENZEL, M.; DIEDRICH, M.; FLIEDNER A. Environmental Hazard Assessment of Pharmaceuticals. Regulatory Toxicology and Pharmacology, v. 25, p.220-225, 2002.

HIROSHI, S.; KUMIKO, O.; HIROYUKI, K.; SHINICHIRO, O. Effects of low- or medium-pressure ultraviolet lamp irradiation on Microcystis Aeruginosa and Anabaena variabilis. Water Research, v. 41, p.11-18, 2007

HU. L.; FLANDERS, P. M.; MILLER, P. L.; STRATHMANN, T. J. Oxidation of sulfamethoxazole and related antimicrobial agent by $\mathrm{TiO}_{2}$ photocatalysis. Water Research, v. 41, p. 2612-2626, 2007.

IBGE Disponível em <www.ibge.gov.br> Acesso em: 5 jun. 2010

ISIDORI, M.; LAVORGNA, M.; NARDELII, A.; PASCARELLA, L.; PARRELA, A. Toxic and genotoxic evaluantion of six antibiotics on non-target organism. Science of the Total Environment, v. 36, p. 87-98, 2005.

IQUEGO: sulfametoxazol + trimetoprima. Dra. Maria Aparecida Rodrigues. Goias. INDÚSTRIA QUÍMICA DO ESTADO DE GOIÁS S.A. Bula de remédio

JØRGENSEN, S.E.; HALLING-SØRENSEN, B. Editorial: drugs in the environment. Chemosphere, v.40, p.691-699, 2000.

KAREL, M.; LUND, D.B. Physical Principles of Food Preservation .New York: Marcel Dekker, 2003.

KRAUSE, L. G. T. V. Degradação do antibiótico sulfametoxazol por ozonização e avaliação da atividade microbiana. 2009. 69p. Tese (doutorado) - Engenharia Química- Universidade Federal do Rio de Janeiro Rio de Janeiro, 2009.

KÜMMERER, K.; STEGER-HARTMANN, T.; MEYER, M. Biodegradability of the anti -tumor agentifosfamideand its occurrance in hospital effluents and communal sewage. Water Research, v. 31, n.11, p. 2705-2710, 1997.

LAM, M.W.; YOUNG, C. J.; BRAIN, R. A.; JOHNSON, D. J.;HANSON, M. A.; J. WILSON, C.J.; RICHARDS, S. M.; SOLOMON, K. R.; MABURY, S. A. Aquatic 
persistence of eight pharmaceutical in a microcosm study. Environmental Toxicology and Chemistry, v. 23, n.6, p.1431-1440, 2004.

LI, B.; ZHANG, T. Biodegradation and adsorption of antibiotics in the activated sludge process .Environmental Science and Technology, v. 44, p.3468-3473, 2010.

LOCATELLI, M. A.F.; SODRÉ, F. F.; JARDIM, W.F.Determination of antibiotics in Brazilian Surface Water using liquid cromathography-electrospray tandem mass spectrometry. Archives of Environmental Contamination and Toxicology, v. 60, n. 3, p. 385-393, 2011.

MICROTOX® TEST SYSTEMS FOR TOXICITY TESTING, Disponível em: <http://www.ambriex.com.br/Produto.aspx?idProduct=53> acesso em: 20 set. 2011

MELO, S. A. S.; TROVÓ, G.T.; BAUTITZ, I. R.; NOGUEIRA, R. F. P. Degradação de fármacos residuais por processos oxidativos avançados. Química Nova,São Paulo, v. 32, n. 1, p. 188-197, 2009.

MILLS, L.J.; CHICHESTER, C. Review of evidence: Are endocrine-disrupting chemicals in the aquatic environment impacting fish populations? Science of theTotal Environment, v.343, p.1-34, 2005.

NASUHOGLU, D.; YARGEAU, V.; BERK, D. Photo-removal of sulfamethoxazole (SMX) by photolytic and photocatalytic processes in a batch reactor under UV-C radiation (254 nm). Journal of Hazardous Materials, v. 186, p. 67-75, 2011

NOGUEIRA, R. F. P.; JARDIM, W. F. A fotocatálise heterogênea e sua aplicação ambiental. Química Nova, v. 21, n.1, p. 69-72, 1998.

OPPENLÄNDER, T. Photochemical Purification of Water and Air: Advanced Oxidation Processes (AOPs): Principles, Reaction Mechanisms, Reactor Concepts, Wiley-VCH, 2003.

PARSONS, S. Advanced Oxidation Processes for Water and Wastewater Treatment, IWA Publishing, 2005

RODRIGUES, N. L. V. B. Teste de Toxicidade Aguda através de Bioensaios no extrato solubilizados do resíduos classe II A - não inertes e classe II B inertes. 2005. 122p. Dissertação (Mestrado) - Engenharia de Recursos Hídricos e Ambiental, Universidade Federal do Paraná, Curitiba, 2005. 
SADAÑA, L. S; ANDUAGA, E. S.;MENDOZA, J. P.; YOKOTA, P. L.; CARPIO, R. C. Antibióticos sistémicos endermatología. Segunda parte: tetraciclinas, lincosaminas, fluoroquinolonas, sulfonamidas, rifamicinas, cloranfenicoles, ácido fusídico, metronidazol y nuevos antibióticos. Dermatologist Peru, v.14, n. 3, 2004.

SAHOO, K. C.; TAMHANKAR, A. J.; JOHANSSON, E.; LUNDBORG C. S. Antibiotic use, resistance development and environmental factors: a qualitative study among healthcare professionals in Orissa. BMC Public Health, 2010.

SANDERSON, H.; BRAIN, R.A.; JOHNSON, D.J.; WILSON, C.J.; SOLOMON, K.R. Toxicity classification and evaluation of four pharmaceuticals classes: antibiotics, antineoplastics, cardiovascular, and sex hormones. Toxicology, v.203, p.27-40, 2004.

STUMPF, M.; TERNES, T. A.; WILKEN, R.D.; RODRIGUES, S. V., BAUMANN, W. Polar drug residues in sewage and natural waters in the state of Rio de Janeiro, Brazil. .Science of theTotal Environment, v. 225, n.1, p.132-141, 1999.

TAMBOSI, J.L. Remoção de fármacos e avaliação de seus produtos de degradação através de tecnologias avançadas de tratamento. 2008. 141 p. Tese (Doutorado) - Engenharia Química, Centro Tecnológico da Universidade Federal de Santa Catarina, Florianópolis, 2008.

TERNES, T.A.; STUMPF, M.; MUELLER, J.; HABERER, K.; WILKEN, R.; SERVOS, $M$. Behavior and occurrence of estrogens in municipal sewage treatment plants Investigation in Germany, Canada and Brazil. .Science of theTotal Environment, v. 225, n. 1, p.81-90, 1999.

TERNES, T. A. Human pharmaceuticals, hormones and fragrances - the challenge of micropolluants in urban water management .Publishing IW, 2006

TROVÓ, A.G.; NOGUEIRA, R. F. P; AGUERA, A.; FERNANDEZ-ALBA, A.R.; SIRTORI, C.; MALATO, S. Degration of sulfamethoxazole in water by solar photophenton. Chemicalandtoxicologicalevaluantion. Water Reseach, v. 43, p. 3922-3931, 2009.

VASCONCELOS, D. V.; GOMES, A. Tratamento de efluentes de postos de combustíveis para o reúso usando processos oxidativos avançados. Caderno UNIFOA, v. 11, p. 35-46. 2009. 
VICENTE R. Procesos químicos y fotoquímicos ambientalmente benignos para la degradación de efluentes acuosos industriales. Cuadernos de investigación en la ingeniería, v. 1, p. 54-57, 2009.

ZHOU, W.; MOORE, D. E. Photchemical decomposition of sulfamethoxazole. International journal of Pharmaceutics, v. 110, p. 55-63, 1994.

ZHOU, W.; MOORE, D. E. Photosensitizing activity of the anti-bacterial drugs sulfamethoxazole and trimethoprim. Journal of Photochemistry and Photobiology B: Biology, v. 39, p.63-72, 1997. 